\title{
Population Trends and Policy Responses in the UNECE Region: \\ Outcomes, Policies and Possibilities
}

\author{
Jana Vobecká \\ William P. Butz \\ Gerald Cirilo Reyes
}

6 June 2013

View the final online version at: http://eeca.unfpa.org/public/pid/14622

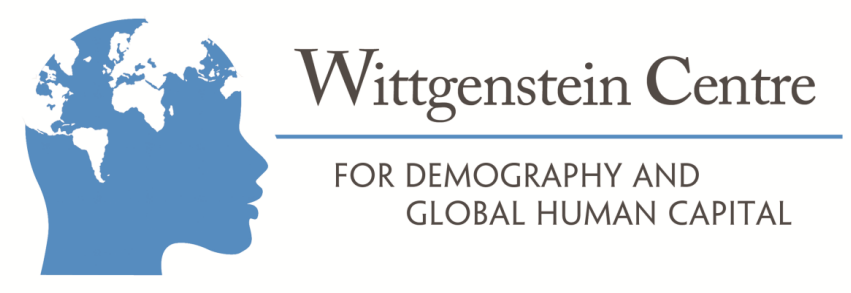




\section{Introduction}

The two decades since the International Conference on Population and Development (ICPD) in Cairo have seen a continuation of strong population and sustainability trends in some parts of the ECE region but stalling in others. Public policies and programs have experienced similar disparities. Taken together, the countries of this region constitute a globally relevant laboratory in which much can be learned about the relationships between policy and outcomes, and in which emerging issues can be identified along with policies and practices that might effectively amplify or constrain their consequences. Indeed, many challenges that the ECE region is facing today are expected to become relevant in other parts of the world. With this global perspective in mind, this Report discusses recent trends in population and related outcomes as well as the policies that may influence these outcomes in the ECE region, always through a lens focusing attention on the future. ${ }^{1}$

The Report is structured into three analytical parts. Part 1 contains a description and analysis of recent trends in population and related matters, as well as future population prospects. Part 2 focuses on analysis of policy responses to these recent demographic trends and challenges, highlighting concrete examples of policy implementation, particularly best practices across the region. We emphasize policies that appear most efficient and the conditions under which such policies best operate. Part 3 extends the two previous parts with a set of policy recommendations derived from the analysis of best practices and a forecast of possible population trends under different policy scenarios.

Our focus throughout is on trends that are seen as most pressing in the ECE region and most likely to continue, or that may well emerge over the next 20-40 years. Among these, we emphasize particularly the trends that will require special policy attention. Both the trends and the policies will be found to vary considerably across the sub-regions and across the countries within them. Because we combine analysis of past trends with a view of future developments, we emphasize indicators for which trend data in time series are available for most countries in the region. Individual country values are presented in Appendix 2. Our prospective analysis is based on the 2013 Wittgenstein Centre (WIC) expert argument-based population projections by age, sex and education (Lutz et al., 2013), hereafter called the "WIC projections." We use these projections rather than alternatives because their unique design features expert argument-based scenarios of future population components by level of education in addition to the usual distinctions of age and sex.

Among the wide-ranging aspects of population issues, we distinguish those that are seen as the most pressing in the ECE region. We translate those into four "Hot Questions." We pay particular attention to the rationale for each Hot Question, the scientific evidence regarding its relevance, and the policy alternatives for addressing it.

The Hot Questions are:

1. Is population ageing a threat for the ECE countries?

\footnotetext{
${ }^{1}$ The authors acknowledge and appreciate the contributions of Samir KC, Wolfgang Lutz, and Nikola Sander to the overall conception of this report and the generation and representation of data. Werner Haug, Marta Diavolova, and $\mathrm{xx}$ have contributed significantly to the report's content and clarity. All remaining errors are the responsibility of the authors.
} 
2. Is migration a threat or opportunity for development?

3. Is fertility in the ECE region too low?

4. Are ECE countries becoming less equal societies?

Two cross-cutting themes run through the Hot Questions as well as the whole report, leading to the emerging trends and policy emphases formulated explicitly in Part 3. The cross-cutting themes are:

- Investment in human capital, particularly education and health, is essential.

Policies and programmes that increase investments in education and human capital more broadly expand people's choices. More productive work in the labour market yields higher incomes for individuals and families while supporting aggregate economic growth and expanding the possibilities for sustainability. Moreover, knowing about and using family planning expands opportunities to fulfil fertility desires. Adaptation to natural disasters is now known to be facilitated by a more educated population. Even more broadly, education has a crucial societal dimension: it enables the transition to democracy and promotes development of citizens in a globalizing society. Good health throughout the life cycle facilitates productivity and participation not only in the labour market but also in the family and society.

- Societies can prosper without growing populations. Continuing population growth is now known to be less important to a country's economic growth than long assumed by macroeconomic models and policymakers. In fact, it is human capital, the embodied capabilities and skills of people and the duration of their lives in good health and active participation, that matters for economic growth and more broadly for national prosperity, rather than the numbers of people. Nations facing slowing population growth and even moderate decline need not fear an ageing of population or a diminution of national influence, if their human capital development policies are strong and effective and their social welfare systems adjust adequately to the demographic changes.

For purposes of the analysis we divide the ECE region into seven sub-regions. This regional division distinguishes EU from non-EU countries, which is particularly relevant for the analysis of policies and strategies because the EU often provides policy guidelines or frameworks for member states. The regional division also respects geographic proximity, with the partial exception of the region comprising Canada, the U.S.A. and Israel. Neither geographic nor political alignment places Israel naturally among other countries in the region, so we consider it along with two countries at a similar level of development. The division of the ECE region into sub-regions is presented in Appendix 3.

Our analysis of past trends and future prospects regarding population size and structure includes both the analysis of demographic change (fertility, mortality, migration, and population size and structure by age and education) and also social and economic characteristics such as labour force participation, poverty, health and reproductive health, and issues of environmental sustainability linked to health. Accordingly, we analyse future population trends and the effects of alternative policy regimes on future outcomes by comparing the results of three very different policy scenarios at the global level: Continuation of current policy trends, Sustainable development policies, and Global fragmentation. ${ }^{2}$ These describe three

${ }^{2}$ The Intergovernmental Panel on Climate Change (IPCC) is currently finalizing its Fifth Assessment Report. In this context the global modeling community on Integrated Assessment and Vulnerability, Risk and Adaptation has agreed to refer to a common set of Shared Socioeconomic Pathways (SSPs) that describe alternative future worlds 
radically different directions that population and development policies might take in the world. Countries of the ECE region take their places in these policy scenarios according to their different levels of development and their different positions in the global economy. In turn, these alternative scenarios imply three different futures for the size and characteristics of the region's population, as reflected in the WIC projections. We feature these particular scenarios because they enclose the most likely courses relevant policies are likely to take, because they place the ECE region consistently within its global policy contexts, and because the associated WIC projections for the ECE countries are part of an internally consistent set of projections for all countries. In Section 3, these scenarios will illustrate how the policy gaps identified in Section 2 may play out if policies continue much as they are, compared with alternative regimes of sustainability emphasis, on the optimistic side, or increasing global fragmentation, in the other direction.

In Part 1 we concentrate on the scenario of "Continuation," in which trends of recent decades persist, with some progress towards achieving development goals, reductions in resource and energy intensity at historic rates, and slowly decreasing fossil fuel dependency. Some international cooperation and investments in technology development and transfer support moderate economic growth in low-income countries, with slower economic growth in high-income countries. Technology development proceeds in industrialized countries, but is not shared with low-income countries. There is evidence of degradation of the environment. This middle-of-the-road scenario corresponds to the medium variant of the new WIC population projections. It combines assumptions of medium fertility with medium mortality and medium migration for all countries. The population growth projections featured in Part 1 of the Report are derived from this scenario. ${ }^{3}$

Population change results from an interplay of fertility, mortality, and migration, and the observed and projected population growth in the individual countries is a result of a different mixture of the three. What the region had in common in the last two decades was progressive population ageing, increases in the mean age of childbearing, and increasing importance of net migration effects on overall population growth or decline. We now focus on these processes that lay behind population change.

\section{Hot Question 1: Is population ageing a threat for the ECE countries?}

Today, the most important process that moulds population dynamics in the ECE region is population ageing through low birth rates and the increasing life span of the population. In 2010, the median age of the population in the ECE region was 37.7 years, and it is expected to rise to 45.5 by 2050 (See Table $1.1)^{4}$ Population ageing will certainly be the source of important challenges in coming decades, not only in the ECE region where it is a prominent issue already but also in most other parts of the World.

Under this Hot Question we focus on the aspects of population ageing linked to mortality, longevity and changes in life expectancy. The aspects of ageing linked to birth rates are developed under the Hot Question 2.

with respect to social and economic mitigation and adaptation challenges. WIC/IIASA staff have contributed substantially to this formulation. The three scenarios described in this Report are selected from those developed for the IPCC.

${ }^{3}$ Full descriptions of the three scenarios can be found in Appendix 1 .

${ }^{4}$ Median age divides the population into two numerically equal groups, with half of the population being younger than this age and half older. 
Table 1.1 Median population age, 2010-2050

\begin{tabular}{|l|r|r|r|}
\hline & $\mathbf{2 0 1 0}$ & $\mathbf{2 0 3 0}$ & $\mathbf{2 0 5 0}$ \\
\hline South-Eastern Europe & 30.0 & 36.8 & 42.2 \\
\hline Eastern Europe and Caucasus & 37.7 & 43.3 & 45.8 \\
\hline Central Asia & 25.0 & 31.8 & 37.5 \\
\hline New EU States & 38.9 & 46.0 & 51.1 \\
\hline EU15 & 41.5 & 46.4 & 49.0 \\
\hline Western Europe - Non EU Member & 40.2 & 44.8 & 47.8 \\
\hline North America and Israel & 37.0 & 40.4 & 43.0 \\
\hline Total & 37.7 & 42.5 & 45.5 \\
\hline
\end{tabular}

Source: Ediev et al. (2012)

In order to understand well the current and future challenges of ageing societies, adequate measures of ageing must be used. Expectations and fears of the increasing burden of older persons on national welfare systems and prosperity have nearly always been based on conventional measures of ageing that link characteristics and conditions of persons to their chronological ages (Sanderson and Scherbov, 2010). But this can be very misleading since people are not only living longer but also staying healthy longer.

\section{$\underline{\text { Life expectancy }}$}

Life expectancy at birth grew by five years on average for men and about three years for women in the ECE region between 1990 and 2010. The highest levels were for both sexes in Western Europe with the highest male life expectancy of almost 81 years in Switzerland and Iceland, and the highest female life expectancy of over 85 years in France, Iceland, and Italy. In all the ECE sub-regions, the life expectancy of both sexes grew between 2000 and 2010, but in the 1990s and 2000s the sub-regions of Eastern-Europe and Caucasus, and Central Asia went through an actual decrease in life expectancy for both sexes, particularly for men (Table 1.2, Figure 1.1 and 1.2). The decrease in life expectancy in Eastern Europe was driven mainly by Russia and Ukraine. Current life expectancy levels for women in both Russia and Ukraine have after a previous decrease progressed back to the same level as in 1990; men life expectancy in these two countries is remain lower now than in 1990 but has been trending upward the last several years (Appendix 2, Table 1 for individual countries). Life expectancy is clearly higher among the more highly educated than among the lower educated (Appendix 2, Table 1). 
Table 1.2 Life Expectancy at Birth by sex 1990-2050

\begin{tabular}{|c|c|c|c|c|c|}
\hline \multicolumn{6}{|c|}{ Life Expectancy at Birth, men 1990-2050 } \\
\hline & 1990 & 2000 & 2010 & 2030 & 2050 \\
\hline South-Eastern Europe & 62 & 68 & 72 & 75 & 79 \\
\hline Eastern Europe and Caucasus & 64 & 60 & 64 & 70 & 75 \\
\hline Central Asia & 63 & 62 & 64 & 70 & 75 \\
\hline New EU States & 67 & 69 & 72 & 77 & 82 \\
\hline EU15 & 73 & 75 & 79 & 83 & 88 \\
\hline Western Europe - Non EU & 74 & 77 & 80 & 85 & 89 \\
\hline North America and Israel & 72 & 74 & 76 & 80 & 84 \\
\hline Total & 69 & 71 & 74 & 78 & 83 \\
\hline \multicolumn{6}{|c|}{ Life Expectancy at Birth, women 1990-2050 } \\
\hline & 1990 & 2000 & 2010 & 2030 & 2050 \\
\hline South-Eastern Europe & 67 & 73 & 76 & 80 & 84 \\
\hline Eastern Europe and Caucasus & 74 & 72 & 75 & 79 & 83 \\
\hline Central Asia & 71 & 70 & 72 & 77 & 81 \\
\hline New EU States & 75 & 77 & 80 & 84 & 88 \\
\hline EU15 & 80 & 81 & 84 & 88 & 92 \\
\hline Western Europe - Non EU & 80 & 82 & 85 & 89 & 93 \\
\hline North America and Israel & 79 & 80 & 81 & 85 & 89 \\
\hline Total & 77 & 78 & 80 & 84 & 88 \\
\hline
\end{tabular}

Source: UNDP (2011) and Ediev et al. (2012) 
Figure 1.1 Life expectancy at birth (Men)

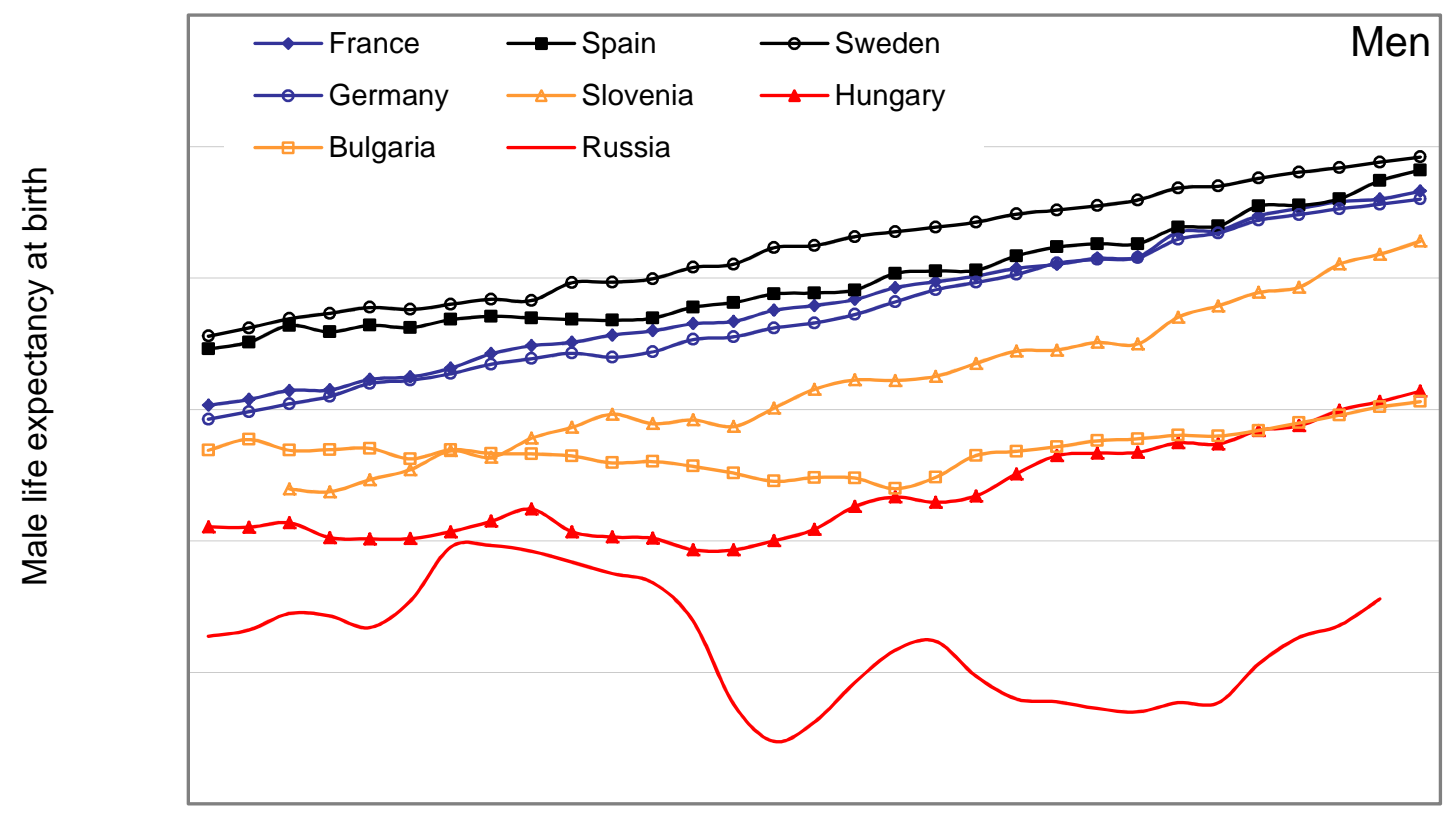

Source: Ediev et al. (2012)

Figure 1.2 Life expectancy at birth (Women)

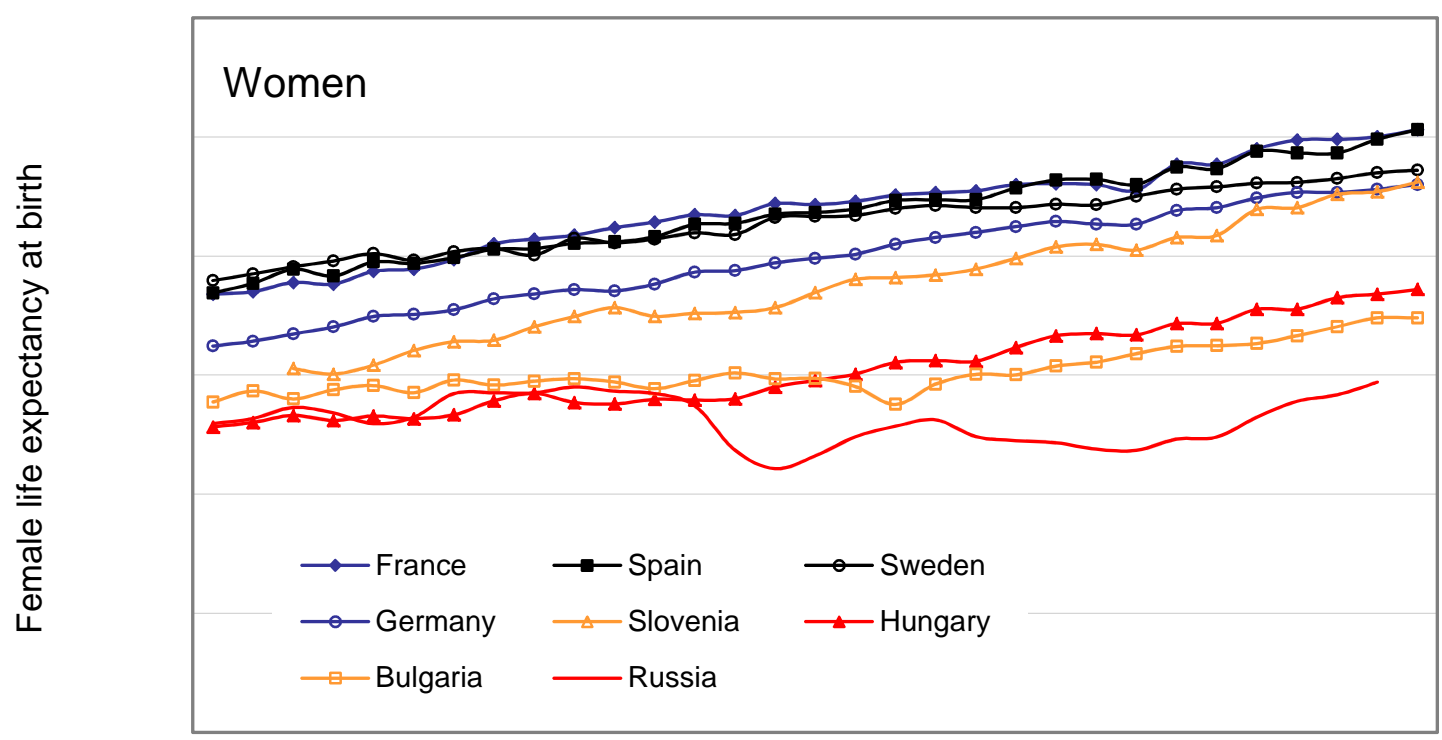

Source: Ediev et al. (2012) 
Considerable life expectancy increase is expected in the coming decades in all ECE countries, with the levels for women reaching well over 90 years and men around 88 years in Western Europe, Israel, and Canada by 2050, and reaching close to 90 for women and well above 80 in the New EU States and USA (See Appendix 2, Table 1). Thus, the WIC population projections anticipate at least the same pace of life expectancy increase in the coming decades as has been observed in the past two decades. In the countries with the highest life expectancy today, further gains in life expectancy are expected to be concentrated mostly in age groups older than 50, as was the case in recent decades (Luy et al., 2011). In the Eastern European and Central Asian countries there is further scope for mortality improvement in the younger ages, as well.

Increasing life expectancy contributes to the increasing proportion of the population aged 65 and older in the population. Although in the last two decades the share of persons 65-plus in the ECE countries grew relatively slowly at about $2.3 \%$ annually and reached $14.1 \%$ in 2010 , it is expected to grow much faster in the coming decades to reach about $20 \%$ by 2030 and $26 \%$ by 2050 (See Table 1.3). This increase will propel growth of the old age dependency ratio (Table 1.4). ${ }^{5}$ For example, Germany, the country with the oldest population in the ECE region (with median population age of 44.3 in 2010), has an old age dependency ratio of $34 \%$ in 2011, which is expected to reach $68 \%$ in $2050{ }^{6}$ This looks like an alarming number. Indeed, it is unless we take into account not only the chronological ageing but also the actual changes in disability-free life expectancy.

Table 1.3 Population ages 65 and above (per cent of total) 1990-2050

\begin{tabular}{|l|r|r|r|r|r|}
\hline & $\mathbf{1 9 9 0}$ & $\mathbf{2 0 0 0}$ & $\mathbf{2 0 1 0}$ & $\mathbf{2 0 3 0}$ & $\mathbf{2 0 5 0}$ \\
\hline South-Eastern Europe & 4.75 & 6.46 & 7.50 & 12.6 & 20 \\
\hline Eastern Europe and Caucasus & 10.37 & 12.49 & 13.10 & 18.8 & 24 \\
\hline Central Asia & 4.66 & 5.00 & 4.88 & 9.15 & 15 \\
\hline New EU States & 11.08 & 13.47 & 14.84 & 21.8 & 31 \\
\hline EU15 & 14.63 & 16.37 & 18.10 & 24.9 & 31 \\
\hline Western Europe - Non EU & 15.14 & 15.17 & 15.82 & 23.2 & 29 \\
\hline North America and Israel & 12.31 & 12.35 & 13.11 & 20.0 & 23 \\
\hline Total & 11.75 & 13.05 & 14.06 & 20.4 & 26 \\
\hline
\end{tabular}

Source: UNDP (2011) and Ediev et al. (2012)

\footnotetext{
${ }^{5}$ Old age dependency ratio is computed here as number of the population age 65 and more divided by the population aged 20 to 64 .

${ }^{6}$ Source: Ediev et al. (2012). Old age dependency ratio is defined here as a proportion of the population aged $65+$ over the population aged 20-64 years.
} 
Table 1.4 Old-age dependency ratio 65+/20-64, 2011 and 2050. Prospective old-age dependency ratio, 2011 and 2050

\begin{tabular}{|c|c|c|}
\hline \multicolumn{3}{|c|}{ Old-age dependency ratio $65+/ 20-64,2011$ and 2050} \\
\hline & 2011 & 2050 \\
\hline South-Eastern Europe & 14.3 & 40.69 \\
\hline Eastern Europe and Caucasus & 19.5 & 44.04 \\
\hline \multicolumn{3}{|l|}{ Central Asia } \\
\hline New EU States & 23.4 & 55.93 \\
\hline EU15 & 30.0 & 59.25 \\
\hline Western Europe - Non EU Member & 26.4 & 56.67 \\
\hline North America and Israel & 21.9 & 37.30 \\
\hline Total & 23.9 & 47.98 \\
\hline \multicolumn{3}{|c|}{ Prospective old-age dependency ratio, 2011 and 2050} \\
\hline & 2011 & 2050 \\
\hline South-Eastern Europe & 12.3 & 20.36 \\
\hline Eastern Europe and Caucasus & 22.9 & 30.08 \\
\hline \multicolumn{3}{|l|}{ Central Asia } \\
\hline New EU States & 19.9 & 28.61 \\
\hline EU15 & 18.4 & 25.11 \\
\hline Western Europe - Non EU Member & 14.9 & 22.57 \\
\hline \multicolumn{3}{|l|}{ North America and Israel } \\
\hline Total & 19.1 & 26.01 \\
\hline
\end{tabular}

Note 1: Please note that the regional averages may be biased by missing country-specific data.

Note 2: Prospective old-age dependency ratio is defined as the number of people with life expectancies of 15 and fewer years, divided by the number of people at least 20 years old in age groups with life expectancies greater than 15 years

Source: Ediev et al. (2012)

\section{Health-adjusted life expectancy}

Health-adjusted life expectancy (see Table 1.5), which describes how many years of life are spent in good health, is increasing rapidly in most countries in the region, at approximately the same rate as unconditional life expectancy (Bhattacharya et al., 2004; Sanderson and Scherbov, 2010). This reflects the fact that more and more people now are living healthy lives well above the age of 65 . Therefore, they can still be economically productive, participate in social life, do not need to be dependent, and are not a particular burden to the health care systems. In Germany the healthy life expectancy is 72 years. In other Western European countries and in Canada and Israel it is between 72 and 75 years, in the New EU States about 67 years, but lower in the eastern part of the ECE region (Data for 2007, source: WHO, Table 1.5 and Appendix 2, Table 1). Hence, more important than biological ageing is the actual health condition of the population (not only of older persons) and the proportion of those who are really in disability and in need of assistance and special care. 
Table 1.5 Health-Adjusted Life Expectancy 2007 (both sexes)

\begin{tabular}{|l|r|}
\hline & $\mathbf{2 0 0 7}$ \\
\hline South-Eastern Europe & 65.9 \\
\hline Eastern Europe and Caucasus & 60.2 \\
\hline Central Asia & 57.5 \\
\hline New EU States & 66.7 \\
\hline EU15 & 72.6 \\
\hline Western Europe - Non EU Member & 74.4 \\
\hline North America and Israel & 70.4 \\
\hline Total & 68.0 \\
\hline
\end{tabular}

Note: Please note that the regional averages may be biased by missing country-specific data. Source:UNDP (2011)

As life without disability gets longer it is useful to think about ageing not only in terms of chronological age but also in relative terms, for example, relative to the expected remaining years of life. If we assume that 15 years of remaining life is roughly a threshold when the probability of health impairment is getting considerably higher, we can formulate an alternative indicator of old age dependency, the Prospective Old Age Dependency Ratio (Sanderson and Scherbov, 2008). Prospective Old Age Dependency Ratio is defined as "the number of people with life expectancies of 15 and fewer years, divided by the number of people at least 20 years old in age groups with life expectancies greater than 15 years" (Sanderson and Scherbov, 2010: 1287). Prospective Old Age Dependency Ratio shows a slower pace of ageing than its conventional counterpart, and therefore the picture of ageing looks much less dramatic in all the ECE countries than it does with conventional measures (Table 1.4). In Germany, for example, the Prospective Old Age Dependency Ratio in 2011 is $22 \%$ and the projected the Prospective Old Age Dependency Ratio for 2050 is $31 \%$, less than half of the projected value of the conventional OADR (Figures 1.3 and 1.4. For individual country values see Appendix 2, Table 1). 
Figure 1.3 Conventional old-age dependency ratio as projected for 2030

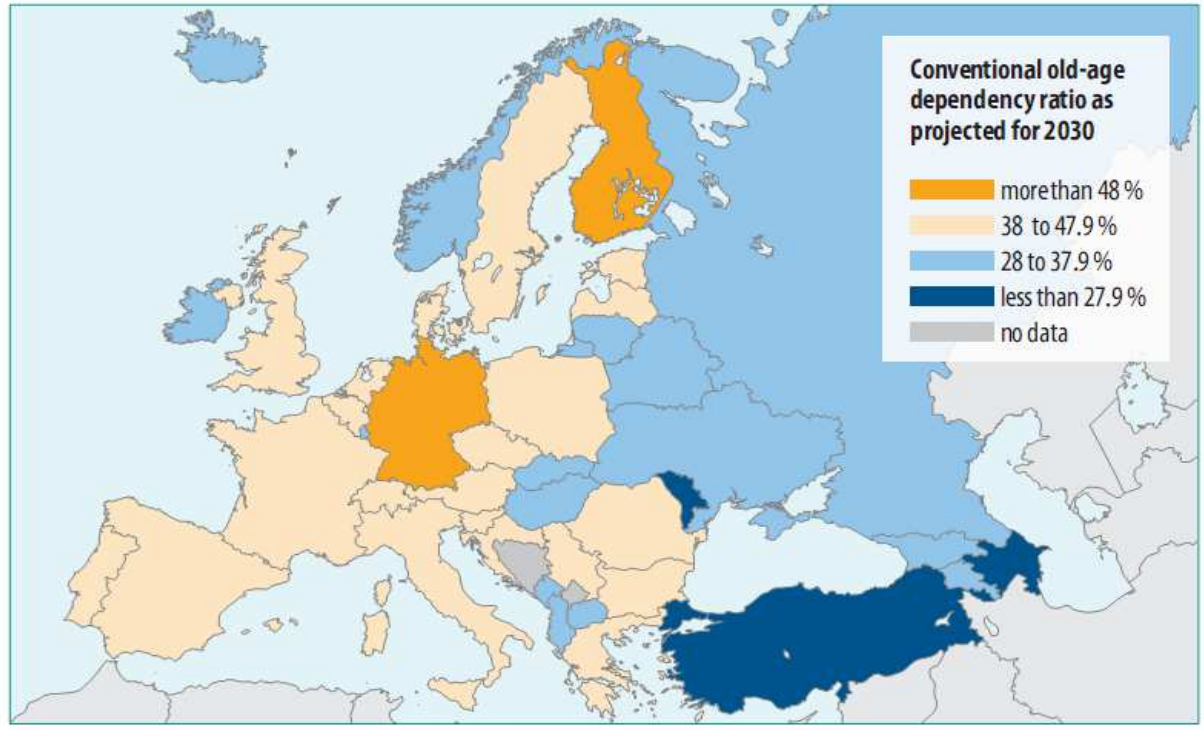

Source: Ediev et al. (2012)

Figure 1.4 Prospective old-age dependency ratio as projected for 2030

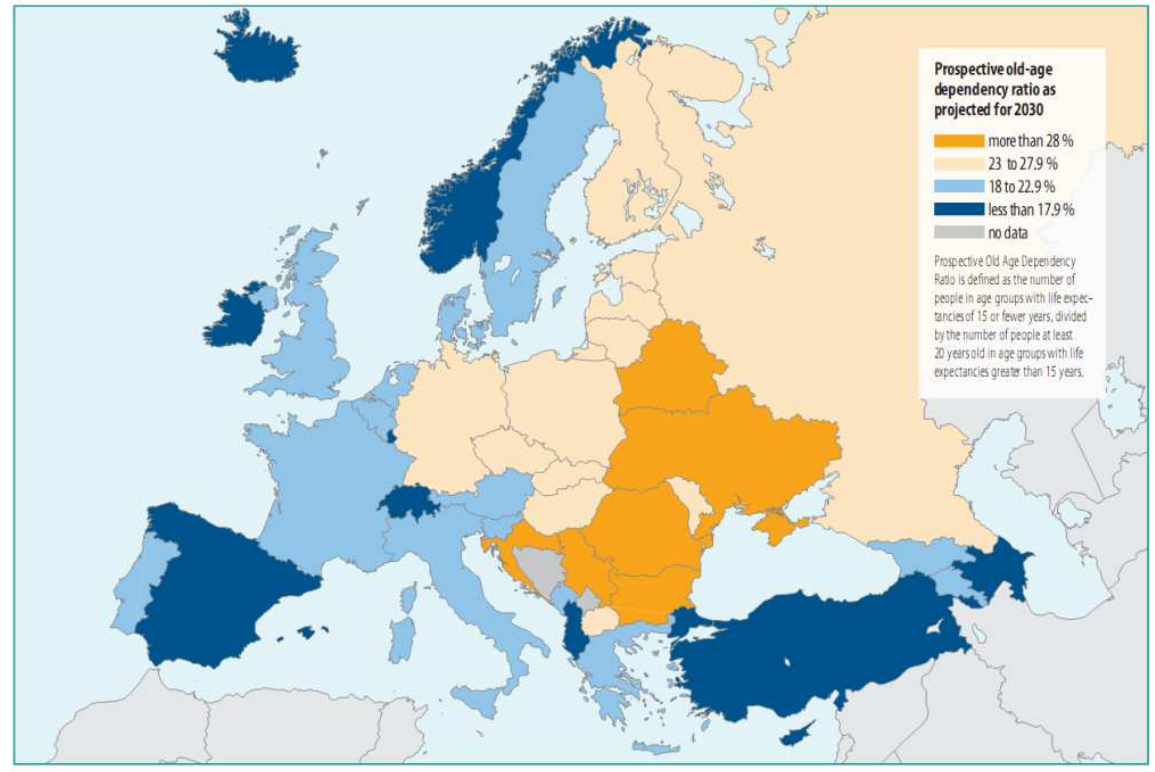

Source: Ediev et al. (2012) 
Another relevant concern related to the burden of aging is the share of disabled adults in the total population. Following the conventional extrapolation of the current health status of the population we should expect considerable absolute as well as relative growth of disability in the population. But Sanderson and Scherbov (2010) show that because age- and sex-specific disability rates are changing over time, the ratio of disabled adults to non-disabled adults will not change dramatically in the coming decades. Further data harmonization across the countries and improved data availability are needed to develop internationally comparable measures of disability.

Not only physical capacities but also maintained cognitive skills are important to longer fitness and disability-free independent life in the older ages. Internationally comparable tests of seniors' cognitive capacity allow measurement of differences in cognitive capacity among older persons in different countries. These comparisons (Skirbekk et al., 2012) show important international variation among seniors' cognitive abilities as well as differences in the age dynamics of these capacities. In the test of immediate recall of words from 10 read-out nouns, seniors from the USA and Western European countries score the best followed by the Central Europeans and, at further distance, the South Europeans (Skirbekk et al., 2012). Higher levels of education have been identified as an important predictor of better cognitive skills of elderly individuals, while cognitive training in advanced ages has also shown positive results (Ball et al., 2002; Le Carret et al., 2003; Skirbekk et al., 2012). Furthermore, it has been demonstrated that cognitive performance is increasing in successive cohorts (Flynn, 1987; Sacuiu et al., 2010; Tuddenham, 1948) under conditions of improving educational attainment, nutrition, mortality and economic conditions (Sacuiu et al., 2010).Taken together, this evidence leads to the conclusion that "nations that are truly challenged by ageing may be those where the cognitive performance among their seniors is poor; not those who have chronologically older age structures" (Skirbekk et al., 2012: 772).

Aging and economic performance

"Working longer and retiring later is not only a matter of whether older individuals want to remain active in the labour market as long as possible, but also depends on employers' capacities and willingness to employ and retain older workers" (van Dalen et al. 2010). A recent study among employers in five European countries (Greece, Hungary, The Netherlands, Spain, and United Kingdom) showed that most employers associate older workers with more experience but perceive that their cost is higher than the productivity gain. This is also reflected in a relatively low proportion of employers that find it desirable that workers work until higher ages. Less than 50 per cent of the employers surveyed agreed that it is desirable for a worker to work after the age of 60 . The exception was the United Kingdom where 60 per cent agreed. Less than 10 per cent of the employers in Greece, Hungary and The Netherlands found it desirable that workers work over the age of 65; in Spain and the UK the proportion was higher but still less than 30\% (van Dalen et al., 2010).

These perceptions of employers are, however, contradicted by some research on the age-wage, ageproductivity relationships. Studies at the aggregate level of firms do not bring clear evidence that older workers are less productive and/or more costly (Mahlberg et al., 2013 provides a literature review). Some studies show that productivity of older workers remains constant over a range of ages as does the cost of their work (Aubert and Crépon, 2006). A mismatch between cost and productivity was also not found in the study of Austrian firms (Mahlberg et al., 2013). Some other studies show however that separation of 
older workers can be profitable for certain firms, especially those in manufacturing and information and communication technology (Ilmakunnas and Maliranta, 2007).

Pension ages

Many countries have introduced mechanisms that are increasing normal pension age in reaction to the increasing life expectancies. These policy measures are however often unpopular and in some countries progress too slowly to adequately reflect the gains in life expectancy (as for example in France and Austria).

As of 2010 only a few ECE countries (USA, Israel, Norway, and Iceland) have set legal retirement age at higher than 65. All other ECE countries have legal retirement age of 65 or even lower. In many countries, especially in the East ECE region, women are still entitled to earlier retirement than men, despite their longer life expectancy (Appendix 2 Table 2). We observe also a mismatch between legally set and de facto retirement age. In most of the ECE countries the average effective labour market exit age is actually lower for both men and women than the legally set retirement age (See Table 1.6)

Table 1.6 Average effective labour market exit age, 2000 and 2010

\begin{tabular}{|l|l|l|l|l|}
\hline & $\begin{array}{l}\text { Average } \\
\text { effective } \\
\text { labour } \\
\text { market exit } \\
\text { age 2000 } \\
\text { Men }\end{array}$ & $\begin{array}{l}\text { Average } \\
\text { effective } \\
\text { labour } \\
\text { market exit } \\
\text { age 2010 } \\
\text { Men }\end{array}$ & $\begin{array}{l}\text { Average } \\
\text { effective } \\
\text { labour } \\
\text { market exit } \\
\text { age 2000 } \\
\text { Women }\end{array}$ & $\begin{array}{l}\text { Average } \\
\text { effective } \\
\text { labour } \\
\text { market exit } \\
\text { age 2010 } \\
\text { Women }\end{array}$ \\
\hline South-Eastern Europe & $\ldots$ & $\ldots$ & $\ldots$ & $\ldots$ \\
\hline Eastern Europe and Caucasus & $\ldots$ & $\ldots$ & $\ldots$ & $\ldots$ \\
\hline Central Asia & $\ldots$ & $\ldots$ & $\ldots$ & $\ldots$ \\
\hline New EU States & 59.07 & 62.32 & 56.94 & 59.78 \\
\hline EU15 & 60.64 & 62.09 & 59.97 & 61.67 \\
\hline Western Europe - Non EU Member & 64.05 & 64.10 & 63.35 & 62.63 \\
\hline North America and Israel & 64.37 & 64.42 & 63.01 & 63.65 \\
\hline Total & 61.97 & 63.09 & 60.85 & 62.27 \\
\hline
\end{tabular}

Source: Eurostat (2012a), OECD (2012), European Commission White Paper on Pensions (2012b) and national reports and surveys.

Smoking, alcohol consumption, and obesity

Health conditions of the population over the whole life cycle determine life expectancy and disability-free life expectancy. The health status of populations in the ECE region is quite diverse and depends on various factors such as medical standards, access to quality health care and behavioural risk factors such as smoking.

Smoking is considered "a major health hazard and one of the most important factors that contribute to mortality differences between individuals and populations" (Luy et al., 2011). Smoking has been shown 
to be positively associated with higher occurrence of several types of tumor, lower fecundity, many cardiovascular diseases and other undesirable outcomes. In most countries in the ECE region, smoking is more prevalent among men than among women, which is considered a strong contributing factor to the life expectancy differentials between men and women. Through various interventions, national governments of most of the ECE countries try to reduce smoking prevalence. Over the past twenty years the proportion of regular daily smokers decreased in most of the ECE countries but still remains on average at about $25 \%$ of the population aged 15 and above. The most progress in reducing number of regular smokers was in the Western Europe Region where the number declined from 34.5 in 1990 to 19.5 in 2010 (Table 1.7. Individual countries values are in Appendix 2, Table 3).

Table 1.7 Percentage of regular daily smokers in the population 1990-2010

\begin{tabular}{|l|r|r|r|}
\hline & $\mathbf{1 9 9 0}$ & $\mathbf{2 0 0 0}$ & $\mathbf{2 0 1 0}$ \\
\hline South-Eastern Europe & 34.68 & 33.15 & 24.99 \\
\hline Eastern Europe and Caucasus & 37.95 & 33.92 & 31.48 \\
\hline Central Asia & 14.00 & 19.37 & 22.33 \\
\hline New EU States & 30.05 & 28.66 & 24.81 \\
\hline EU15 & 30.08 & 29.12 & 22.76 \\
\hline Western Europe - Non EU Member & 34.54 & 26.68 & 19.48 \\
\hline North America and Israel & 34.00 & 27.00 & 21.70 \\
\hline Total & 31.62 & 30.10 & 25.94 \\
\hline
\end{tabular}

Source: WHO (2013)

Although there is clear progress in reducing smoking prevalence in the ECE region, alcohol consumption, another important contributor to mortality, has stayed relatively unchanged. In 2010, it was about 9.5 litres per capita of population aged 15-plus in the ECE region. In the last two decades, alcohol consumption increased considerably in some countries, notably in Belarus, Moldova, Russia, Ukraine, and the Czech Republic.

Obesity is another factor known to increase risk of serious diseases, impacting life quality and life expectancy both for individuals and in the aggregate. According to the World Health Organization (WHO, 2013), a person is considered obese if he or she has a Body Mass Index (BMI) of 30 or more. The populations of developed countries are getting more obese over at least the second half of the twentieth century, now constituting a serious problem. Almost one quarter of the population in the ECE region was obese in $2008(24.5 \%)^{7}$, with slightly more obese women than men. The national differences are quite high. The lowest level of obesity is in the Central Asian republics with the lowest level in Tajikistan (10\%), while the highest level is in the USA (32\%). Some countries exhibit a striking difference between the level of obesity in men and women. In Turkey about 36 per cent of women are obese, compared with 23 per cent of men. Armenia and Azerbaijan show even higher differences. (Appendix 2, Table 3, regional averages are in Table 1.8).

\footnotetext{
${ }^{7}$ This is an age-standardized estimate.
} 
Table 1.8 BMI $\geq 30$ (age-standardized estimate) Total, Women and Men 2008

\begin{tabular}{|l|r|r|r|}
\hline & Total & Women & Men \\
\hline South-Eastern Europe & 27.88 & 32.55 & 23.02 \\
\hline Eastern Europe and Caucasus & 23.66 & 28.36 & 17.50 \\
\hline Central Asia & 18.08 & 20.59 & 14.97 \\
\hline New EU States & 22.71 & 22.26 & 22.76 \\
\hline EU15 & 20.06 & 18.84 & 21.12 \\
\hline Western Europe - Non EU Member & 16.93 & 14.21 & 19.68 \\
\hline North America and Israel & 30.94 & 32.18 & 29.51 \\
\hline Total & 24.46 & 25.65 & 22.83 \\
\hline
\end{tabular}

Source: WHO (2013)

High blood pressure is a wide-spread problem in the ECE region; about $35 \%$ of men and $29 \%$ of women suffer from high blood pressure. ${ }^{8}$ The sub-regional differences are marginal although national differences exist. However, the age-standardized measures may be of varied reliability.

\section{$\underline{\text { Environmental health }}$}

Good health and quality of life depend on, among other factors, the quality of the environment in which the population lives. Access to a clean water source and $\mathrm{CO} 2$ emissions per capita are two environmental quality indicators. The first reflects quality of life and good health prospects for individuals; the latter reflects the ecological footprint society leaves behind, due principally to production and consumption methods and patterns. The cumulative impacts of the latter are felt globally and will also affect the wellbeing of future generations.

Access to a high-quality water source in satisfactory amounts is almost universal in the ECE region, as it was already in 1990. ${ }^{9}$ Some countries, such as Turkey and Georgia, with non-universal access in 1990 have subsequently made significant progress towards universal provision of secure water sources. In some other countries progress has been slower and requires further attention, as in Tajikistan, Azerbaijan, and Uzbekistan (see Table 1.9 and Appendix 2, Table 4)

\footnotetext{
${ }^{8}$ Unstandardized measure, defined as (SBP $\geq 140$ OR DBP $\left.\geq 90\right)$.

${ }^{9}$ Access to an improved water source refers to the percentage of the population with reasonable access to an adequate amount of water from an improved source, such as a household connection, public standpipe, borehole, protected well or spring, and rainwater collection. Unimproved sources include vendors, tanker trucks, and unprotected wells and springs. Reasonable access is defined as the availability of at least 20 liters a person a day from a source within one kilometer of the dwelling.
} 
Table 1.9 CO2 emissions (metric tons per capita) and Improved water source (per cent of population with access) 1990-2010

\begin{tabular}{|l|r|r|r|}
\hline CO2 emission (metric tons per capita) & $1990-2010$ & \\
\hline & $\mathbf{1 9 9 0}$ & $\mathbf{2 0 0 0}$ & $\mathbf{2 0 1 0}$ \\
\hline South-Eastern Europe & 2.67 & 3.5 & 4.0 \\
\hline Eastern Europe and Caucasus & $\ldots$ & 8.8 & 9.1 \\
\hline Central Asia & $\ldots$ & 5.3 & 6.6 \\
\hline New EU States & 8.23 & 6.6 & 6.4 \\
\hline EU15 & 7.88 & 8.4 & 7.4 \\
\hline Western Europe - Non EU Member & 6.80 & 6.7 & 7.1 \\
\hline North America and Israel & 19.01 & 19.8 & 16.9 \\
\hline Total & 11.85 & 10.9 & 10.1 \\
\hline Improved water source (\% of population & with access) & $1990-2010$ & \\
\hline & $\mathbf{1 9 9 0}$ & $\mathbf{2 0 0 0}$ & $\mathbf{2 0 1 0}$ \\
\hline South-Eastern Europe & 88.25 & 94.15 & 99.67 \\
\hline Eastern Europe and Caucasus & 92.11 & 94.72 & 96.64 \\
\hline Central Asia & 92.66 & 86.64 & 86.75 \\
\hline New EU States & 90.98 & 94.31 & 99.75 \\
\hline EU15 & 99.78 & 99.94 & 99.97 \\
\hline Western Europe - Non EU Member & 100.00 & 100.00 & 100.00 \\
\hline North America and Israel & 99.12 & 99.12 & 99.12 \\
\hline Total & 96.61 & 97.28 & 98.44 \\
\hline
\end{tabular}

Source: Carbon Dioxide Information Analysis Center, Environmental Sciences Division, Oak Ridge National Laboratory, World Health Organization and United Nations Children's Fund, Joint Measurement Programme

$\mathrm{CO} 2$ emissions per capita vary greatly in the ECE region; in general the countries with higher GDP per capita have higher $\mathrm{CO} 2$ emissions per capita than economically less developed countries (see Figure 1.5). The biggest $\mathrm{CO} 2$ polluting country is the USA with 17.3 metric tons of $\mathrm{CO} 2$ per capita per year, while the smallest polluter is Tajikistan with 0.4 metric tons. Most of the West ECE region countries managed to decrease their per capita CO2 emissions between 1990 and 2010, including the USA. New EU states showed positive progress in the 1990s but experienced stagnation or only a small decrease in the subsequent decade However, the biggest per capita polluting country in the New EU States, the Czech Republic, has been relatively successful in decreasing its $\mathrm{CO} 2$ emissions. Further east and south-east, the ECE countries had a slight increase in per capita CO2 emissions in the last two decades (see Table 1.9 and Appendix 2, Table 4). 
Figure 1.5 GDP per capita (current US\$) 2010 and CO2 emission (metric tons per capita) 2010

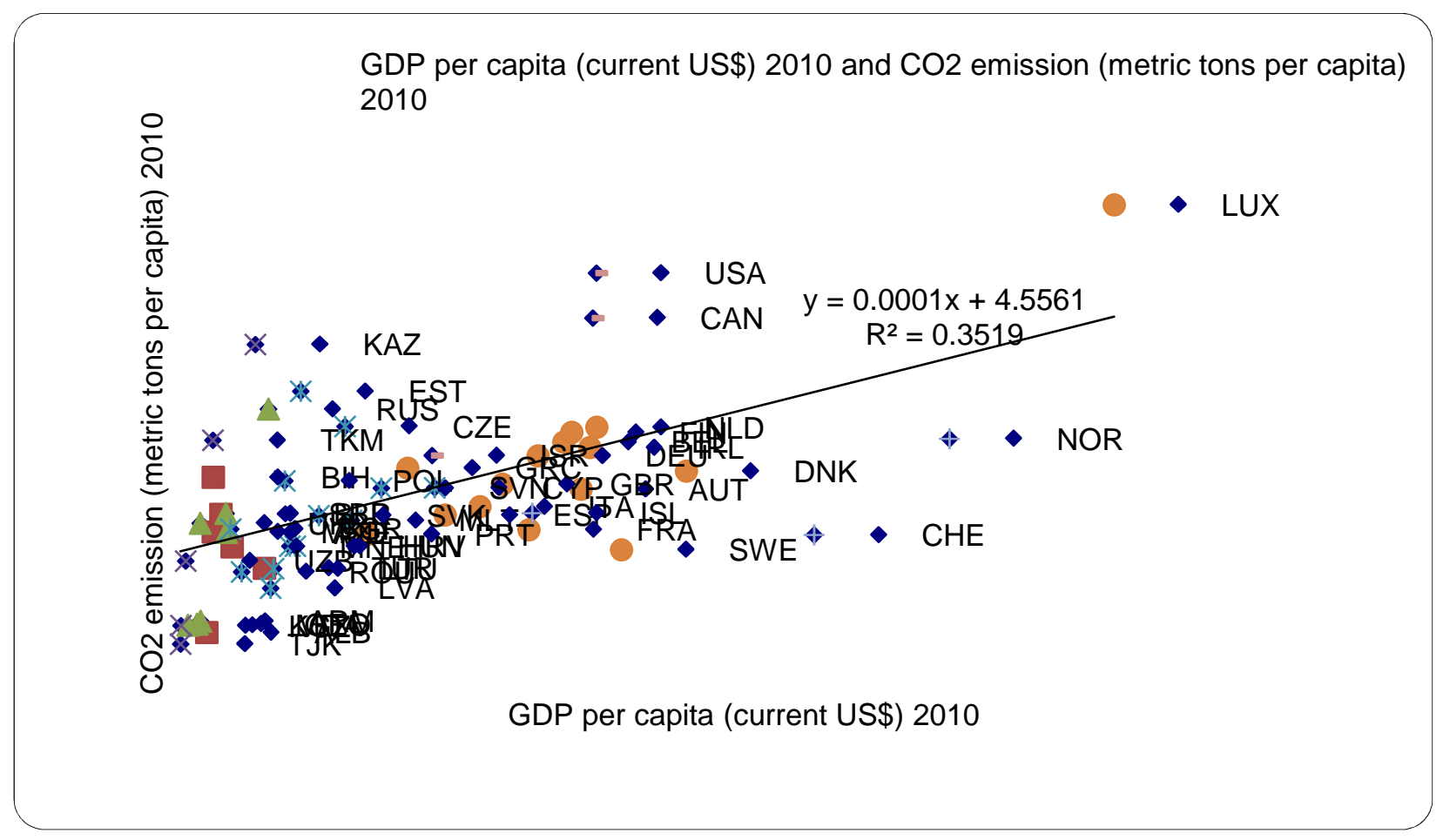

Source: World Bank Database (http://data.worldbank.org/indicator)

The answer to Hot Question 1

The answer is more nuanced and useful than would result from simply looking at changing age structures. Chronological ageing of the population in the ECE region is going to accelerate in the decades to come but relative population ageing as measured by fitness, health, disability and cognitive capacity will progress much more slowly than chronological ageing. Age- and sex-specific disability is constantly changing in the successive cohorts. This is expected to continue improving in the ECE countries over time. None of the ECE countries can escape ageing. But the healthier societies with fitter elderly populations will age more slowly, in the respects that matter most, than even chronologically younger societies. So for example, when comparing Russia and France, much chronologically younger Russia in 2050 will have a higher Prospective Old Age Dependency Ratio than much chronologically older France. Which of the two societies will be older? In important respects, the answer will be Russia.

More generally, the answer to Hot Question 1 depends importantly on the educational, social, health and welfare systems in each country and on their environmental policies as these affect health. What hampers national economic performance is not population ageing, per se. It is rather insufficient activity of the national governments and firms to prepare for population ageing and adjust to it. Countries with successively healthier, better educated and economically active cohorts entering traditional retirement ages may well find themselves better off than if fewer people were reaching retirement age but with lower health and cognitive functioning and economic dependency. National governments should design policies 
to: keep older persons in economic activity by adjusting age at retirement to growing healthy life expectancy; institute policies to reduce smoking and obesity; control unhealthy emissions; adjust pension schemes to the increasing remaining time people can be expected to remain in pension; and educate younger cohorts so as to maintain their economic productivity at older ages. We focus on the policy debates and on social and welfare systems that are working toward these goals in Part 2 of the Report.

\section{Hot Question 2: Is Migration a Threat or Opportunity for Development?}

Migration is a principal means by which people try to maintain or improve their wellbeing. Apart from forced migration, this motivation frequently succeeds for the individuals and families who migrate, but the consequences of migration for the areas entered and those left behind are much more mixed. These consequences arise in labour markets, settlement patterns, and characteristics of social cohesion. When migration in or out is substantial enough to affect countries' or areas' age and/or sex distributions, consequences can be long-lasting. Consequences for fertility levels are discussed along with other fertility considerations.

\section{$\underline{\text { Volume of migration }}$}

A basic distinction is between migration that occurs within the boundaries of countries and migration that crosses international borders. Although many of the processes shaping internal and international migration are similar, the controls countries exert over international migration are much greater than those within countries. Internal migration is usually a more available option than international migration, involving less regulation, smaller distances, lower costs, ease of travel, and less economic, social and cultural disruption. Accordingly, in most contexts the rates of internal migration are much greater than the rates of international movement. But because international migration influences country-level demographic change, we concentrate here on the former.

While only 3.1 per cent of the world's population lives outside of their country of birth, this percentage is above 10 per cent for nationals of some countries. Foreign-born shares can also be substantial relative to the population of countries of destination, with levels above 10 per cent in North America and most of Western Europe and Oceania, and parts of South East Asia. In some of those countries, the percentage is significantly higher than 10 per cent.

Table 1.10 shows the importance of international migration across the ECE sub-regions in several dimensions (Country detail is in Appendix 2. Table 5). In 2000, the EU15, Western Europe non-EU, and North America and Israel had substantially larger relative stocks of immigrants than the sub-regions farther east and south. Their population proportions also gained over the subsequent decade, while the eastern and southern sub-regions held relatively steady. Differences in net migration-number of immigrants minus emigrants over a five-year period-largely correspond to these percentage differences. However, one important flow is hidden in these regional averages (but evident in the Appendix table), that from the former Soviet countries to the Russian Federation. 
Table 1.10 Migration Stocks and Flows

\begin{tabular}{|c|c|c|c|c|c|}
\hline & $\begin{array}{l}\text { International } \\
\text { migrant } \\
\text { stock (\% of } \\
\text { population) } \\
2000\end{array}$ & $\begin{array}{l}\text { International } \\
\text { migrant } \\
\text { stock (\% of } \\
\text { population) } \\
2010\end{array}$ & $\begin{array}{l}\text { Net } \\
\text { Migration } \\
10 \quad 1996- \\
2000\end{array}$ & $\begin{array}{l}\text { Net } \\
\text { migration } \\
2006- \\
2010\end{array}$ & $\begin{array}{l}\text { Emigration } \\
\text { rate of tertiary } \\
\text { educated (\% of } \\
\text { total tertiary } \\
\text { educated } \\
\text { population) } \\
2000\end{array}$ \\
\hline South-Eastern Europe & 3.0 & 2.6 & $-130,147$ & $-46,429$ & 8 \\
\hline $\begin{array}{lll}\text { Eastern } & \text { Europe } & \text { and } \\
\text { Caucasus } & & \\
\end{array}$ & 9.0 & 9.1 & $1,359,372$ & 728,922 & 2 \\
\hline Central Asia & 9.4 & 8.0 & $-579,374$ & $-282,103$ & 1 \\
\hline New EU States & 3.4 & 3.4 & $-138,160$ & 28,481 & 13 \\
\hline EU15 & 8.4 & 11.0 & 424,437 & 948,080 & 9 \\
\hline Western Europe - Non EU & 15.7 & 17.5 & 61,276 & 174,123 & 9 \\
\hline North America and Israel & 13.4 & 15.1 & $7,607,677$ & $4,483,341$ & 1 \\
\hline
\end{tabular}

Note: Please note that the regional averages may be biased by missing country-specific data

Source: United Nations Population Division, World Population Prospects

Figure 1.6 gives a snapshot of gross international migration flows between 2005-2009, aggregated at the level of the ECE sub-regions and other major world regions. ${ }^{11}$ The size of the bands is proportional to the number of migrants, the colours of the bands correspond to the colours of the inner circle segments of each region that is sending migrants, and the end points of the bands indicate the regions receiving the immigrants. Hence, Eastern Asia is sending many immigrants to the North America and Israel region (mostly to North America) and relatively few to EU15. Africa, on the other hand, sends many migrants to EU15 but relatively few to North America and Israel. Apart from these instances, the large flow from Latin America to North America and flows from Western Asia, the ECE region "trades" people with the rest of the world considerably less than do the other world regions. In particular, the counter-flows from North America and Europe to Asia are negligible, highlighting the strong impact of migration on the redistribution of population. Overall, most international migration occurs within the greater ECE region rather than between the ECE and other world regions, and much of that within sub-regions.

\footnotetext{
${ }^{10}$ Net migration is the net total of migrants during the period, that is, the total number of immigrants less the annual number of emigrants, including both citizens and noncitizens. Data are five-year estimates.

${ }^{11}$ These flow data are a time series forecast of the data presented in Abel, Reiomena, and Sander (2013), representing the number of people changing country of residence over the five-year period. These cannot be readily compared to annual flow statistics published by Eurostat and some countries.
} 
Figure 1.6 "Circos” Plot of Gross International Migration Flows
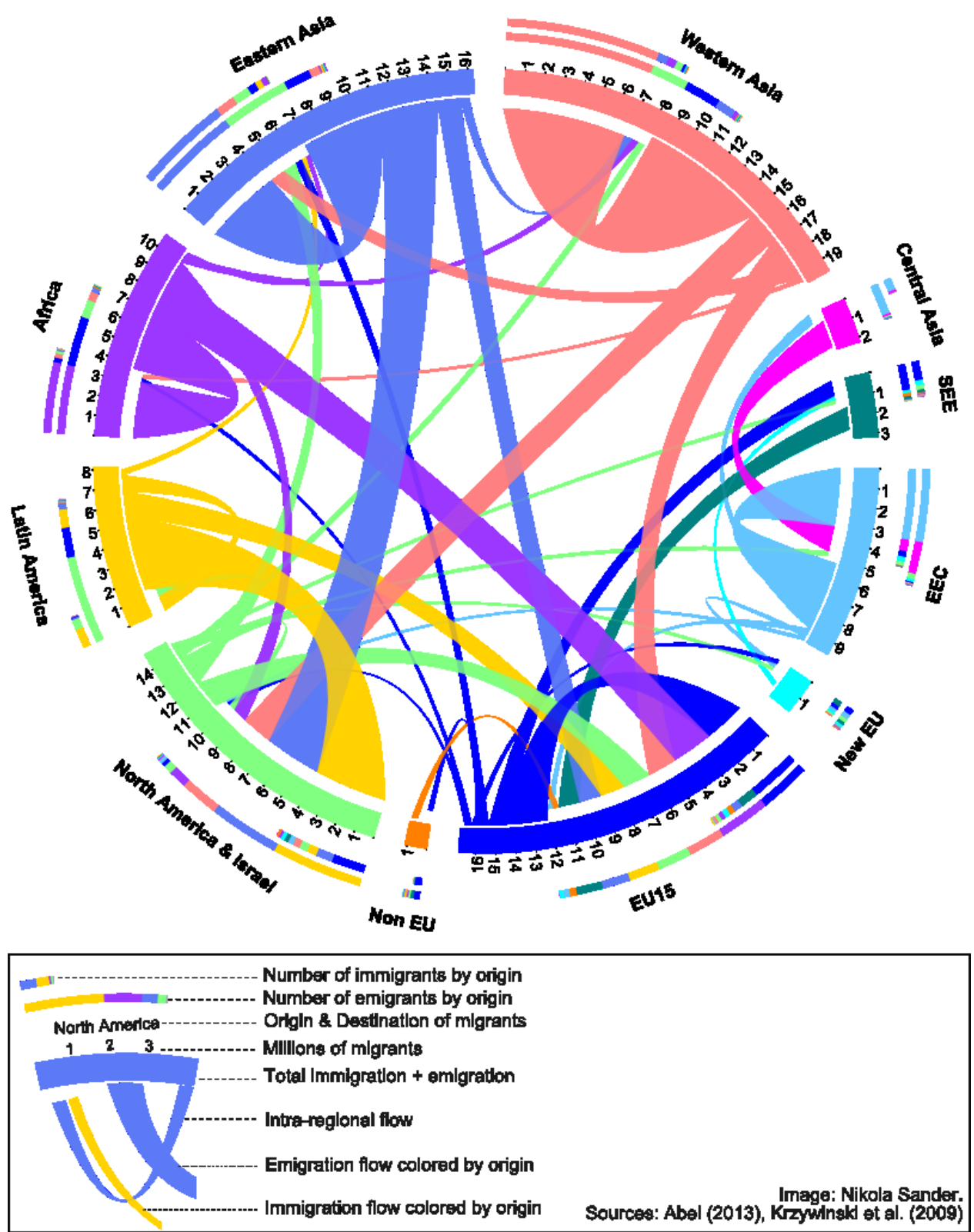
Factors influencing international migration ${ }^{12}$

In general, people may change their place of residence for economic, demographic, migration policy, environmental, or political reasons. Often, migration is the result of an interaction of these factors, making it difficult to distinguish the relative importance of each.

Most commonly, people migrate to further their economic position or to join family members who migrated before them. But other economic and non-economic factors play a role in influencing the timing and geography of international migration flows, as the poorest people from the poorest countries are generally not the most likely to migrate to the richest countries. Many move with more explicit purposes, to reduce different forms of social, economic, political, and environmental vulnerability (Bardsley and Hugo, 2013). Such purposeful migration typically spans international borders and often occurs despite multiple barriers to movement. Explicit migration policy can play a significant role. For instance, several kinds of active private and public recruitment efforts jump-started Turkish migration to Germany (Abadan-Unat, 1995; Massey et al., 1993).

Whatever the original motivation for international migration, it can set in motion a series of social and economic changes in both sending and receiving societies, occurring through the progressive expansion and elaboration of migrant networks. When a migrant gets a job in a high-wage country, news can spread over that person's social network. Friends and relatives acquire a tie to someone who might lower the costs of movement and overcome the barriers to entry. Each new departure from the source country may expand the migrant network further. Among the effects in the sending country can be the splitting of families, leaving children behind in the care of grandparents. Once begun, international flows thus tend to become self-perpetuating and acquire momentum that can persist even after the original conditions have disappeared.

\section{The answer to Hot Question 2}

For many host countries in Western Europe, North America (and the Russian Federation), migration has partially compensated for the smaller cohort size of the "native" population compared to the generation of their parents. Most migrants migrate in younger adulthood. They contribute to the size of the reproductive cohort and therefore contribute to the host society not only by their economic activity but potentially also as parents to children born in the country. Moreover, apart from explicit policies to attract student migrants, the host country did not bear the burden of their schooling and rearing. When well integrated and employed, migrants are an asset for the host society. Apart from migrant worker situations that often succeed, the causes of difficulties are invariably inadequate integration, social exclusion and unemployment of migrants, challenges that are much easier to state than to overcome.

On the other hand, in the countries in the East ECE region that have experienced massive net outmigration such as Bulgaria, Romania, Serbia, Macedonia, Albania, Moldova, Ukraine, Belarus, Central Asian Republics, and Baltic states, productivity, ageing, family support systems and sustainability are negatively affected by the migration losses, despite the remittances by migrant workers. In these countries, it will be difficult if not impossible to find substitutes for the out-migrants, whether in the labor market or civil society more broadly. Neither increased investments in physical capital and infrastructure

\footnotetext{
${ }^{12}$ The material in this section is partly based on Abel, Reiomena, and Sander (2013).
} 
nor productive uses of remittances can make up for the varied but lost contributions to a society of educated and ambitious young adults, gainfully employed.

Altogether, the challenges and opportunities of international migration merge domestic with multinational interests like few other phenomena. At the base are first the incentives to migrate and the motivations of those who migrate. Following closely are the wellbeing and human rights of particular people, both the migrants and those left behind. The effects then spread broadly in both sending and receiving nations. We shall see in Part 2 that cooperative international policies, while they are difficult to establish and maintain, tend to meet the challenges and take advantage of the opportunities better than when countries act alone in their own interests.

\section{Hot Question 3: Is fertility in the ECE region too low?}

Most countries in the ECE region have below replacement or just replacement levels of fertility. The concept of replacement fertility is a simple one: to have aggregate fertility of today's women in reproductive ages that would allow them to be replaced numerically. Under current mortality conditions this implies a fertility level of on average 2.1 children per woman over her reproductive lifetime. In the policy debate, this benchmark of replacement fertility as the desired level is very present. Consequently, many national governments are concerned that their fertility level is too low if it does not reach replacement fertility.

\section{Fertility patterns and trends}

Although most countries in the ECE region belong to the group of countries having a period total fertility rate (TFR) below the replacement level, the region represents a very heterogeneous group of countries in terms of fertility histories (Table 1.11). In general, the TFR fell significantly in the 1990s in the eastern part of the ECE region and then stabilized or even increased slightly in the first decade of the $21^{\text {st }}$ century, whereas in the western part of the region this dynamic was much weaker. In all the countries of SouthEastern Europe the TFR was declining between 1990 and 2010, most substantially in Turkey and Albania (from 3.00 in 1990 to 2.07 in 2010 and from 3.2 to 1.41, respectively). The countries of Eastern Europe and the Caucasus saw a decline in the TFR after 1990 and a slight increase after 2005. Similar dynamics can be observed also in the New EU States. All countries in the above mentioned sub-regions now have a TFR of less than 2.1 with the exception of Azerbaijan.

The highest fertility among the ECE countries is in the Central Asian republics. Although their TFR dramatically decreased in the 1990s, it increased again in the last several years, now surpassing 2.5 in all five republics with the highest levels in Tajikistan (3.58) and Kyrgyzstan (3.08). ${ }^{13}$ The Western European and North American countries and Israel had higher or nearly the same levels of TFR in 2010 as in 1990.

\footnotetext{
${ }^{13}$ Data source UNICEF (2012)
} 
Table 1.11 Total Fertility Rate 1990-2050

\begin{tabular}{|l|r|r|r|r|r|}
\hline & $\mathbf{1 9 9 0}$ & $\mathbf{2 0 0 0}$ & $\mathbf{2 0 1 0}$ & $\mathbf{2 0 3 0}$ & $\mathbf{2 0 5 0}$ \\
\hline South-Eastern Europe Europe and & 2.80 & 2.17 & 1.93 & 1.83 & 1.72 \\
\hline $\begin{array}{l}\text { Eastern } \\
\text { Caucasus }\end{array}$ & 1.96 & 1.23 & 1.53 & 1.54 & 1.68 \\
\hline Central Asia & 3.83 & 2.55 & 2.37 & 1.95 & 1.76 \\
\hline New EU States & 1.90 & 1.33 & 1.39 & 1.52 & 1.58 \\
\hline EU15 & 1.55 & 1.52 & 1.65 & 1.75 & 1.76 \\
\hline $\begin{array}{l}\text { Western Europe - Non EU } \\
\text { Member }\end{array}$ & 1.67 & 1.66 & 1.69 & 1.83 & 1.86 \\
\hline North America and Israel & 1.90 & 2.06 & 1.93 & 1.94 & 1.91 \\
\hline Total & 1.94 & 1.69 & 1.74 & 1.77 & 1.78 \\
\hline
\end{tabular}

Source: United Nations Population Division, World Population Prospects and Wittgenstein Centre for Demography and Global Human Capital

This brief overview shows a certain reversal of the long-lasting pattern in which the economically most developed and richest countries also experienced the lowest fertility. This is no longer the case, not only within the ECE region but also globally with very low fertility in countries such as China and Iran, and rapidly decreasing fertility in most of the world's countries except for sub-Saharan Africa and a few Asian countries. How can such a pattern be explained? Is the low fertility in some ECE countries going to persist or is it merely in a transition period after which their fertility will stabilize again at higher levels?

A broad demographic, economic and sociology literature exists on different potential explanations of fertility decline. They are well summarized in Basten et al. (2013) and we shall follow here these authors' arguments. Several factors act together to determine period fertility as well as long-term fertility trends. Reviewing these factors will facilitate understanding not only why fertility has developed in the ECE countries as it has but also whether these countries' fertility can be expected to increase and under what conditions. In addition, this review will shed light on the usefulness of the replacement fertility level as an ideal and provide a realistic answer to the question of whether the fertility in the ECE region is too low.

\section{$\underline{\text { Replacement fertility }}$}

"In a precise demographic sense, replacement fertility only leads to constant population size and age structure in the absence of migration, under constant mortality conditions and the absence of irregular age structures. In most existing populations none of these conditions is met. Moreover, it is not clear whether constant population size is actually a desirable policy target and how population heterogeneity affects such criteria." (Striessnig and Lutz, 2013)

The fertility indicator that is most often interpreted as measuring the current level of fertility of women in the reproductive ages is the period total fertility rate (TFR). This indicator is very sensitive to changing in timing of fertility among women and in particular to fertility postponement. Several studies have shown that this indicator is misleading for these reasons and does not reflect well the actual number of children women have over their reproductive life (Sobotka and Lutz, 2011). In this respect, the only absolutely reliable indicator is to measure the completed cohort fertility rate of women who have completed their 
reproductive age. Table 1.13 and Appendix 2 Table 6 show these indicators for women born in 1970 with almost completed fertility. Other alternative period measure such as adjusted TFR ${ }^{14}$ and tempo- and parity-adjusted TFR are attempts to overcome the problems of TFR and when compared to cohort fertility give much more accurate results (Table 1.13 and Appendix 2, Table 6). Where data permit, the alternative TFR indicators should be used rather than the conventional ones (Bongaarts and Feeney, 1998; Bongaarts and Sobotka, 2012).

Not only numerical replacement matters when we are interested in measuring population sustainability in a broader societal context. The productivity of people matters as well. A population constituted of more productive but less numerous people can be more sustainable than a population with numeric replacement of generations but without increases in productivity. The economic contribution to society differs among individuals. This can be taken into account by modelling the productivity contribution of the population by the level of education. Striessnig and Lutz (2013) modelled the impact of education on productivity differentials and concluded that "if education is assumed to present a cost at young age and results in higher productivity during working age, then for most countries the desirable long-term total fertility rate turns out to be well below replacement level."

In this context, the employment of the population in economically active ages is very important. If a country has a young population with replacement fertility but its youth suffer high unemployment, the country is experiencing a burden to the social system rather than contributions to its sustainability. Similar issues may arise with long parental leaves for young mothers. Women are not economically active during long leaves and often have problems finding an adequate job after labour market absence. Not only the women but also the state is losing productivity when women are not provided with adequate options to combine parenthood with a professional career.

\section{Fertility postponement}

Postponement of the age of childbearing is a process that is inherently linked to the transition from higher to lower fertility levels in the last fifty years. In the West ECE region, the current mean age at first birth ranges between 28 and 30 years, four-to-six years later than in the early 1970s (Basten et al., 2013; Schmidt et al., 2012). In the East ECE region, the fertility postponement started only after 1989, and the mean age at first birth grew from a quite universal level of 23 to levels between 25 and 28. The trends suggest that further postponement will take place in the region in the coming years. A slightly different situation is found in the Caucasus and Central Asian republics where mean age at first birth has increased only slowly and remains under age 25 (Appendix 2, Table 6).

This postponement of first births is explained primarily as the result of the expansion of higher education and consequent later entrance into the labour market (Basten et al., 2013; Ní Bhrolcháin and Beaujouan, 2012). Other factors include the spread of hormonal contraception, rising economic and employment uncertainty in young adulthood, decline of marriage and rise of more unstable forms of partnerships, and spread of values incompatible with parenthood (Basten et al., 2013). As a consequence the proportion of births to mothers aged 35 and older is increasing, reaching about 24 per cent in Western Europe, 20 per cent in North America and Israel and somewhat less in the East ECE region (Table 1.12). Moreover the

\footnotetext{
${ }^{14}$ An indicator proposed by Bongaarts and Feeney (1998) that is based on fertility data by birth order.
} 
dynamics over time is very strong. In the countries with the highest proportion of mothers $35+$, such as Spain, the proportion of children born to them increased by nearly 10 percentage points over the last ten years (from $19.7 \%$ in 2000 to $29.7 \%$ in 2010 ).

Table 1.12 Percentage of all live births to mothers, age $35+$ years 2000 and 2010

\begin{tabular}{|l|r|r|}
\hline & $\mathbf{2 0 0 0}$ & $\mathbf{2 0 1 0}$ \\
\hline South-Eastern Europe & 8.32 & 12.33 \\
\hline Eastern Europe and Caucasus & 5.63 & 8.03 \\
\hline Central Asia & 5.04 & 6.74 \\
\hline New EU States & 7.53 & 12.92 \\
\hline EU15 & 17.73 & 23.57 \\
\hline Western Europe - Non EU Member & 18.11 & 25.19 \\
\hline North America and Israel & 15.32 & 20.07 \\
\hline Total & 12.01 & 16.91 \\
\hline Note: Please note that the regional & averages & may be biased by missing country-specific data \\
Source: UNDP (2011) & &
\end{tabular}

In a situation of postponing parenthood, the period indicator most commonly used to measure fertility, the TFR, is exposed to a "tempo effect" distortion, particularly strong in the years when the cohorts of younger women start postponing their births and older women have already given births to their children (Sobotka and Lutz, 2011). This results in low levels of TFR. This effect can explain the particularly low TFR in the East ECE countries between roughly 1995 and 2005. However, some observers tend to incorrectly interpret these values as implying similarly low cohort fertility levels in the future, suggesting an alarmist interpretation. A more accurate estimate of the period fertility is the Adjusted TFR (see Figure 1.7 to 1.9 and Table 1.13). In almost all countries of the ECE region, the current period TFR is influenced by the tempo effect: hence, higher fertility levels should be finally expected when the female cohort of today's childbearing age reaches menopause. The WIC population projections take this into account, showing expected TFR levels in 2050 between 1.5 and 2.0 in the countries of the ECE region (for the countries' TFRs and Adjusted TFRs see Appendix 2 Table 6). ${ }^{15}$

\footnotetext{
${ }^{15}$ For countries where data are available we use tempo- and parity-adjusted TFR; where data do not allow, we use tempo-adjusted TFR.
} 
Figure 1.7: Fertility trends in the Czech Republic, 1988-2010

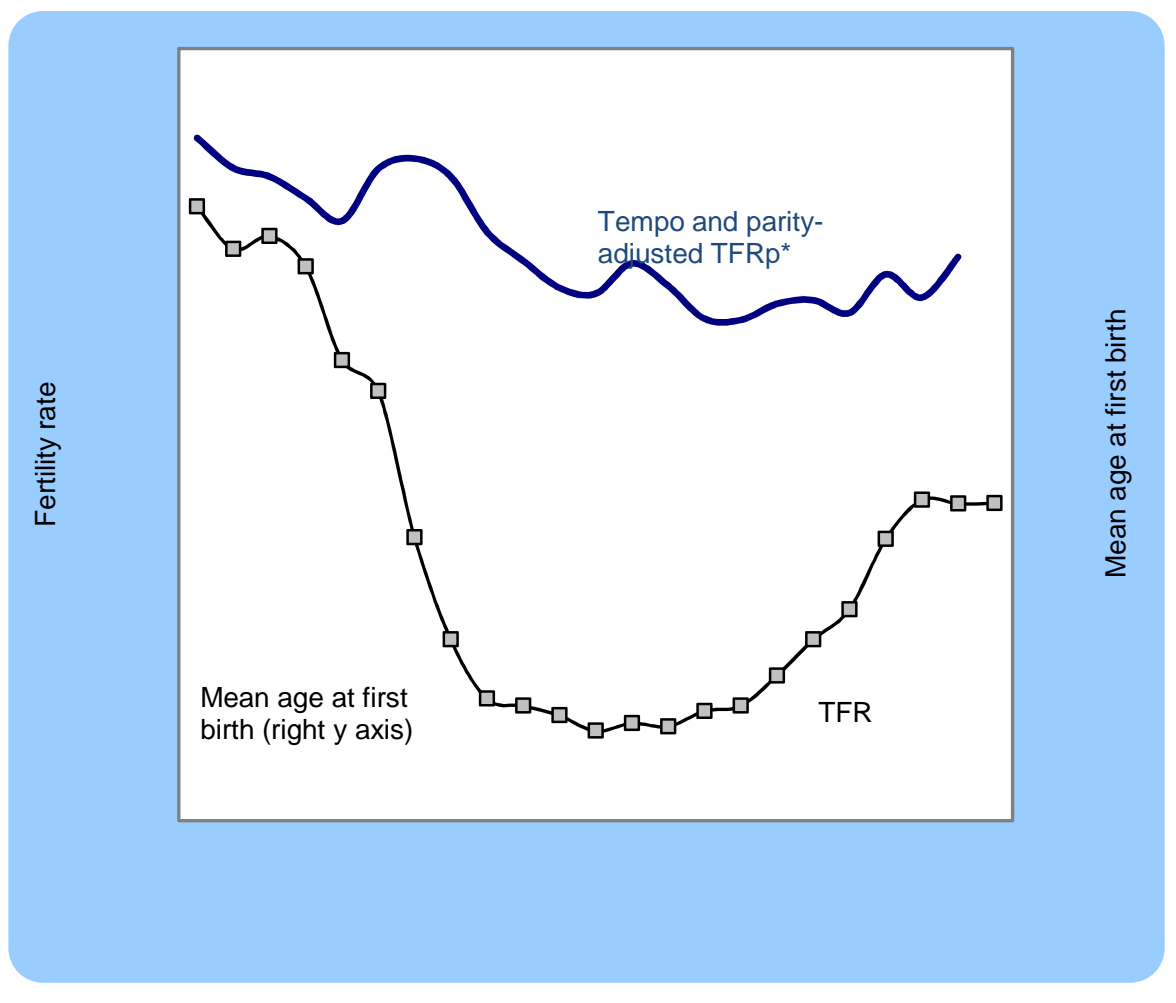
Source: Ediev et al.
(2012)

Figure 1.8: Fertility trends in Austria, 1974-2010

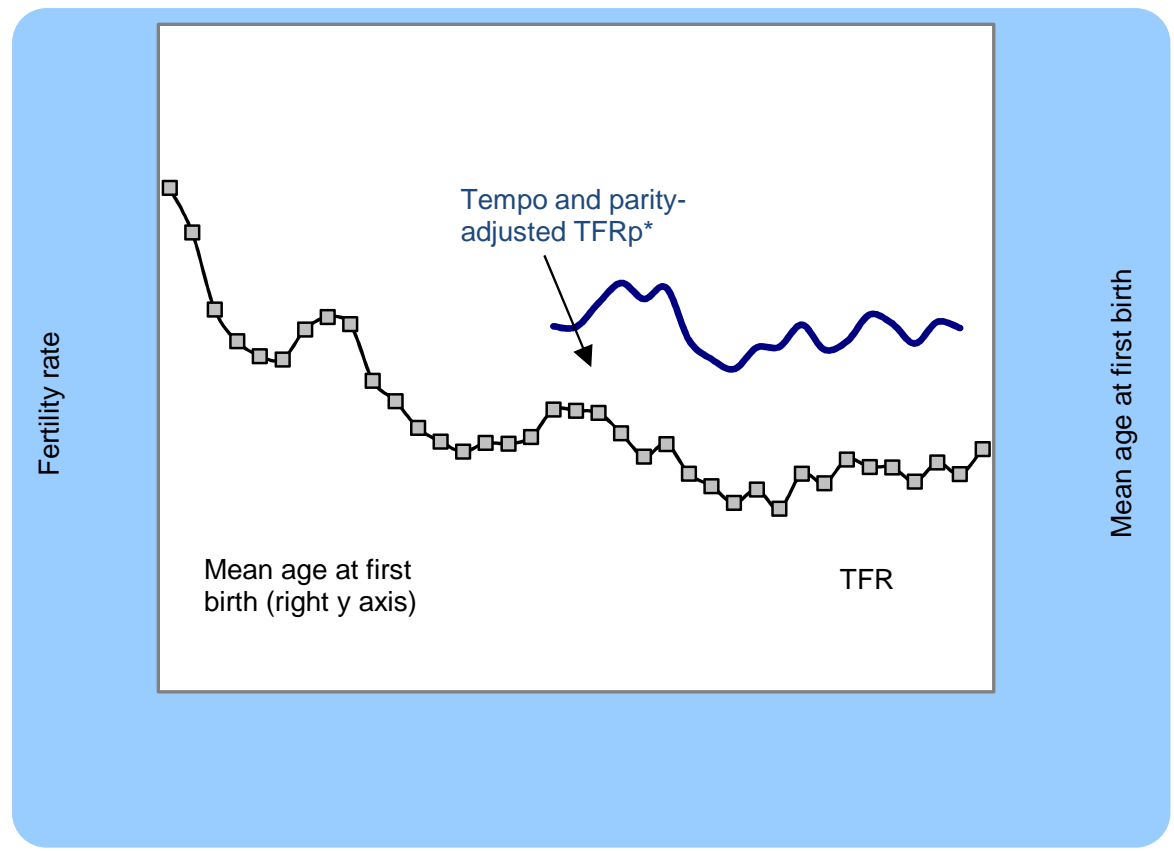

Source: Ediev et al. (2012) 
Figure 1.9: Fertility trends in Spain, 1980-2010

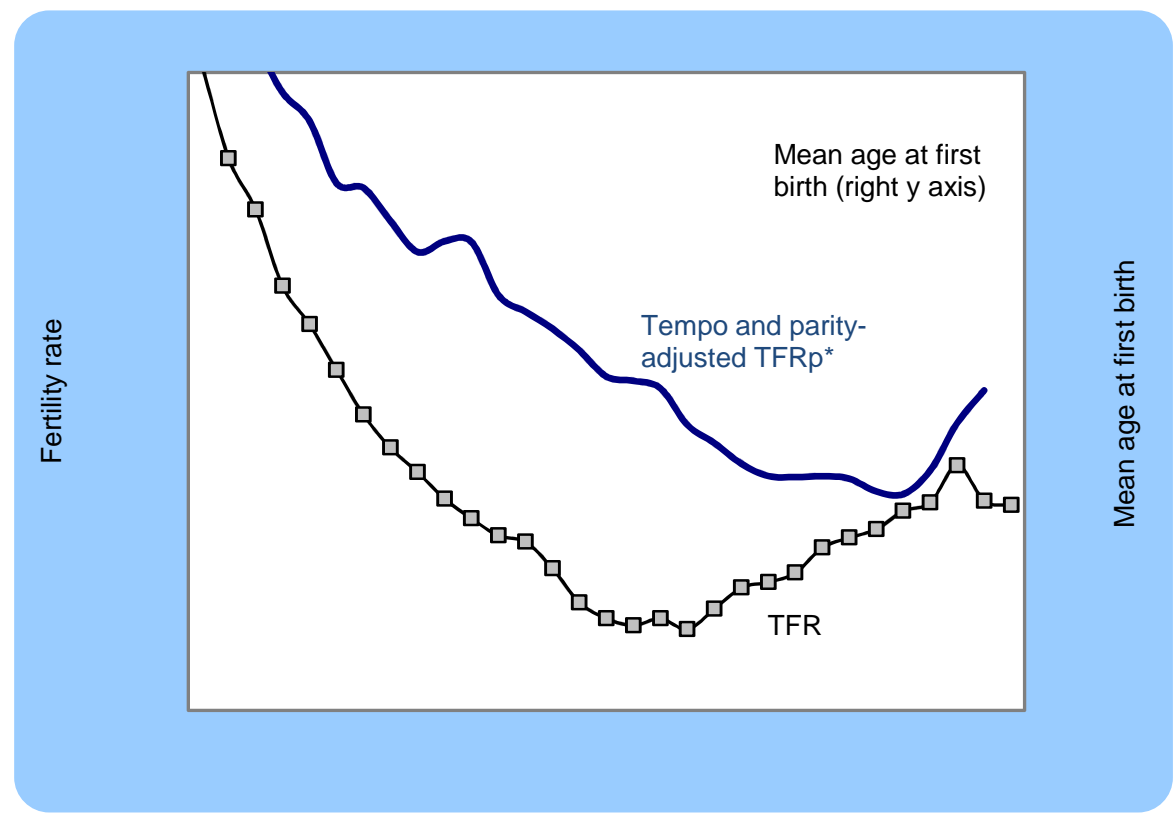

Source: Ediev et al. (2012)

Table 1.13 Total Fertility Rate 2010, Adjusted Fertility Rate 2010 and Completed Cohort Fertility 1970 (children per woman)

\begin{tabular}{|l|r|r|r|}
\hline & $\begin{array}{l}\text { Total Fertility } \\
\text { Rate 2010 }\end{array}$ & $\begin{array}{l}\text { Adjusted Total } \\
\text { Fertility Rate 2010 }\end{array}$ & $\begin{array}{l}\text { Completed Cohort Fertility, } \\
\text { women born 1970 (Children } \\
\text { per woman) }\end{array}$ \\
\hline South-Eastern Europe & 1.9 & 2.2 & 2.87 \\
\hline $\begin{array}{l}\text { Eastern Europe and } \\
\text { Caucasus }\end{array}$ & 1.5 & 1.7 & 1.59 \\
\hline Central Asia & 2.4 & $\ldots$ & $\ldots$ \\
\hline New EU States & 1.4 & 1.6 & 1.82 \\
\hline EU15 & 1.6 & 1.8 & 2.04 \\
\hline $\begin{array}{l}\text { Western Europe - Non } \\
\text { EU Member }\end{array}$ & 1.7 & 1.9 & 2.12 \\
\hline $\begin{array}{l}\text { North America and } \\
\text { Israel }\end{array}$ & 1.9 & 2.1 & 1.94 \\
\hline Total & 1.7 & 1.9 & \\
\hline
\end{tabular}

Note 1: Please note that the regional averages may be biased by missing country-specific data

Note 2: Adjusted TFR for the individual countries is computed mostly as tempo- and parity-adjusted TFR, where not available as Adjusted TFR.

Source: Ediev (2012) 
The best indicator for measuring fertility is the completed cohort fertility rate of the generation of women close to the end or after the end of their reproductive age. Unfortunately, this cannot be computed for women still in the childbearing ages, who may still have more children. Currently, the youngest generation with almost complete fertility is the generation of women born in 1970. The lowest 1970 cohort fertility in the ECE region is registered in Italy (1.46), Spain (1.47), Germany (1.50), and Ukraine (1.55). Relatively high fertility of the 1970 cohort, above two children per woman, is found in Turkey, USA, Ireland, Iceland, Sweden, Norway, France, Cyprus and Albania (see data in Appendix 2 Table 6).

These patterns suggest that the postponement of fertility leads to a different result in different countries. Although it seems that fertility postponement in the Nordic countries leads to recuperation and fertility levels of around two children per woman, in Spain and Italy it does not. Similar differences can be observed among the East ECE countries. In the New EU States, women born in 1970 have cohort fertility of around 1.8, a much higher level than would be indicated by the period TFR. However in the Eastern European countries, the 1970 cohort fertility is much lower than in the New EU States.

\section{$\underline{\text { Cultural factors }}$}

Cultural factors determining fertility are important because they create the environment in which women and couples make decisions about having children. These factors influence their desire for children (fertility intentions), the role they expect to have for themselves after the child is born, and their expectations about the cultural environment into which children would be born. The latter expectations are strongly linked to gender roles and the importance of religion in the society, as well as to family arrangements.

Fertility intentions refer to desired number of children and are most commonly measured among women. It is an important indicator because it foreshadows actual fertility behaviour to some extent. Despite some problematic points in measurement (Testa et al., 2011), the measure also has high policy relevance for at least two reasons. First, desired number of children represents in the aggregate approximately the ideal fertility women would like to have. Under the condition of widespread accessibility of modern contraceptives, women can achieve their desired intentions. When aggregate fertility is lower than desired fertility, it indicates the presence of some obstacles that did not allow women to fulfil their fertility desires. To understand these barriers and work on diminishing them is a relevant policy issue. Second, pronatalist policies that aim to increase fertility above the desired number of children women actually want to have are very unlikely to succeed.

Women in the EU countries have on average a quite stable desire for a two-child family, as shown in many consecutive waves of the Eurobarometer survey (Testa, 2012, 2006). The same survey also shows that more than one-third of Europeans stop childbearing with fewer children than initially desired (Basten et al., 2013; Testa, 2012). At the same time about 10-15 per cent of Europeans respond that they actually have more children than they initially desired. Far from all newborn children in the ECE region result from careful planning. For example, the proportion of unintended and unwanted pregnancies in the United States is very high, about 46 per cent in 2006 (Basten et al., 2013). It is particularly high among nevermarried young women and Latinos (Basten et al., 2013; Rocca et al., 2010). More generally, it is 
estimated that 47 per cent of pregnancies and 22 per cent of births in more developed countries are still unintended (Basten et al., 2013; Singh et al., 2010).

Gender relations and gender equality seem to play an important role in the developed countries when it comes to childbearing, although the evidence is mixed. The relationships depend on what sort of gender equity is measured, whether it is societal (political empowerment), household (division of labour), or attitudinal on the individual level (gender role attitudes) (Basten et al., 2013). Some evidence suggests that in the countries with more role equality between men and women fertility is higher than in countries with less equal gender relationships, even when general economic development and individual affluence are taken into account. Research conducted in the Nordic countries implies that gender equity between men and women in childcare has a positive impact on the number of children the family has (Duvander et al., 2010; Oláh and Bernhardt, 2008).

On the societal level, the Nordic countries are also among those with the highest proportion of women in leading positions. For example, they score the highest in the proportion of women in the national parliament, already in 1990 and reaching more than 40 per cent in 2010. The East ECE region scores very low on this measure, with the proportion of women in national parliaments still well below 20 per cent. Central Asia is somewhat higher in 2010 at 20 per cent. Some other Western ECE countries score no better. In the USA the share was also well below 20\%, as it was in Great Britain, France, Ireland, and Greece in 2010 (see Appendix 2 Table 8).

The culturally embedded role expectations for women-mothers also play an important role. In the societies where women are expected to devote time fully to childrearing for several years, the decision to have a child may be more difficult than in societies where such a social norm is not present. Contrasting countries in this respect are the German speaking countries and France. In Germany, Austria and Switzerland, women are commonly considered the best prime caregiver for the child until the age of three, whereas in France this norm does not exist. High childlessness of women (and especially of higher educated women) in the German speaking countries maybe be partly attributed to the conflict between career and childrearing that is particularly strong there. Similar conflicting situations for young women exist in the East ECE region. Evidence from the Czech Republic from the 2000s shows that particularly for women with high education it is difficult to combine a professional career with motherhood, as the prevailing public opinion considers long maternity leave (three years) to be the best option for children (Chaloupková, 2005; Kulhavý and Bartáková, 2007). In mid-2000 about 92 per cent of Czech women stayed on parental leave for at least two years after birth of their child. This is a higher proportion than before 1989. The fear that motherhood means personal isolation and a threat to the professional career also became widespread among young people without tertiary education (Kulhavý and Bartáková, 2007).

Religion is positively correlated with higher fertility in Western countries when measured by church attendance or self-assessed religiosity (Philipov and Berghammer, 2007). It is more individual religious practice and membership in a religious community that make the difference rather than mere formal adherence to a church. However, even some rather secular societies such as France and Sweden have relatively high fertility, while societies like Spain and Italy have among the lowest. Hence, the relationship between religion and fertility on the aggregate level is more complex than on the individual level (Basten et al., 2013). 
Sex ratio at birth is normally a biological constant, but in some societies with strong preference for sons it may occur that female foetuses are aborted more often, thereby skewing the sex ratio at birth and creating imbalances in the age structure. In more general terms, this is a sign of the inferior position of women and girls in such societies. In the ECE region, Armenia and Azerbaijan show a skewed sex ratio at birth in 2010 as do Georgia, Tajikistan, and Albania in 2000 (Appendix 2 Table 8).

\section{Employment and economic uncertainty}

The relationship between employment and economic uncertainty, on the one hand, and fertility, on the other hand, has been long observed, ever since the simultaneous development of increasing female labour force participation and declining fertility in developed countries. The competition of work experience, career growth and accumulation of capital for setting oneself up independently, and the long-time commitment connected with childbearing, present conflicting decisions today and much more so for young women than for young men. Factors on both the individual and aggregate levels matter for the depression of fertility, so that not only the individual experience of unemployment and difficulty finding a job matters, but also the social distress from living and working in an environment where unemployment threatens and contract duration is limited. Short-term contracts with meagre provisions and higher turnover have expanded, in particular, since the 1990s. This development has often resulted in a dualization of the labour market where the young have mostly unstable contracts and the older generation still regulated ones, pressing particularly on the cohorts in the prime childbearing ages (Basten et al., 2013). This is particularly the case in the Southern European countries but also in France and elsewhere.

Studies on the impact of the current economic crisis have shown a relationship with fertility across countries with different severities of the crisis. In most countries, the previously rising fertility trends halted and did not show any further increase after 2009. Some even started to decrease (Sobotka et al., 2011). Basten et al. (2013) state further that "in a recession, women who are at a point in their life-cycle when human capital accumulation is crucial may postpone childbearing to acquire more work experience and education. The pervasive long-term and youth unemployment characterised by the recent recession is bound to have a large negative impact on household permanent income. It may render childbearing unattractive not only for those directly affected by unemployment but also to those threatened by it."

The youth unemployment rate (of those aged 15-24 that are not fulltime students) is currently much higher than ten years ago in all countries of the ECE region and is also much higher than among the total population age 15+ (Table 1.14 and Appendix 2, Table 9). Accordingly, youth unemployment stands at more than 40 per cent in Spain, Serbia, Armenia, and Bosnia and Herzegovina. 

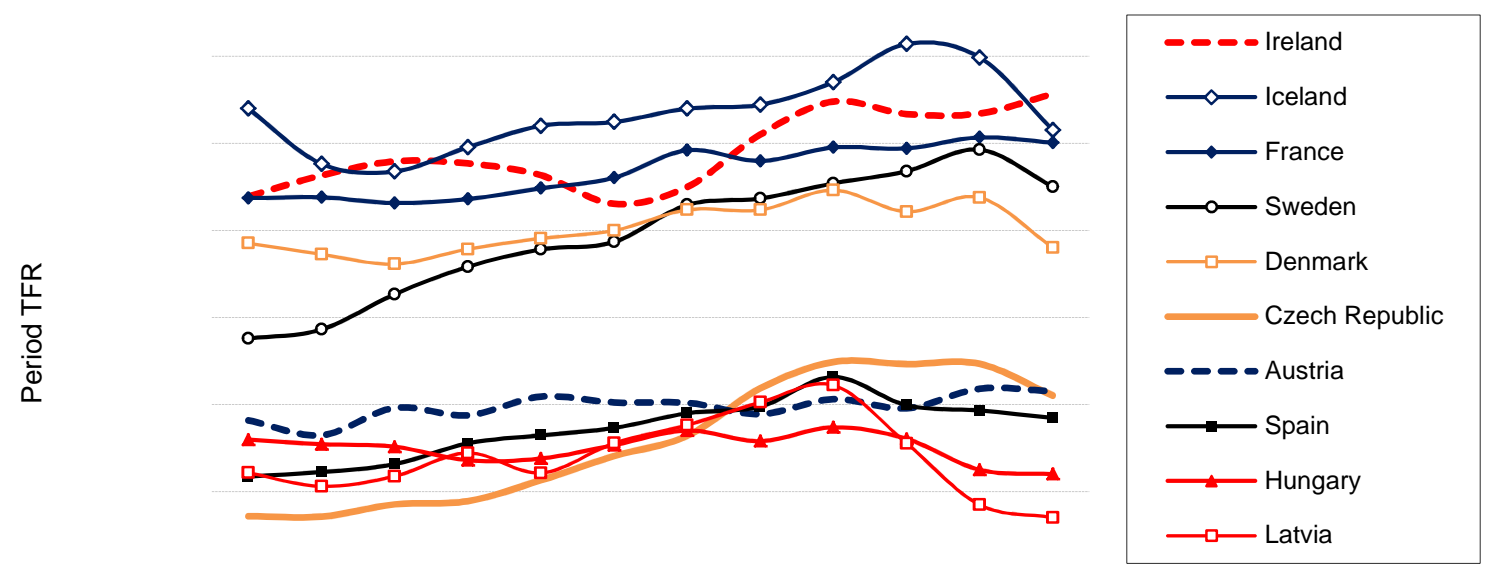

Source: Ediev et al. (2012)

Table 1.14 Unemployment, youth total (\% of total labor force ages 15-24) 200 and 2010

\begin{tabular}{|l|r|r|}
\hline \multicolumn{3}{|l|}{ Unemployment, youth total (\% of total labor force ages 15-24) 2000 and } \\
\hline & $\mathbf{2 0 0 0}$ & $\mathbf{2 0 1 0}$ \\
\hline South-Eastern Europe & 15.47 & 22.17 \\
\hline Eastern Europe and Caucasus & 21.12 & 18.09 \\
\hline Central Asia & 17.30 & 6.70 \\
\hline New EU States & 26.92 & 24.32 \\
\hline EU15 & 16.95 & 21.72 \\
\hline Western Europe - Non EU Member & 6.95 & 8.22 \\
\hline North America and Israel & 9.78 & 17.95 \\
\hline Total & 16.26 & 19.94 \\
\hline
\end{tabular}

Source: International Labour Organization (2011)

Economic uncertainty was a principal reason for the rapid fertility decline in the post-communist countries in the first decade of transformation. Sobotka et al. (2008, p. 403) conclude for the case of the Czech Republic that "the rapidity of observed changes can be explained as the outcome of a simultaneous occurrence of several factors, especially the expansion of higher education, the emergence of new opportunities competing with family life, increasing job competition, rising economic uncertainty in young adulthood, and changing partnership behaviour". 


\section{Migrants' fertility}

Migrants tend to have higher fertility than the "native" women in the ECE region (Sobotka et al., 2008). However, the origin of migrants matters in this regard. Where the second generation is concerned, very often they show similar fertility patterns as the "native women". In this context it is useful to stress that "in most European countries with sizeable immigration, migrants' fertility has had a small positive effect on country TFR around 2007 and 2008, ranging from 0.03 in Germany to 0.13 (England and Wales) in absolute terms" (Basten et al., 2013). These findings contradict the common wisdom that birth rates among immigrants have huge impacts on the domestic fertility rate.

\section{Biomedical factors}

With the increasing mean age at birth and postponement of conception, the risks that women will not succeed in getting pregnant and not carry the pregnancy successfully to term are increasing. Natural sterility or the inability to get pregnant increases slowly after age 30 and progresses much faster after age 40. By age 40 almost 17 per cent of all women are permanently sterile and about 35 per cent of women who will try to conceive for the first time will remain childless (Leridon, 2008). This effect combined with more and more women postponing childbearing is increasing the demand for assisted reproduction services. These are, however, quite costly and at older ages not so successful unless the oocytes (eggs) come from a donor woman. In 2008 about 4.6 per cent of children were conceived via assisted reproduction in Denmark and about 0.5 per cent in Turkey (according to ESHRE 2011, cited from Basten et al., 2013).

Male infecundity and low sperm quality are other factors that may prevent a successful conception. The link to age is, however, less direct and the progression of male infecundity while ageing is much slower and later in life than among women. A secular decline in sperm quality over time is observed in some biomedical research, but the evidence and causes are still inconclusive.

\section{Education}

Traditionally, higher levels of education of women have been associated with lower fertility. However, today in the low fertility countries where higher education of women is increasing, this relationship is less straightforward and less universal. There are multiple effects that higher education has on fertility behaviour. As more women today get higher education these effects are relevant for a larger share of the cohorts in the prime reproductive age. First, the fact that women spend more years in education leads to a postponement of childbearing into higher ages, since it is generally considered undesirable to have children during the studies. Moreover, women with higher education (and therefore higher time and financial investment in education) may want to establish themselves in the labour market and create financial independence for themselves before considering a career break due to childbearing. This relates to the second point, that higher educated women have higher opportunity costs of childbearing. This may contribute not only to delay but also to decline of fertility (Basten et al., 2013).

Gender equality and accessible formal childcare seem to be particularly important for the fertility decision of highly educated women (Van Bavel and Różańska-Putek, 2010)). It has been shown that in the Nordic countries, "the fertility gradient by level of education has almost disappeared for women, and parity progression ratios to a second and third child are positively associated with women's education level" (Basten et al., 2013; see also Kravdal and Rindfuss, 2008). It seems that this positive association is linked 
to generous family policies in the Nordic countries, to accessible child care for children under the age of three, and to promotion of gender equity in family life (Basten et al., 2013; see also Kravdal and Rindfuss, 2008) .

In the ECE countries where female education is growing rapidly, the key factor in maintaining higher fertility or increasing it is to give women the opportunity to combine work and family life and to promote gender equality in the cultural framework, and therefore in women's and couples' mindset.

\section{Reproductive health}

The maternal mortality ratio ${ }^{16}$ in the ECE region has generally declined in the last two decades. The West ECE region had a very low maternal mortality ratio already in 1990 and has maintained these very low levels. The eastern ECE countries have made good progress in substantially decreasing maternal mortality over the last two decades (Table 1.15 and Appendix 2, Table 7). In particular, the New EU States have made significant progress, with some countries achieving comparable levels of maternal mortality with the West ECE countries. Countries such as Estonia have championed the decrease in maternal mortality from 48 to 5 in the last two decades.

Central Asia and Eastern Europe and the Caucasus still have relatively high maternal mortality ratios but have slowly progressed compared to the 1990 estimates. The highest levels are in the Central Asian republics and Georgia with levels above 50 (except for Uzbekistan, where it is much lower). Although in most countries maternal mortality decreased over time, the USA was one of the few countries with an increase between 2000 and 2010. The US maternal mortality ratio in 2010 was at comparable levels to Turkey (ratio of 21).

Table 1.15 Maternal Mortality Ratio (Modeled estimate, per 100,000 live births)

\begin{tabular}{|l|r|r|r|}
\hline & $\mathbf{1 9 9 0}$ & $\mathbf{2 0 0 0}$ & $\mathbf{2 0 1 0}$ \\
\hline South-Eastern Europe & 57 & 34 & 19 \\
\hline Eastern Europe and Caucasus & 65 & 51 & 33 \\
\hline Central Asia & 76 & 62 & 45 \\
\hline New EU States & 51 & 20 & 13 \\
\hline EU15 & 11 & 8 & 7 \\
\hline Western Europe - Non EU Member & 8 & 7 & 8 \\
\hline North America and Israel & 11 & 13 & 20 \\
\hline Total & 32 & 23 & 19 \\
\hline
\end{tabular}

Note: Please note that the regional averages may be biased by missing country-specific data

Source: UNFPA, UNICEF, WHO and the World Bank(2012)

The proportion of teenage mothers has been decreasing in the ECE region and is very low in all the subregions. Less than five per cent of all children are born to teenage mothers on average in the ECE region with the highest proportion in Georgia at 13 per cent (Table 1.16 and Appendix 2, Table 6). Eastern

\footnotetext{
${ }^{16}$ The maternal mortality ratio is the number of women who die during pregnancy and childbirth, per 100,000 live births. Here we use modeled estimates based on regression models with information on fertility, birth attendants, and HIV prevalence. Data source: World Bank Database
} 
Europe and the Caucasus have experienced a large decrease in the proportion of young mothers in the last decade, particularly in Ukraine, Armenia, and Belarus.

The decrease in teenage pregnancies could be caused by a higher prevalence of contraception and spread of modern contraceptives or by increased abortions among teenage pregnant women. In the East ECE region where the decrease in the proportion of newborns to teenage mothers was the strongest, we do not observe an increase in abortions of teenage women (as far as measured by the number of abortions per 1000 live births). This means that most of the decrease in teenage births had to be due to more efficient and more frequent contraceptive use.

When teenage pregnancy happens, abortion is a much more common outcome in West ECE countries than in the East (Table 1.17. For individual country data see Appendix 2, Table 7). Most of the Western European countries with available data have more teenage pregnancies ending in abortion than in live births and this is a growing tendency over time. In Central Asia and Eastern Europe and the Caucasus, the abortion outcome is the least frequent with a decreasing tendency over time.

Table 1.16 Percentage of Live births to mothers, age under 20, 2000 and 2010

\begin{tabular}{|l|r|r|}
\hline & $\mathbf{2 0 0 0}$ & $\mathbf{2 0 1 0}$ \\
\hline South-Eastern Europe & 8.1 & 5.9 \\
\hline Eastern Europe and Caucasus & 14.1 & 8.4 \\
\hline Central Asia & 7.3 & 4.4 \\
\hline New EU States & 9.3 & 6.1 \\
\hline EU15 & 4.2 & 3.1 \\
\hline Western Europe - Non EU Member & 1.7 & 1.3 \\
\hline North America and Israel & 3.3 & 2.3 \\
\hline Total & 7.3 & 4.7 \\
\hline
\end{tabular}

Note: Please note that the regional averages may be biased by missing country-specific data Source: UNDP (2011)

In general however, abortion rates are declining in the ECE region. This trend is particularly strong in the East ECE countries where the abortion rate was very high in the past. Still today, with the exception of some Central Asian Republics, the ECE countries have a higher number of abortions per 1000 live births than in Western Europe. Currently the highest ratio of abortions to live births is in Russia, Hungary, Estonia and Romania, where for every two live births there is one abortion. Nevertheless, in particular in Russia, the decrease in abortion over the last decade was very significant, although in 2000 there were still more pregnancies ended by abortion than by birth of a child (Table 1.17, Appendix 2 Table 7). 
Table 1.17 Abortions per 1000 live births, age under 20 and total, 2000 and 2010

\begin{tabular}{|c|c|c|}
\hline \multicolumn{3}{|c|}{ Abortions per 1000 live births, age under 20 years old 2000-2010 } \\
\hline & 2000 & 2010 \\
\hline South-Eastern Europe & 184 & 206 \\
\hline Eastern Europe and Caucasus & 540 & 226 \\
\hline Central Asia & 192 & 119 \\
\hline New EU States & 646 & 555 \\
\hline EU15 & 1032 & 1206 \\
\hline Western Europe - Non EU Member & 1658 & 1724 \\
\hline North America and Israel & 622 & 687 \\
\hline Total & 831 & 848 \\
\hline \multicolumn{3}{|c|}{ Abortions per 1000 live births $2000-2010$} \\
\hline & 2000 & 2010 \\
\hline South-Eastern Europe & 473 & 87 \\
\hline Eastern Europe and Caucasus & 1291 & 477 \\
\hline Central Asia & 254 & 137 \\
\hline New EU States & 464 & 231 \\
\hline EU15 & 217 & 206 \\
\hline Western Europe - Non EU Member & 192 & 184 \\
\hline North America and Israel & 142 & 118 \\
\hline Total & 568 & 269 \\
\hline
\end{tabular}

Source: UNDP (2011)

Prevalence of HIV in the ECE region has shown a significant increase, especially in the last two decades. In particular, HIV prevalence in the population aged 15-49 has exhibited an increasing trend over the last 20 years, especially in some countries (Table 1.18 and Appendix 2, Table 7). ${ }^{17}$ For instance, Ukraine and Macedonia have shown substantially increased HIV prevalence between 1990 and 2000. Also, Estonia and Latvia have shown large increases in HIV prevalence. Causes of the HIV epidemic vary across countries in the Region. In Estonia, injecting drug users are the most at risk (Rüütel et al., 2011). Other countries have shown similar trends wherein the people at risk are intra-venal drug users, men having sex with men, and young people in the 15-24 age group.

\footnotetext{
${ }^{17}$ Prevalence of HIV refers to the percentage of people ages 15-49 who are infected with HIV. Data source: World Bank Database
} 
Table 1.18 Prevalence of HIV, total (per cent of population aged 15-49)1990-2010

\begin{tabular}{|l|r|r|r|}
\hline & $\mathbf{1 9 9 0}$ & $\mathbf{2 0 0 0}$ & $\mathbf{2 0 1 0}$ \\
\hline South-Eastern Europe & 0.10 & 0.10 & 0.10 \\
\hline Eastern Europe and Caucasus & 0.10 & 0.56 & 0.59 \\
\hline Central Asia & 0.10 & 0.12 & 0.24 \\
\hline New EU States & 0.10 & 0.11 & 0.13 \\
\hline EU15 & 0.21 & 0.24 & 0.32 \\
\hline Western Europe - Non EU Member & 0.16 & 0.22 & 0.32 \\
\hline North America and Israel & 0.46 & 0.56 & 0.65 \\
\hline Total & 0.25 & 0.34 & 0.41 \\
\hline
\end{tabular}

Note: Please note that the regional averages may be biased by missing country-specific data Source: UNAIDS (2012)

\section{The answer to Hot Question 3}

Optimal fertility is not replacement fertility, not 2.1 children per woman. Optimal fertility is not replacement fertility because the quality of people in terms of their education, health, and productivity matters for the things nations value at least as much as the number of people. Population size and its composition by age and sex are only one part of the story (Striessnig and Lutz, 2013). In most of the ECE countries, where reproductive and general health is good and education levels high, optimal fertility lies below 2.1. Although nations with exceptionally low fertility might seek to increase it, investing in people, their education and work opportunities, their health and wellbeing as well as in gender equality is generally more important.

\section{Hot Question 4: Are ECE Countries becoming less equal societies?}

Among the world's more developed countries, there is a pervasive question of whether the resources and products of society are as equally shared as they should be. This concern often extends beyond employment and money to other aspects of wellbeing-education, health, and the aggregated concept of social cohesion. This generalized concern about inequality, arguably as strong in the ECE region as elsewhere, is both generated and reflected in the popular press, academic debates, and political deliberations. It features many dimensions and distinctions that are easily confused.

\section{Concepts of inequality}

Economic inequality is nearly always an important component of the discussion. One distinction that matters is between income and wealth, the former being a flow per unit time, the other a stock or accumulation, built up from past positive and negative flows. How unequally income may be distributed in a society, wealth is even less equally distributed. So where wealth matters more, as in support during retirement, surviving a period of sickness or unemployment, buying property, or leaving bequests to one's heirs, wealth is the relevant concept. Another distinction is between what economists call the factor and personal distributions of income. The factor distribution of income describes how income is divided among categories of factors of production, that is, between labour earnings, returns to financial 
investments, profits, and rent to land owners. By contrast, the personal distribution of income describes how the total income pie is divided up among persons or households.

The personal distribution of income is the dimension of monetary inequality most reliably measured in official statistics and, at the same time, most prominently noted and discussed. Indeed, as we shall see in Part 2, much policy concern in ECE region countries focuses on this dimension. This concern can take different forms depending on the populations of interest: intergenerational inequality, gender inequality, urban-rural inequality, regional inequality, and migrant or ethnic inequality.

\section{Population indicators}

Accordingly, we here examine briefly several measures of inequality that allow comparisons over time. We will find that sub-regions of the ECE region vary considerably according to these measures, with individual countries varying even more. Unfortunately, data availability also varies.

Table 1.19 displays two measures, the Gini Index and the poverty gap at \$2 a day, both for 2000 and 2010 for regions supplying data. Data for particular countries are in Appendix 2, Table 9. With perfect equality and complete inequality corresponding to 0.0 and 1.0 respectively, the Gini Index has in fact declined over this period in each included sub-region, indicating declines in income inequality. Only seven countries of the 36 with data for both years experienced increasing inequality by this measure. These include Germany and Sweden, although both, especially Sweden, had among the most equal income distributions of all the Region's countries in both years.

Table 1.19 Gini Index and Poverty gap at $\$ 2$ a day (PPP) (per cent) 2000 and 2010

\begin{tabular}{|c|c|c|c|c|}
\hline & $\begin{array}{ll}\text { Gini } & \text { Index } \\
2000 & \end{array}$ & $\begin{array}{l}\text { Gini Index } \\
2010\end{array}$ & $\begin{array}{l}\text { Poverty } \\
\text { Gap at } \$ 2 \\
\text { a day } 2000\end{array}$ & $\begin{array}{l}\text { Poverty Gap } \\
\text { at } \$ 2 \text { a day } \\
2010\end{array}$ \\
\hline South-Eastern Europe & 40.3 & 37.6 & 1.3 & 0.5 \\
\hline Eastern Europe and Caucasus & 36.7 & 36.2 & 2.5 & 0.3 \\
\hline Central Asia & 41.1 & 30.8 & 18.9 & 2.9 \\
\hline New EU States & 31.7 & 29.6 & 1.3 & 0.2 \\
\hline EU15 & 32.6 & 31.0 & $\ldots$ & $\ldots$ \\
\hline Western Europe - Non EU Member & 30.6 & 28.3 & $\ldots$ & $\ldots$ \\
\hline North America and Israel & 40.0 & 37.3 & $\ldots$ & $\ldots$ \\
\hline Total & 36.5 & 34.1 & 3.6 & 0.5 \\
\hline
\end{tabular}

Note: Please note that the regional averages may be biased by missing country-specific data

Source: UNDP (2011) and World Bank (2012) 
The same story is told by data on the poverty gap at $\$ 2$ a day. ${ }^{18}$ This measure of impoverishment has fallen markedly between 2000 and 2010 in the four sub-regions with published data and in every country but one.

These data extend only to 2010 and do not show changes within the ten-year trend. Subsequent indicators strongly suggest that the financial crisis that began in 2008 has taken its toll on income equality, reversing the trend in many countries in the region. However, research has yet to adequately partition the responsibility for this reversal between the recession, itself, and government actions to deal with the recession and other factors, for example, attempts to control the levels of national debt (Jenkins et al., 2013).

Unemployment is a strong contributor to poverty, although measures are very sensitive to current economic conditions. Reporting countries in the ECE region show no consistent pattern of change in the unemployment rate between 2000 and 2010, with 26 countries reporting an increase and 15 countries a decrease. This pattern repeats for the unemployment rate for ages 15-24 (see Table 1.20). These differences likely reflect the different paths of economic recovery or stagnation following the great recession, with most countries still suffering.

Table 1.20 Unemployment, youth total (\% of total labor force ages 15-24) 2000 and 2010

\begin{tabular}{|l|r|r|}
\hline & $\mathbf{2 0 0 0}$ & $\mathbf{2 0 1 0}$ \\
\hline South-Eastern Europe & 15.5 & 22.2 \\
\hline Eastern Europe and Caucasus & 21.1 & 18.1 \\
\hline Central Asia & 17.3 & 6.7 \\
\hline New EU States & 26.9 & 24.3 \\
\hline EU15 & 16.9 & 21.7 \\
\hline Western Europe - Non EU Member & 6.9 & 8.2 \\
\hline North America and Israel & 9.8 & 18.0 \\
\hline Total & 16.3 & 19.9 \\
\hline Note: Please note that the regional averages may & be biased by missing country-specific data
\end{tabular}

Source: International Labour Organization (2011)

\section{$\underline{\text { Subpopulation indicators }}$}

Other indicators can suggest less directly the course of inequality over time by charting the changing wellbeing of segments of the population most likely to be disadvantaged. This evidence suggests a less consistently favourable picture than do the general income and poverty indicators. Looking first at children, the ratio of children in residential care (per 100,000 population aged 0-17) declined between 2000 and 2010 in 14 of the 23 countries of the region for which this indicator is reported, but rose in nine (see Table 1.21). The highest proportions in 2010 were in Kazakhstan, the Czech Republic and Lithuania. This pattern can be complemented by the cross section picture of the child poverty rate in 2008, as

\footnotetext{
${ }^{18}$ The poverty gap is the mean distance below the poverty line (in this case \$2) as a proportion of the poverty line where the mean is taken over the whole population, counting the non-poor as having zero poverty gap. A larger poverty gap means more poverty.
} 
reported by the OECD. Israel, Turkey and the USA are the only reporting countries with rates of child poverty above 20 per cent, indicating clearly that high GDP per-capita is not a guarantor of low child poverty. Policy makes a difference. Spain and Portugal are close behind. However, only Turkey among countries in the South-Eastern Europe, Eastern Europe and Caucasus, and Central Asia regions reports this statistic; some of the missing countries are likely among those with high child poverty rates.

Table 1.21 Rate of children in residential care (per 100,000 population aged 0-17) 1990-2010

\begin{tabular}{|l|r|r|r|}
\hline & $\mathbf{1 9 9 0}$ & $\mathbf{2 0 0 0}$ & $\mathbf{2 0 1 0}$ \\
\hline South-Eastern Europe & 234 & 245 & 239 \\
\hline Eastern Europe and Caucasus & 970 & 835 & 1097 \\
\hline Central Asia & 280 & 242 & 1182 \\
\hline New EU States & 688 & 568 & 690 \\
\hline EU15 & $\ldots$ & $\ldots$ & $\ldots$ \\
\hline Western Europe - Non EU Member & $\ldots$ & $\ldots$ & $\ldots$ \\
\hline North America and Israel & $\ldots$ & $\ldots$ & $\ldots$ \\
\hline Total & 815 & 702 & 946 \\
\hline Note: Please note that the regional averages & may be biased by missing country-specific data
\end{tabular}

Source: UNICEF (2012)

At the other end of the life cycle, people nearing and exceeding retirement age may also be at elevated risk of poverty. Of these, statistics on percentage of people at risk of poverty or social exclusion in 2010 indicate that women are at higher risk than men in every country in the EU and Europe more broadly, and at all three age groups, 50-64, 65-74, and 75+ (The other sub-regions, along with Israel and USA, do not report.). This completely consistent gender difference in a comprehensive risk measure is the most systematic of all the indicators examined in this report. Given the range of countries included, there is no reason to expect exceptions in the countries not included.

Some diseases show consistently higher incidence among the poor. The incidence of tuberculosis tends to be much higher in low-income populations. Among the sub-regions, it rose between 2000 and 2010 in Eastern Europe and the Caucasus and Central Asia (see Table 1.22), suggesting that in some of the poorer countries, the less well-off portions of the population may have suffered declining health conditions over the decade. Among the New EU States, four countries-Bulgaria, Estonia, Lithuania, and Maltaexperienced rising incidence. Every country in the other sub-regions experienced declining incidence. 
Table 1.22 Incidence of tuberculosis (per 100,000 people) 2000 and 2010

\begin{tabular}{|l|r|r|}
\hline & $\mathbf{2 0 0 0}$ & $\mathbf{2 0 1 0}$ \\
\hline South-Eastern Europe & 37 & 27 \\
\hline Eastern Europe and Caucasus & 142 & 104 \\
\hline Central Asia & 287 & 136 \\
\hline New EU States & 68 & 39 \\
\hline EU15 & 13 & 8 \\
\hline Western Europe - Non EU Member & 8 & 6 \\
\hline North America and Israel & 7 & 4 \\
\hline Total & 56 & 34 \\
\hline
\end{tabular}

Source: WHO

Disease and other conditions of poverty can vary between urban and rural populations. These relationships are more pronounced and systematic in less developed countries than in the ECE region. Nevertheless, urbanization is a process of considerable predictability over time and related to several outcome indicators of interest in this Report. In the region as a whole, the proportion of persons living in an urban place rose from 71.3 to 73.5 between 2000 and 2010 (see Table 1.23). However, 11 countries, entirely in Central Asia and the New EU States, became less urban over the decade. Many of these were already among the least urbanized, so their regression in this regard is something of an anomaly. It may reflect return migration to rural areas, and even to subsistence agriculture, during particularly unfavourable urban economic conditions in the latter year.

Table 1.23 Urban population (per cent of total) 2000 and 2010

\begin{tabular}{|l|r|r|}
\hline & $\mathbf{2 0 0 0}$ & $\mathbf{2 0 1 0}$ \\
\hline South-Eastern Europe & 62 & 67 \\
\hline Eastern Europe and Caucasus & 70 & 71 \\
\hline Central Asia & 42 & 41 \\
\hline New EU States & 62 & 62 \\
\hline EU15 & 74 & 77 \\
\hline Western Europe - Non EU Member & 75 & 76 \\
\hline North America and Israel & 79 & 82 \\
\hline Total & 71 & 73 \\
\hline
\end{tabular}

Note: Please note that the regional averages may be biased by missing country-specific data Source: United Nations (2012)

A particular concern in many countries of the region, especially in Europe and North America, is the weakening of the "middle class" and related concern about the growing distance between income and wealth of the upper part of the distribution from those in the middle. Countries that may be considered progressive in their poverty policies now find evidence of these trends that affect the rest of their populations. These tendencies emerged first in the English-speaking countries and recently spread to much of Western Europe, although there are exceptions (see Bigot et al., 2012). Research is just beginning to understand the reasons for this development and the patterns of policies that may be contributing to it or, at least, failing to stop it. This research is well organized and presented in papers 
associated with the Luxembourg Income Study (see particularly Kollmeyer, 2012). Dallinger (2013) presents strong evidence for a range of developed countries, including many in the ECE region, that increased female employment reduces income inequality, but increased prevalence of single-mother families heightens it.

\section{The answer to Hot Question 4}

Economic inequality encompasses flows of income that over time produce stocks of wealth. Beyond economics, inequality encompasses opportunities to succeed as well as outcomes of relative success or failure. And success has many dimensions-political, social, and economic-while spanning many distinctions-age, gender, ethnicity and geography. Historically, inequality is a concept of little note in poor societies, coming to the fore instead as nations develop. Within the ECE region, both concern about inequality and data to inform this concern are widespread.

General indicators of economic inequality show decreasing inequality in 80 per cent of the countries of the region from 2000 to 2010 . However, recent evidence points to a slowly shrinking middle class in North America and the countries of Western Europe. Movement out of the middle class seems to be occurring at both ends, into both the higher income group and the lower. Beyond economic considerations, trends in indicators of child and youth wellbeing show worsening conditions in many of the countries over this same period. In every country, older women are at greater risk of poverty or social exclusion than men of the same age. These trends indicate the importance of focusing on populations at risk, when describing and analysing inequality, not just country-level indicators, as well as looking beyond the obvious economic indicators.

\section{Conclusions}

The four hot questions addressed in this report have answers.

1. Is population ageing a threat for the ECE countries?

In coming decades we can expect older populations in the ECE region but with more people staying healthy into higher ages, remaining independent and capable of economic activity, and without being a larger burden to health care systems than in the past. How this potential of fitter elderly shall be realized is not a demographic question but instead an issue of appropriate adjustment of the social and welfare systems. The experiences of countries that are now making appropriate adjustments strongly suggest that it can be done. More than financial means, political will, acting on the strong and encouraging evidence summarized here, is the crucial driver.

2. Is migration a threat or opportunity for development?

Migration among countries in the ECE region and into some of these countries from outside the region is also likely to increase. The only effective countervailing force would be equalization of economic opportunity across countries or much stronger and effective legal barriers. Neither of these is likely to happen on a scale that would much reduce the powerful underlying incentives to migrate or people's ability to respond. As it is the younger, better trained, and more risk-tolerant individuals who tend to pick up and move, the sending countries are likely to be harmed. On the other end, receiving countries can gain substantially, but this is not a foregone conclusion. It is clear from common experience, not just the 
confirming research, that effective opportunities for employment and social integration in the host countries are essential, without which international migration can constitute a burden for both countries, even if it improves the wellbeing of the migrants.

3. Is fertility in the ECE region too low?

The course of fertility in the region is difficult to predict, although the WIC projections under the Continuation scenario, as well as other projections, indicate fertility rates that may rise somewhat in the lowest fertility countries and decline slowly in others. Family- and gender-related policies that reduce the time and money trade-offs between employment and childbearing for women can moderate very low fertility. However, research indicates that, in the fertility range of most if not all countries in the ECE region, it is far more important to invest in the education, health and gender equality than to spend substantial resources trying to increase the population through higher fertility. The optimal fertility in most ECE countries is below the replacement fertility level of 2.1. This results from the increased productivity of people with higher education and better health, which is more prevalent among the young than among the older cohorts. In West ECE countries, moreover, net migration gains add to the cohorts of reproductive age. In the East ECE countries, on the other hand, the net migration losses have a negative impact on the size of the cohorts of reproductive age. In neither case does the replacement fertility of 2.1 assure a sustainable cohort succession. The misleading benchmark of replacement fertility should not be used as a measure of desirable national fertility levels.

4. Are ECE countries becoming less equal societies?

Inequality of economic and social outcomes, and even of opportunities, still persists among the members of society in every ECE country, as indeed in every other country in the world. Still, many ECE countries are among the international leaders in addressing inequality and creating equal opportunities, and the general situation is improving in most. Since 2008, the financial crisis and the Euro crisis have however led to a reversal of trends in several countries in the region. Evidence suggests, that children, young adults, older women and some ethnic minorities are the most vulnerable. Older women are at higher risk of poverty or social exclusion than are men in every country, the most universally consistent pattern reported here.

Answers to these four questions are interrelated through our two cross-cutting themes:

- Investment in human capital, particularly education and health, is essential.

- Societies can prosper without growing populations.

Indeed, concerted attention to the first theme-in families, communities, and at the national and EU level-insures the second theme. Neither experience nor the research that analyses it has so far revealed just how policy can effectively induce either higher fertility or slower numerical ageing. How to invest in human capital to meet people's and societies' objectives for wellbeing, however, is well established. Part 2 now examines the policy environments in the ECE region that have shown the most promise. 


\section{Part 2: Policy Responses and Best Practices}

Governments in the ECE Region, as elsewhere, have important concerns beyond the four Hot Questions that have motivated our analysis of trends. However, as this analysis has suggested, these trends extend their influence widely and deeply into multiple aspects of people's lives and of governments' ability to influence people's behaviour and increase their wellbeing. Accordingly, we now turn to an examination of government policy in the ECE Region, casting the net broadly across the domain of policy concerns that are known through research to influence the outcomes of interest in this report. It remains useful to do so under the rubric of the same Hot Questions.

\section{Hot Question 1. Is population ageing a threat for the ECE countries?}

\section{The role of health care system and preventive health care}

Health care, its organisation, its financing, its equity and accessibility are crucial for population health outcomes, including prevention of disease. All countries in the ECE Region have policies and laws establishing primary and secondary health care access for the population residing in their territories. The health care systems in the ECE region are generally financed through taxation, social insurance contributions, voluntary insurance premia and out-of-pocket payments or user charges. Most of the West ECE countries and the New EU States cover the health expenditure through a combination of revenues from taxation and social health insurance. Out-of-pocket payment and private schemes account often for less than $15 \%$ of expenditure on health care in these countries. The exceptions in Western Europe are Greece, Italy, Portugal and Switzerland that have $30 \%$ or more expenditure on health from private sources (Mossialos et al., 2002). The various forms of prepayment allow for a health care that is largely free at the point of use. Many countries in West ECE Region have also special funds that cover the basic and emergency health care to population segments that are out the insurance schemes such as homeless, asylum seekers, or illegal immigrants. In the U.S., insurance plans differ so much among states, public and private providers, and categories of services, that generalization is difficult.

The non-EU post-communist countries, but also Romania and Bulgaria, witnessed a deterioration in health care provision in the last twenty years as compared to the situation before 1989. In most of these countries the situation is improving slightly in recent years but is far from being stabilized. The postcommunist transition and macroeconomic context in many East-European countries led to a sizeable decline in state revenues and therefore also in sources for payment for health care. During state socialism there existed a constitutional right to health care for all. Health care provision was universal and unrelated to contribution status. This contrasts with the situation in the West ECE countries where the system of health care coverage and public insurance developed progressively.

A legacy of the communist system was an incompatibility of health care contributions and expenditures, which were usually larger than the contributions (Mossialos et al., 2002). The result was unsustainability of the health care systems in many post-communist countries after 1989. The pre-payment of health care has nearly collapsed there, so that most of the health care has been covered by out-of-pocket payments including so-called informal payments. In Caucasus and Central Asian Republics out-of-pocket payments are estimated to account for more than half of total health expenditure. This deterioration of health care has had a negative impact on primary and preventive health care availability, geographic accessibility of health care, and affordability for large segments of the population. The collapse of the socialist health care 
systems had far reaching consequences and certainly is one of the determining factors in the increased mortality and decreased life expectancy in nearly all post-soviet countries in the 1990s and early 2000s.

The soviet system of organisation of health care survives in a different stage of transformation in all the post-soviet countries. It was designed to provide universal care and cover all the territory. This system suffered, however, from many drawbacks, including high centralisation, over-orientation to inpatient hospital care at the expense of primary care, and insufficient coverage by general practitioners. In the Central Asian republics in the post-soviet era the hierarchical system of care remained in place but the infrastructure has deteriorated, sometimes lacking even basic amenities such as running water (McKee et al., 2002). Hospitals dominate the health care system in the post-soviet republics consuming most of the health care expenditures. In Central Asian republics it is as high as 70\% (McKee et al. 2002). This results in an excess in impatient care, too many hospital beds per capita, and non-necessary long stays of patients under hospital care. The low quality and low accessibility of primary health care both geographically and financially lead to significant inequalities in terms of health outcomes in these countries. In Kazakhstan in 2010 life expectancy at birth varied between 66.3 in the North Kazakhstan oblast and 73.2 in Astana city. There were also strong variations in infant and maternal mortality (Katsaga et al., 2012). There are no national screening programmes in most of the post-soviet countries although, for example, in Russia an opportunistic screening is provided through the periodic health check that people expected to attend.

In most of the countries in this sub-region, political representatives started to pay higher attention to the health status of the population and to the health care services and system of provision in the last decade. Russia has introduced a National Priority Project-Health in 2006 to improve health prevention programmes and mother and child health services. This programme is thought to have some partial success and could have contributed to the decreases in maternal, perinatal, and infant mortality, in tuberculosis mortality, and through early detection in cancer (Golikova, 2010). However the reforms need to be taken further. Particular attention should be paid to the efficiency of expenditures in the underfinanced health care sector. For example ,the efficiency of social spending in the Russian Federation, including health expenditure, has been assessed as poor because similar health outcomes in terms of mortality as in the Russian Federation are observed in other countries spending 30-40 per cent less on health" (Popovich et al., 2011, p. 23).

Remedies to the health care system in the post-soviet countries will not be easy to devise and put into effect. Doing so is highly dependent on overall economic development and the institutional capacity of the countries, conditions made even more difficult in the recent global recession. In particular, the prevalence of out-of-pocket payment for health care is unsustainable, particularly when a priority of the health care system in the post-soviet countries is to promote equity in access to health care. This is a hard goal in itself since social inequality is rising, as are the disparities between incomes of rural and urban populations.

Another urgent issue is to respond to the pressure for privatization. A hasty privatization of health care services may deteriorate even more the accessibility of health care and the possibility of public control in these countries with still a relatively poor financial systems and control mechanisms.

A comparative analysis of health care systems in the ECE region reveals that there does not exist one-fitfor-all model of health care system financing and organisation. Instead, a functional health care system and its supporting revenue potential reflect a fragile balance across a wide range of factors including 
political structures (including administrative capacity and level of corruption), economic activity (of population, and as reflected in overall GDP), and external pressures (such as EU directives), but also social values (such as support for welfare state, prevalence of informal payments, and the rule of law), and environmental factors (such as occurrence of war, epidemics, and revolutions) (Mossialos et al., 2002). The demographic profile of the national population (including age structure, household structure, and level of urbanization) influences the balance of the health care systems as well, but are not generally dominant over the other factors mentioned above.

There are apparent advantages of publicly funded health care systems in terms of equity and efficiency, including free access at the point of use, extensive risk pooling, near universal coverage and cost control. In comparison with publically funded care, user charges, out-of-pocket payment and other features of voluntary health insurance schemes are dependent on ability to pay. In addition, risk pooling is limited and cost control tends to be weaker (Mossialos et al., 2002). The introduction of user charges in many ECE countries reflects an effort to reduce unnecessary or excessive use of services and to raise additional revenues. However they tend to have adverse outcomes because they deter both unnecessary and necessary services. The user charges may also have adverse effects on the population in danger of social exclusion that may be particularly reluctant to immediate payments for health care.

\section{$\underline{\text { Long term care and active ageing }}$}

The European Commission (2013) defines long-term care (LTC) as "a range of medical and social services for persons who are dependent on help with basic activities of daily living, caused by chronic conditions of physical or mental disability." Long-term care operates at the boundaries between health care and social care. Different divisions of responsibilities between families and public, different organisations of health care and social care, as well as differences in defining boundaries between medical and social care result in great variations of long-term care services, their organization, and their role within the social protection systems of the ECE countries.

In the future, we can expect that the need for long term care services will increase as the population is ageing and the number of oldest olds is growing both in absolute and relative terms in all ECE countries. Even if we can expect an increase in healthy life expectancy and postponement of disabilities into later ages, this cannot mitigate completely the effect of the large absolute increase of the elderly population. All ECE countries do have policies, programs, and strategies to deal with LTC. The challenge of ageing is to adjust and reform these systems so as to provide sufficient and effective care at acceptable costs to the growing number of users.

At present, the backbone of any long term care system is family caregivers. In the OECD countries more than ten per cent of adults are providing care for frail people. The proportion is the highest in Italy and Spain. Two-thirds of informal caregivers aged over 50 are women. The informal caregivers usually provide care for less than ten hours per week and are unpaid (Colombo et al., 2011). More intense informal care is very demanding and is not generally well rewarded. High intensity care giving is associated with a reduction in labour supply for paid work, a higher risk of poverty, and a $20 \%$ higher prevalence of mental health problems among family caregivers, than non-caregivers (Colombo et al., 2011). The reliance on the family care-givers may be problematic in the future because of the higher employment participation of women, expected work activity into later ages, smaller families, and higher education of women. According to a survey, most people in the OECD countries agree that the system of 
long term care relies too much on the informal care of relatives. This feeling is particularly strong in the new EU countries reaching more than 80 per cent of those surveyed. These are also the countries with the lowest expenditures on long term care (as per cent of GDP) of all OECD countries. In the future, the engagement of family members will most likely shift even more towards less time consuming activities and financial support. This is why the pool of formal care givers should be broadened.

Formal care givers are usually found in institutional care settings. Still, in many countries in the ECE Region it is increasingly common to have a formal care giver in a home care setting, usually immigrant females. This situation is very widespread in Israel and Italy, but also in Austria and other West ECE countries. These workers in long term care are facing difficult working circumstances both physically and psychologically and at relatively low pay. This leads to undesirable results such as high turnover and low retention of workers, and often low quality of services and low productivity.

Although most LTC users receive the services at home (67 per cent in OECD countries) most of the LTC spending is consumed by institutional care (62 per cent of total LTC expenditure in the OECD). Institutional care may be more costly because the more care-intensive patients tend to be treated in institutional care, but the observed disproportion of expenditure is unlikely to be a sole reflection of that. Home care is less costly and more convenient for most of the care recipients. The trend in the West ECE countries is towards deinstitutionalization of LTC and individualization of care (see the example of Denmark below).

In the East ECE region LTC services are less effective, more underfinanced, and generally less developed. The weight of LTC on family members is high. There is often lack of coordination of care between health and social protection authorities (for example in Russia, Czech Republic, or Slovakia). The capacities of LTC institutional care are insufficient and as a result many LTC patients are staying in hospitals beyond their need for inpatient hospital care. This makes such care costly and ineffective. Accessibility of LTC services tends to be regionally uneven, in particular in Russia, and Central Asian republics. The best services are in the big towns whereas they are scarce in rural areas.

LTC services are very well developed in the Nordic countries. Denmark is working toward an approach to long-term care that takes into account individual needs of patients, keeping them as long as possible in their own homes with only in-house care and assistance. This is a decentralized system linked to a range of preventive care services including medical care, rehabilitation, and cognitive training.

Long-term care facilities are varied and numerous in Denmark including conventional nursing homes, psychiatric nursing homes, small apartments (located adjacent to nursing homes and providing basic medical care), group homes and foster homes (Olejaz et al., 2012). Services of LTC as well as rehabilitation are decentralized, mainly under the responsibilities of municipalities. The service needs are assessed together by the general practitioner and the client, special assistance is available to inform clients about all care options and to assist in finding the best individually tailored solutions as well as to help fill out necessary forms. Services are provided by nursing homes and also in protected housing where clients have nursing service at their disposal according to their individual needs. These services resemble rental housing with expenses covered by the clients, themselves. The expenses of low-income clients are paid from a proportion of their old-age pension allowance (Olejaz et al., 2012). 
Home nurses offer day and night services for patient education, care and treatment, as well as help filling out applications for various needs. All disabled or ill individuals can have an emergency or safety call system installed in their home that provides them with direct 24-hour contact to their public health nurse (Olejaz et al., 2012). Denmark is one of few OECD countries that spend more money on home care than on LTC in institutions. Older people in need of another living arrangement for health reasons may be offered a more suitable residence from the array of specially designed housing with different degrees of nursing and other assistance.

Denmark is also advanced in providing support for informal caregivers. Someone who wishes to be an informal caregiver for a close relative may be employed by the municipality. If the care needed is equivalent to a full time job and after fulfilling some formal criteria, an informal caregiver can be employed for up to six month by the municipality and benefit from a salary that corresponds approximately to three-quarters of the average annual Danish income. Relatively favourable conditions of leave are also given to people who wish to care for a relative with a terminal illness. About 80 per cent of Danish establishments offer care leave to their employees, which makes Denmark the leader among OECD countries (Colombo et al., 2011).

\section{$\underline{\text { Active ageing and pension systems }}$}

Increasing longevity is a reality in all ECE countries today and in West ECE countries already for several decades (Tepe and Vanhuysse, 2009; Vanhuysse and Goerres, 2012). By international comparison, East ECE countries tend to have relatively inactive welfare states that are, in addition, comparatively heavily biased towards elderly citizens (Vanhuysse, 2013). Today, legacies from earlier post-communist policies and practices such as inadequate health-care practices, internationally very low labour market participation rates among women and older workers (Cerami and Vanhuysse, 2009) and historically unprecedented "great abnormal pensioner booms" (early and disability retirement) (Vanhuysse, 2004) have prepared East ECE countries badly for the coming three decades, when their societies will enter a period of particularly fast demographic aging. Aging populations have both demographic and policy aspects. The demographic aspect is described in Part 1 under Hot Question 1. This discussion emphasized that people will not only live longer but they will live longer in better health. Despite this important qualification, the absolute number of older persons will grow, including those who will need care and assistance. The social security schemes should reflect these demographic changes and undergo reforms that will allow them to remain sustainable. A number of countries in the ECE region have taken steps to reform their social security and welfare systems accordingly. Most commonly, the reforms concentrated on the pension systems. In general, pension schemes are financed by obligatory contributions of both employers and employees. This can be complemented by social pension schemes. Often mandatory, pension insurance system exists alongside voluntary options. Currently most of the pension systems in Europe are heavily dependent on "pay-as-you-go" systems in which the current economically active pay into the social security system for the pensions of the currently retired. This system is based on the expectation that also in the future the economically active will be able to cover pension needs of the cohorts that are retiring. This system may be less sustainable given the effects of population ageing.

To assure sustainability of the pension systems important reforms must be adopted. The minimal reform requirements are an increase in contributory periods, limiting early retirement options, and increasing the 
retirement age. However, these reforms face implementation challenges. They are politically sensitive, unpopular among many, and often not well communicated to the public.

The OECD Pension Outlook 2012 states that "It may not feel like it, but today's retirees are living through what might prove to have been a golden age for pensions and pensioners. Far fewer older people live in poverty than in the past: about a quarter fewer than in the mid-1980s. They also can expect to live longer. Today's and tomorrow's workers, in contrast, will have to work longer before retiring and have smaller public pensions. Their private pensions are much more likely to be of the defined-contribution type, meaning that individuals are more directly exposed to investment risk and themselves bear the pension cost of living longer." (OECD, 2012).

The governments of the ECE countries must not only try to reform their pension systems but are also committed to tackle other ageing-related issues. The 2012 Vienna Ministerial Declaration stated under the general motto "Ensuring a Society for All Ages: Promoting quality of life and active ageing" (UNECE, 2012) a commitment to promote and support:

- Longer working life and maintenance of the ability to work

- Participation, non-discrimination and social inclusion of older persons

- Dignity, health and independence in older age

- Maintenance of intergenerational solidarity

Active ageing promotion and support is crucial for the future sustainability of social welfare systems and the economic prosperity of individuals and the whole society. Longer working life as a part of active ageing is, however, a challenge. Meeting the challenge depends not only on commitment and activity of governments but also on the efforts of employers to keep older workers in employment and the will of employees to work longer than the previous cohorts. The general understanding of the adequacy of current retirement ages is based on a number of myths "that are highly questionable in light of scientific evidence from the Survey of Health, Ageing and Retirement in Europe (Share) ${ }^{19}$ " (Börsch-Supan et al., 2012). The authors highlight in particular the following:

Myth 1: Older people cannot work because they are unhealthy. Health is not a primary cause of retirement in Europe. Older people aged 60-69 perceive themselves as relatively healthy (about 80 per cent aged between 60 to 69 years) and more than 60 per cent of them have no functional limitations. The authors suggest that a flexible retirement age would be much more effective in dealing with these differences than a fixed age: people with health problems need to retire earlier whereas most people could easily work longer.

Myth 2: Older people should not work because they are much less efficient than younger workers. Research in manufacturing industry shows that older workers tend more often to make small mistakes but that younger workers tend to make less larger and more costly mistakes (Börsch-Supan et al., 2008). Older workers show high productivity in the work that they know and are experienced in, although they accommodate less readily to a new job. Other research on the productivity of older workers has not

\footnotetext{
${ }^{19}$ The survey includes 19 EU countries and Israel. More information on the survey on http://www.share-project.org/home0.html .
} 
produced much evidence that older workers' productivity would be either lower or higher than of younger workers. Altogether, these studies imply that it is advisable to keep experienced workers in their current workplaces instead of forcing them to look for new jobs (Börsch-Supan et al., 2008).

Myth 3: Life after retirement is blissful. Life satisfaction after early retirement decreases faster than after retirement at a later age (Börsch-Supan and Jürges, 2006). Later retirement is also shown to have positive effects on cognitive abilities and their retention.

Myth 4: Active ageing harms the young. This argument does not hold. If it did, countries with early retirements should have a lower unemployment rate of the young. This is not the case. One of the reasons is that early retirement is expensive and a serious burden on the economy (Börsch-Supan et al., 2012).

Myth 5: Population ageing is a tsunami and its consequences are our demographic destiny. Demography can foresee quite accurately the numbers and proportion of elderly to come and can predict quite well their probable health status and mortality conditions under generally holding conditions. This is why national governments are able to prepare themselves for demographic ageing. Demography is not destiny because policies can mitigate much of the undesirable social and economic effect of ageing and prevent its negative impact on the social welfare systems (Vanhuysse, 2013).

Successful active ageing policies combine many features and incentives from different policy areas. The active ageing policies in Sweden are a useful example. They combine changes in the social welfare systems (pension system, social insurance), tax incentives for employers and older aged employees, lifelong learning, active labour market policy, promotion of healthy working conditions, and policies that combat age discrimination on the labour market.

Sweden began its reforms of pensions and benefits for older workers about two decades ago in mid-1990 when it became very clear that the current "pay as you go" system was unsustainable in the current and prospective demographic development. The adjustment of the system is continuous. The idea behind the reforms was that both employees and employers need incentives to be willing to stay in employment longer and employ older workers. The current Swedish pension system is progressive, allowing retiring and claiming pension benefits from the age of 61 while still being employed. Alternative exit routes to retirement have been limited such that today early retirement can be granted only for medical reasons. It is only granted on a temporal basis, and work incapacity status is evaluated later on a regular basis by the Swedish Social Insurance Agency (Anxo, 2012).

Swedish tax incentives for older workers' employment include a higher in-work tax credit for people who have turned 65. Special employer contributions to workers' wages and the tax income for those over 65 were abolished, so that employers now have to pay only 10.2 per cent of the wage cost instead of the standard pay-roll tax of 31 per cent. This makes older workers cheaper and represents, in fact, implicit subsidies for older workers' employment. The age-wage profile in Sweden is relatively flat by international standards with a relatively low seniority wage premium. This not only makes older workers cheaper but also facilitates their further education financed by employers. Increased productivity of the worker after training does not increase the wage rate proportionally (Acemoglu and Pischke, 1999).

Lifelong learning is an integral part of the Swedish educational and employment system. The system allows employees to return to education after temporal interruption, or to take a special training course 
along with employment. Lifelong learning can be acquired through formal education (the regular school system), or through training provided by employers, municipalities or on an individual basis. The Swedish adult population scores among the highest on lifelong learning in the ECE Region: in 200673 per cent of the population aged 25-64 participated in some form of education or training. Although participation declines slightly with age, it remains still quite high (65 per cent for those aged 55-64 years (data from Anxo, 2012). About half of the lifelong education or training is provided by employers. This high participation in adult training is related to the existence of powerful social partners and welldeveloped social dialogue.

In case of unemployment, Sweden has a wide range of active labour market policies, such as training, job search support and recruitment subsidies. None of them is particularly targeted to older workers, but some have special conditions for the unemployed aged 56 and over. One of these tools, "New Start Job," provides support for the employers that employ a long-term unemployed person. For job seekers over 55, long-term unemployment is defined when lasting for a period of 6 months and longer, instead of 12 month for younger job seekers. The support is accomplished via subtraction from the employer's payroll tax of the wage he gives to the unemployed job-seeker. For those over 55 this subsidy can be attributed for twice the time allowed for the subsidies for younger workers. Research has shown that measures close to the regular labour market are on average more successful to tackle unemployment than other programmes (Forslund et al., 2004). The wage subsidies targeted to senior workers in long-term unemployment may well contribute to reducing early exit of the labour force (Lindqvist, 2007).

\section{Hot Question 2: Is Migration a threat or Opportunity for Development?}

Migration is different. Answers to the other three Hot Questions are based on choices, constrained as they are, that all societies in the ECE region have made. No country would have the increased longevity that arises from better health and living standards go the other way, and no affected country would have the hardships brought on by the collapse of the USSR or the recent global recession continue. Likewise, each wants women and couples to be able to have the numbers of children they want, although some would like this desired number to be higher. And each country appears through its policies to desire less inequality among its people.

But migration is different. Depending on the time and circumstance, and indeed on who is giving an opinion and what kind of migrant is considered, more migrants entering the country is desirable or not. It is the same for migrants leaving the country. And what is deemed good in the country on one end of the flow may be, and often is, deemed bad in the country on the other end.

Policies to deal with migration, that is, to encourage or discourage it and then to turn its consequences to advantage rather than harm, are as complicated as the motivations behind them. In receiving countries, the concerns span diverse policy areas: settlement patterns, ethnicity mixing, job availability, tax-paid economic benefits, impact on upward social mobility, crime, and voting behaviour. Similarly diverse are the opportunities: employment in "undesirable" jobs, trained and innovative minds, the vigor of population variety, and supplementing small segments of the native-born age structure. In sending countries, the concerns and possible opportunities are equally diverse. Where unemployment is high, outmigration can relieve it. Where household income is low, remittances can raise it. Confronted with the 
diversity of policy areas that affect these concerns and opportunities, this section can only suggest the principles involved in useful policy and highlight some best practices to implement these principles.

The United States, because almost its entire population is immigrants or descended from immigrants, is an obvious place to start our brief survey of policies. In spite of relatively restrictive immigration policies and practices, nearly one in five inhabitants is either him/herself an immigrant or the child of at least one immigrant. In most recent years, the U.S. accepted more legal immigrants as permanent residents than all other countries in the world combined. As guided by current legislation, family unification accounts for approximately two-thirds of legal immigration to the US. The number of foreign nationals who became legal permanent residents of the U.S. in recent years as a result of family reunification far exceeded those who were accepted on the basis of employment skills and for humanitarian reasons.

Once arrived, legal immigrants are helped (or hindered) more by state and local laws and practices than national ones. As a rule, they find their way into schools, communities, and jobs without much more difficulty than others. While residential segregation is common, particularly in the first generation, it is usually voluntary and only rarely accompanied by generalized dispute and violence (Tichenor, 2002).

From the fact that the U.S. labour market and social fabric have relatively painlessly absorbed an extraordinary proportion of immigrants in the last half century, one might look to American policy and practice as examples. Unfortunately, the look would be long and ultimately unrewarding. Whether the apt metaphor is "melting pot" in which all come to look alike or "salad bowl" in which each maintains his own flavour to make a savoury combination, the country's geographically diverse practices along with the long tradition of ethnic and language mixing make this case sui generis.

Illegal immigration into the U.S. is a perennial and much more contentious issue. Estimates of the number of illegal immigrants range from 11 to 20 million. Their legal, social, and economic situation is often precarious, but not so much as to reduce pent-up demand to enter. Only the recent severe recession in the U.S. job market has lessened this demand in recent years. ${ }^{20}$

Let us turn instead to Sweden, whose policies toward immigrants are frequently looked to as enlightened and successful. Swedish immigration policies are based on the principles of multiculturalism and diversity, under which the number of immigrants has risen steadily for 25 years. The government has for decades offered language classes and other programs to facilitate labour market success. Residency and citizenship are relatively easily achieved, certainly compared to the U.S., for example, and the country welcomes dual nationality. Liberal family reunification regulations are in effect. Yet, a recent study (Wiesbrock, 2011) found that immigrants are two times more likely to be unemployed than native-born persons. By this criterion, Sweden is an average EU country, many of which provide far less assistance. One cannot know the counterfactual, what immigrants' job experience would be without such welcoming policies, but this outcome, even apart from examination of other measures of success, strongly suggest that the integration of immigrants is not easily achieved.

At the other end of the process, few studies have explored the effects of policies designed to control emigration from a sending country (Kureková, 2011). Most emigration policies that encourage or restrict emigration aim to control the migration of specific groups of individuals based on gender, skill level,

\footnotetext{
${ }^{20}$ For a general treatment of unwanted migration, legal or illegal, see Thielemann (2005)
} 
education, or ethnic affiliation (de Haas and Vezzoli, 2011). The effects of such policies on migration flows seem to be unknown, likely due to the low quality of emigration data, the relatively infrequent emigration policymaking compared to immigration, and the fact that the right to leave one's country is internationally recognized. This last cause is at the heart of the difficulty for countries, such as some in the East European and Central Asia sub-regions, whose national interests, if not the interests of outmigrants, would likely be served by discouraging emigration, even considering the benefits of remittances. There is little in the realm of explicit migration policy that they can do. Instead, they must see to policies that improve employment and living conditions at home, a challenge made harder as skilled and ambitious young persons leave. Or they must try to fill in behind the leavers by embodying in the stayers the same education and training that departed with the leavers. Philippine investments in nursing training is an instance of such a policy.

Governments in sending countries can also ensure by law and regulation that remittances sent home arrive at their destination, and they might, although successful examples are lacking, redirect some proportion of remittances to projects that benefit the society more broadly than just the networked recipients. After all, foreign remittances exceed the sum of foreign direct investment and foreign aid that crosses all international borders. And they continue to grow at the global level. In total, some 250 million migrants are forecast at a recent IFAD conference (http://www.ifad.org/pub/index.htm) to send home $\$ 500$ billion in 2013, an increase in remittances of almost 20 per cent from the previous year.

In all these efforts of sending and receiving countries, perhaps the most encouraging signpost for policy is research findings gathered by the Joint Migration and Development Initiative (JMDI), a program of the UNDP in collaboration with five other UN agencies: IOM, ILO, UNHCR, UNFPA, and UN Women (2013). This evidence-based effort seeks to "effectively harness the potential of migration for development". They find that "the most successful and sustainable M\&D interventions are those with strong anchorage with the local governments in countries of origin and destination, in line with the essential local-to-local dimension of the M\&D nexus. When local authorities share a common vision with civil society partners, they develop a sense of ownership over projects that lead them to commit time, energy and resources, which effectively contribute to the success and sustainability of an M\&D initiative. For these reasons, the drivers and impact of migration are often most strongly felt at the local level, be it in terms of effects on the local labour market, the size and demographic of the local population, or the need for public service provision. This is why provinces and local authorities are strategic levels of governments to be involved."

Carrying these and other experiences into the future, two recent papers (Åkerman Börje, 2013; Knoll and Keijzer, 2013) examine perspectives and priorities for how migration policies could contribute more positively to development policy. Part 3 of this Report suggests even more broadly that explicit migration policies and others that indirectly affect migration must now be viewed in the context of investment in human capital that take place in populations that are no longer growing, the two cross-cutting themes of this Report.

\section{Hot Question 3: Is fertility in the ECE Region too low?}

We analysed levels of fertility in the ECE Region and discussed the reasons for such levels and their trends in Part 1. Here we concentrate on the policy tools that may influence these fertility levels. It is useful first to reflect briefly on who would like to influence fertility levels and why. At the level of 
individuals, couples wish to have children or not and a certain number. Appropriate policies can help them to achieve their fertility desires. At the aggregate level, policymakers and politicians may set a desired fertility level for the country because they think it would benefit the economy and foster prosperity. The aggregate desired fertility that averages many couples' desires may or may not be in line with officials' idea of desired aggregate fertility. There is no reason why they should be the same.

Experience strongly suggests that policy intentions that go against individual desires, for example by setting a numerical goal, are very likely to fail in the long run and can, at the most, change fertility levels only temporally by shifting couples' timing of births (for example, the pronatalist policies in the former communist countries of Central and Eastern Europe before 1989). Policy attempts are therefore best oriented towards creating conditions that make it easier for couples to have their desired number of children. Here we will focus on such policies and strategies that may facilitate couples having their desired number of children while promoting the reconciliation of work and family life.

Since the 1960s, labour force participation of women has been increasing in all countries of the ECE Region. Most women in ECE countries do not picture themselves primarily as housewives but want to participate in the labour market, both as a part of their self-realisation and to (help) support the family. Given the changing family compositions and structures, many women, particularly if single or divorced, are the only breadwinners in the family. At the same time, in all the ECE countries women are still the prime care-givers for their children. It can be difficult in these circumstances for women to harmonise work and family duties.

Evidence regarding the impact of family policies on fertility is rather inconclusive (Gauthier, 2007). There is some evidence that a wider set of policies enabling women and men to combine work with family life encourages fertility, but the patterns are not completely consistent (for a literature review see Gauthier, 2007; and Thévenon, 2011). Family policies do not function in isolation from other policies, and from culture and the economic situation. It is therefore very difficult to measure their effects. However, research on the impact of family policies across Europe finds some indications that family policies, fertility, and women's labour-force participation are interrelated (Neyer, 2005). In most ECE countries, the state through its policies largely determines the availability of services for the distribution of care between public sector and private sector, and between men and women.

Family policies may be designed with different aims and they may also differ in their effects. The aims of family policies can be usefully categorized as follows (following Thévenon, 2011):

- Dual-earner family model. These policies encourage women's employment and reconciliation of work and childcare. They aim to secure women's continuing employment, including support for flexible working hours, and to provide benefits that compensate for income loss during parental leave. These policies include parental leave, formal day care for young children, and tax systems that contain incentives to work. A rationale for these policies is that higher employment participation contributes to the economic and financial stability of the state.

- Improving gender equity. These policies aim at a balanced share of paid and unpaid work between the partners, including childcare. This objective can be promoted by childcare related leave for both parents with a special emphasis on father's leave that would be lost if not taken, or by "fractionable" parental leave. 
- Direct compensation for the economic cost of children. These policies include cash benefits and fiscal transfers. They aim to narrow the gap in earnings between families with children and the childless. The cash benefits are usually directed at nuclear families. In general, they may encourage a relatively traditional division of domestic labour, since they are most likely used by the mother (Crompton ed, 1999; Lappegård, 2009).

- Poverty reduction and income maintenance. These policies focus on the allocation of special benefits to low income families with children and may include housing benefits.

- Support for early childhood development. Many countries design family policies based on this objective. The notion of what is beneficial for children may differ across countries. It usually includes quality formal preschool education and parental care. Norms about the appropriate age for entry to formal education vary greatly across the ECE countries.

- Raising birth rates. Low fertility is a concern in many ECE countries. However in only a few are family policies designed with the explicit aim of raising fertility.

ECE countries differ in the aims, design and outcomes of their family policies (Figure 2.1).

Nordic countries are characterised by generous family support that allows and motivates women with small children to participate fully in the labour market by providing generous compensation for lost income during full-time childcare, and providing state-subsidized and therefore affordable care for young children. Family policies in Nordic countries were designed to allow for gender equity at both work and childcare. They are often described as the most advanced with respect to gender equality.

These Nordic policies allow families relatively wide flexibility in organising their work and childcare tasks. Total investment in childcare and education services for children below age six is costly in Nordic countries, representing about 1.5 percent of GDP, compared to an average of 0.5 percent in Anglo-Saxon countries, and $0.7 \%$ in Southern Europe (Thévenon 2011). This high cost is reflected in high payroll taxes. Overall, the Nordic countries have high women's participation in the labour force, relatively high fertility, and high proportions of children aged 0-3 years in formal childcare (more than 70 per cent in Denmark, 44 per cent in Sweden, and 35 per cent in Norway, Thévenon 2011).

The Anglo-Saxon countries have in many respects an opposite support system for families than the Nordic countries, but they also achieve high rates of female employment and relatively high fertility. Their systems provide much less public investment in parental leave and early child care. Accordingly, it is much more expensive in direct costs for parents to have a child and provide care. Some balance is achieved by generally wide availability of part-time work for mothers with small children, by relatively flexible labour markets that allow easier re-entry, and through tax-breaks for families. Cash benefits are mostly reserved for families in need to protect them from poverty. In United States, for example, there is no state-subsidized maternity leave. Women are entitled to three months of unpaid leave, and further benefits are state- or corporate-dependent.

Southern European countries are also characterized by less extensive provision of child care services. There is no state support consistent with the dual earner family model, and much care for young children relies on family members. Women's labour force participation is low, as well as fertility. 
Figure 2.1: OECD countries by type of family policies

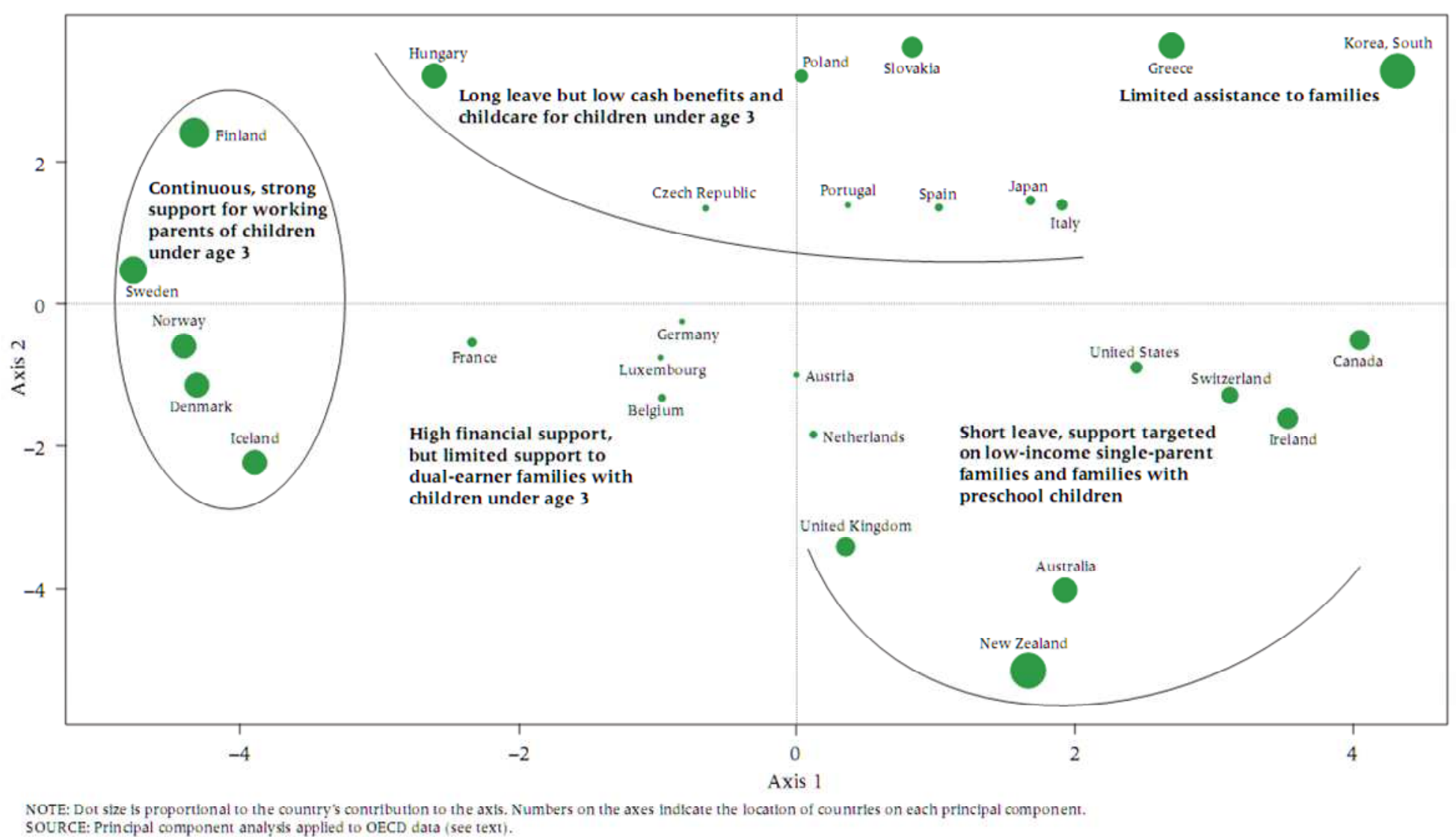

Note 1: The position of the countries gauged by first two principal components derived from the principal component analysis.

Note 2: Axis 1 relate to the support to parent of children under the age of 3 to enable them to combine work and childcare. Countries clustered on the left have relatively high support for families with very young children. Those clustered to the right have most of the spending orient towards middle and late childhood. Axis 2 relate to the "generosity" of leave entitlements. Scoring high on the $\mathrm{Y}$ axis means long leave entitlements.

Source: Figure reproduced from Thévenon (2011) 
Eastern European countries are in many respects similar to Southern Europe. In general they have longer parental leave, but the benefits are very low as are all other monetary or tax compensations for families (with the exception of Hungary). Their systems do not support early return of women into work and are characterised by fragmented policies. As an example, in the Czech Republic women can return to work after six months of maternity leave but cannot benefit from any state subsidies for formal childcare. There is virtually no public childcare for children under the age of three and private care is expensive. Most Czech women stay at home to take care of their children until the age of three. They can engage in economic activity at the same time, but only very few part-time jobs are available.

This overview illustrates that family policies across ECE countries are very diverse. In general, the countries with higher fertility levels have higher labour force participation of women with young children and relatively short parental leaves.

\section{Hot Question 4: Are ECE Countries Becoming Less Equal Societies?}

History suggests that the natural tendency of human societies as they become richer, and even when they simply move sideways over time, is toward inequality. With few exceptions, communal action is required, usually by governments, to thwart this tendency. History also suggests that such action, to be successful, must be multifaceted and continual. Even then, the results are never consistent and complete, as the brief overview in Part 1 suggests. Indeed, the principal conclusion of the World Development Report (2006) still holds: "Inequality of opportunity, both within and among nations, sustains extreme deprivation, results in wasted human potential and often weakens prospects for overall prosperity and economic growth."

This section briefly reviews the tools contemporary governments of the ECE countries employ to reduce inequality, first general inequality of income and wealth, then inequality more broadly in the dimensions of generations, gender, and ethnicity. We pay particular attention to several countries whose policies work well and several others where progress is slow.

Governments seek to influence the distribution of income and wealth most generally through their tax and transfer systems, with progressive tax rates on the revenue side and a great variety of redistributive policies on the expenditure side. Except at the extremes of tax progressivity, taxes have a weaker influence on inequality than do transfers. This is at least partially due to the tighter focus of transfer programs on target populations; taxes are a much blunter tool. However, the distribution of incomes is in fact quite insensitive to both taxes and transfers within the central range of country experiences. To the extent that transfers consist of goods and services that improve well-being without directly increasing measured income - for example, medical care, food supplementation, and job training — such transfers can measurably reduce the inequality of well-being more than is reflected in income statistics. ${ }^{21}$

All countries in the ECE region have progressive income tax schedules on paper and most in actual effect, although the progressivity in effect is usually if not always less than in the spirit of the law. Indeed, the

${ }^{21}$ OECD (2008) reviews the relevant data for these countries and examines how the various government tax-benefit systems affect these trends. 
perceived failure of some national tax systems to collect due taxes from wealthy individuals is near the heart of the current controversy within the EU over the responsibility of some member countries to contribute to the economic recovery of others, in the wake of the great recession.

Accordingly, bringing tax compliance into line with tax law, where the gap is large, can be considered a fundamental policy step toward reducing inequality. Whether such tax reform ends up benefiting persons at the low end of the distribution of well-being and thereby reducing poverty depends on transfer policy, which is quite a different matter. Reducing inequality is not necessarily the same as reducing poverty. There are many other worthwhile ways of spending tax revenue.

Intergenerational equity

We now turn to consideration of policies targeted at increasing the well-being of particular subpopulations often considered at particular risk, beginning with intergenerational equity, particularly that of children and the elderly or, as it sometimes emerges, children versus the elderly. Vanhuysse (2013) surveys patterns of "intergenerational justice" in twenty-nine OECD countries, focusing particularly on the extent to which current socioeconomic policies reflect a bias toward today's older or younger generations. His analysis takes account of different and changing age structures across the countries as well as implications for future generations, resulting in a comprehensive intergenerational justice index that accounts for economic-fiscal, social and environmental aspects of policies and outcomes.

Estonia has the highest overall index rating, followed closely by Israel, Hungary and the North European states of Norway, Denmark, Sweden and Finland. Germany ranks in the middle, with Canada, Greece, Italy and the U.S. at the bottom. Estonia performs particularly strongly in the economic-fiscal dimension at the young end of the intergenerational scale, with the lowest level of public debt per child. A child in Estonia current bears only $\$ 6,400$ in public debt compared with Germany at $\$ 267,000$, Greece at $\$ 299,000$, Italy at $\$ 308,000$. In contrast, Poland, Slovakia, and the Czech Republic feature per-child debt levels of $\$ 50,000$ to $\$ 65,000$ (Vanhuysse, 2013, p. 22). This debt measure will play out as currently young cohorts age. While they are young, though, poverty matters more. The North European states rank best in this dimension, along with Slovenia, with child poverty rates of 3.7 to 7.0 per cent. Worst are Israel, the Southern European states and particularly the U.S. at 21 per cent. In most countries studied, the child poverty rate is higher than that of the elderly.

In the search for policy causes of these intergenerational differences, social spending by target age group is an obvious candidate. Every country in the study allocates more social spending to older rather than younger persons. Poland, Greece, Italy and Slovakia allocate an unusually large share of such expenditure to the elderly, with Poland at an 8.6 ratio. In contrast, Ireland, Belgium and Estonia allocate relatively the most to children and young people, although still less than to older persons. Among the "oldest" countries, Italy shows a strong tilt toward older persons, Germany is in the middle, and Sweden allocates more evenly across the generations, although still favouring the elderly (Tepe and Vanhuysse, 2010; Vanhuysse, 2013).

This relationship between age structure and social spending patterns is suggestive but not at all consistent. Not all older societies have relatively high social spending on the elderly. The relationship is strengthened considerably by adding racial/ethnic composition of a population to the analysis. Mather (2007) and Alesina et al (1999) show that for the case of the U.S., the states with the highest racial/ethnic differences 
between older people and children spent the lowest shares of gross state product on public education, while states with the least such fragmentation spent the highest shares. The same holds true across a sample of American communities. The differences are substantial. More broadly, Alesina and Glaeser (2004) show that racial/ethnic divisions may explain up to half of the gap in social spending on children between Europe as a whole and the U.S.

Partly because of the younger age structure of U.S. immigrants and their generally higher fertility, minority children have accounted for more than 98 per cent of growth in the American child population over the last two decades. By now, minority children constitute about one-half of the population of children under age five. Countries of the ECE region that will experience increasing immigration might anticipate pressures similar to those in the U.S. to constrain expenditures on children who are ethnically different from those paying the supporting taxes.

Particularly in Eastern Europe, the prevalence of out-of-pocket payments and, reportedly, frequent requests by health care providers for informal payments are significant barriers to accessing health care services. The consequences fall disproportionally on women and young children through deficits in sexual, reproductive, and maternal health care (Colombini et al., 2011; Newport, 2009). Relatedly, the Roma populations of Europe have long suffered explicit or informal racial discrimination in employment, housing, financial protection, and health care, a problem that persists when Roma people move among countries.

Program efficiency in delivering money and services to target populations will become increasingly important as immigrant populations increase and as chronically underserved populations, like the Roma, spread more evenly across the EU countries under a regime of open migration. Among the policy measures that have been shown to benefit children, such as child tax credits, nutrition interventions, and generous family allowances and parental leave policies, the research is clear that early childhood education and care programs are the most effective (Esping-Andersen, 2008; Heckman, 2006; Vanhuysse, 2008) Such investments not only benefit children as children, but have been shown to improve employment rates, monthly earnings, welfare receipt status, and crime rates, all later as adults. Along the way, early learning makes later learning easier and more effective.

But how to insure that investments in children persist and even increase in an era of diminished resources and demographic counter-pressures? In an idea once novel but now increasingly discussed, Demeny (1986) proposed giving each parent one-half extra vote (or equivalently each mother one full extra vote) to be cast on behalf of each child younger than voting age. In so acting as trustees for their children, parents would be upholding the democratic one-person, one-vote principle. In Vanhuysse's (2013, p. 42) words, this policy "would add a degree of hard power to the intergenerational politics game because, once enacted, it would change governments' electoral incentives in favour of younger generations." The degree of change would likely be significant but not numerically overwhelming (Sanderson and Scherbov, 2007). To our knowledge, no country has yet implemented such a policy, which would in many countries require a constitutional change. 


\section{Gender}

More than intergenerational inequality, gender inequality has long proven a particularly difficult challenge in the ECE countries and, indeed, across the globe. In recent decades, women's lives around the world have improved dramatically (World Bank, 2012), but gaps remain in many respects and all places. Although, as Part 1 documented, women still fare less well than men across various dimensions (with the notable exception of longevity) and in every country, the discrepancies are larger and with more severe consequences in Eastern Europe and Central Asia than in the other countries of the ECE region. We concentrate here on these countries and on policy initiatives that make a difference in their settings (this discussion is largely based on Colombini et al., 2011; and Newport, 2009).

Alongside less control of monetary resources and less decision making power in the family and community, the lack of programmatic and fiscal emphasis on aspects of life that affect principally women is an enormous hindrance to their equal participation in these countries' wellbeing. What to do about this is no mystery. Both the experience of other countries in the ECE region and program evaluation research globally point to the interventions that make the most difference. Cultural differences across nations make remarkably little difference in these priorities. Legal, geographical and financial access to sexual, reproductive and maternal health care heads the list. In Eastern Europe and Central Asia, broadening health insurance coverage is key. Improved access to family planning makes a difference in these countries as well, including removing costs for the poorest populations. General education about women's existing rights to services and in the face of abuse, such as these rights are, is also shown to make a difference.

As these investments and improvements occur in Eastern Europe and Central Asia, the lack of treatment protocols and of data and analysis for targeting and evaluation will be growing issues, unless they improve apace. Not all countries have standardized administrative data systems that usefully describe inputs, processes, and outcomes. Evidence largely from elsewhere demonstrates that prescribed investments and interventions work, but without the data to document it in-country, political support can wane. On the basis of evidence, that also can be anticipated.

Gender-based violence remains another challenge in in Eastern Europe and Central Asia. The effective policy and program measures to meet this challenge appear more culturally dependent than in the case of health care, as the sources of such violence often lie in deeply rooted social norms and practices that may even encourage it, much less tolerate it. Nevertheless, basic principles seem universal (UNFPA, 2009): Young men, partners and husbands must be involved. So must male-dominated institutions such as the police and military. Commitments from influential officials in local and national government institutions must be obtained. Participation among apathetic groups must be encouraged. And action, not just knowledge, must be the goal.

Finally, women's rights in the areas discussed here are under-enumerated and under-protected in most of these countries. Even de jure, constitutions and legislation do not everywhere conform to international norms. Such provisions as equal protection and anti-discrimination clauses, equal retirement ages, sexual harassment laws, minimum legal ages of marriage, and stand-alone gender inequality laws are missing in various combinations. Where such de jure provisions exist, effective implementation is spotty, including 
establishment of effective monitoring systems. Indeed, UNFPA (2009) concludes that "The overarching theme running through all the domestic country profiles is the inadequate implementation of laws."

\section{$\underline{\text { Education }}$}

The ubiquitous roles of education in nations' economies, polities and societies are well established in research. Increasingly, the questions about causality and selectivity that have long bedevilled firm scientific conclusions and strong policy responses are usefully if not completely dispelled (Lutz and KC, 2011). Indeed, of the policy interventions that can improve the lives of children, now and later as adults, early childhood investment in education and care heads the list (Esping-Andersen, 2008; Heckman, 2006; Vanhuysse, 2008). Through improved secondary school graduation rates, employment rates, monthly earnings, welfare receipt status, and crime rates, these investments pay off well into the future. Indeed, geographically widespread evidence now indicates that more highly skilled people adapt more quickly and usefully to environmental insults and climate change (Butz and Sendzimir, 2013). Even the tendency toward democratization appears causally related to the education level of the citizenry (Lutz and KC, 2011).

In spite of the more recent evidence for decreasing income inequality in ECE countries since 2000, a longer term trend has held sway across the industrialized world since at least the early 1980s. A leading explanation points to the rapid development of sophisticated technologies in the workplace, technologies whose appropriate use requires the knowledge and capabilities that higher levels of education impart. According to this evidence, these ever more sophisticated technologies drive an employment and earnings wedge between the workers who can flourish with them and those that cannot. Hence, the overall distribution of earnings and income becomes less equal (Goldin and Katz, 2008).

Manyika et. al. (2013) and Brynjolfsson et al (2011) argue that innovations in machine learning, voice recognition and nanotechnology, in particular are now rapidly progressing in such a way as to disadvantage even the "knowledge workers" who have mainly benefitted from the information revolution up to now. Instead, "much of the forthcoming gains from future technological change may accrue increasingly to the investors who bankroll these risky endeavours, the innovators who produce them, and the consumers who use the cheaper and better products," leaving the former beneficiaries of a computerequipped workplace out in the cold, along with their less educated contemporaries.

Whether the future of the modern workplace follows the historical path of the last 30 years or an even more accelerated one, the effects will not be confined to the more industrialized countries of the ECE region. As the rewards to education and initiative climb, selective migration of those most likely to benefit can be expected to increase alongside, exacerbating the costs of emigration from countries whose industries do not keep up and from regions of those countries that fall particularly behind.

\section{The Recent Recession}

In the extensive research literature about the effects of economic recessions on the distribution of income, the recent "great recession," beginning in 2008, will likely be the most productive of useful knowledge. This recession has been hard and long, globally widespread, and accompanied by the best data by far for studying its effects, prominently including panel survey data that have documented the adjustments and 
consequences for individual persons and households in many world regions and countries. Because of the recession's tattered and uneven recovery, more years are required for a full picture. Still, some things are known.

Jenkins et al (2013) examine the early cross-national evidence regarding income levels, poverty rates, and income inequality, focusing particularly on case-study evidence for Germany, Ireland, Italy, Sweden, the UK, and the U.S. Between 2007 and 2009, government support through tax and benefit systems provided a cushion against the downturn, and household income distributions did not change much. But after 2009, much greater change in incomes is likely as a result of fiscal measures to address the structural deficits revealed by the recession. The book's main policy lesson is that stabilisation of the household income distribution in the face of macroeconomic turbulence is an achievable policy goal. Most recently, Population Europe (2013) has convened a forum of economic and policy experts to discuss "Recession and Social Vulnerability in Europe: Insights from Demography." A report is forthcoming. ${ }^{22}$

Recessions are a natural feature of market-oriented economic systems and so will continue. Although we can hope that future recessions will be average and not "great," the knowledge gained from this one, particularly in the policy arena, promises to surpass what was previously known and to be applicable across the wide range of countries in the ECE region. It seems likely that every policy or program effective in reducing inequality of income and broader wellbeing in normal and good times will also prove effective in dulling the effects of recessions on the most vulnerable in bad times. Where such complementarities and absence of tradeoffs arise in the policy arena, governments are well advised to take advantage of them.

\section{Conclusions}

Best practices, whether in policy or any other field of human endeavor, must come along with stated conditions under which they are possible and under which they stand a good chance of being effective. Principles may be applicable everywhere, but the best ways to put them into action are not.

Within the ECE Region with its enormous diversity of most everything that matters in determining what policies are possible and which are effective, as well as its equally great diversity of starting positions, nearly every best practice has conditions. We have tried to make these conditions and their implied ranges of applicability evident in the preceding analysis. In concluding this report, we present in Part 3 a less subtle but hopefully more arresting treatment of best practices: an unadorned bulleted list of policy recommendations.

\footnotetext{
${ }^{22}$ In the meantime, see the video stream of the conference: https://scic.ec.europa.eu/streaming/index.php?es=2\&sessionno=f3a3a63a79eb1831b0a2776bfd20d838
} 


\section{Part 3: Policy Gaps and Possibilities}

The ECE region, as the world at large, is in the late-middle stages of a fundamental transformation from population growth to population ageing. Accompanying this transformation is another fundamental global shift: from the importance of population numbers to population quality. A third transformation-far advanced in some industrialized countries, well underway in many developing countries, and surely on the horizon in the rest-is taking place in the structure and functions of families. Meanwhile, migration continues to slowly transform where people live on the globe-in which countries and whether urban or rural.

The first of these transformations, population ageing, is new to the Earth, less than half a century old but now widely recognized and worried over even where it is just beginning, and more so in the ECE region where it is well underway. The second transformation, the emergence of population quality, or human capital, as a more fundamental driver of nations' success or failure than population quantity is yet relatively little recognized, and more in research than in public perception and policy. The third of these transformations - from multi-generational households through nuclear families and on to the variety of ways people in the industrialized countries are now living together, or apart-is everywhere underway in the ECE Region, although at different stages in different places. The fourth transformation, through migration, has been underway for millennia, tracked in public perception if not in data, and forced, encouraged, discouraged or prohibited by governments.

Of these four, it is the second, the emergence of human capital in the form principally of education and health, that governments can most readily influence. In a stoke of global good fortune, this is also the transformation that, if it accelerates, can mitigate many of the anticipated undesirable effects of the other three, even turning them into gains for humankind. Although yet little recognized, this may well be the yardstick by which historians of the future will measure the success of countries and their governments in our time.

Accordingly, we now build on the analyses in Parts 1 and 2 to identify the principal gaps between, on the one hand, the direction current trends in outcome indicators are leading countries in the ECE region and, on the other hand, the policy measures necessary to alter these trends in favorable directions. Corresponding to the four Hot Questions that are oriented to the present and recent past, we now introduce four forward-looking Hot Issues for policy. For each Hot Issue, best practices within the Region provide possible ways forward. However, countries at different levels of development with different cultures and institutions can face very different constraints. One size does not fit all. Hence, some of the best practices must in some settings be thought of, in reality, as best goals. Actual practice may still be a ways off. 


\section{Hot Issue 1: How can the ECE Region's countries assure an ever-rising capability and participation of older persons in the nations' economic and social life?}

Populations will continue to get older everywhere in the Region, increasingly rapidly in more and more countries. The analysis in Part 1 makes clear that increasing investments in persons' schooling and health throughout the life cycle can counteract the possible negative effects of population ageing. Part 2 indicates the most effective ways governments and citizens themselves are carrying out these investments. Business firms can also play an important role in retaining the elderly in the labour market.

The Region contains excellent models for meeting this challenge, as well as cautionary cases that point to possible consequences of under- or mis-investment. We bring this evidence to bear here in suggested integrated policy frameworks to fill the gap being created as low fertility in the past interacts with ongoing increases in life expectancy.

- Institute lifelong education opportunities, including employer-provided programs, for career extension and redirection at older ages.

- Increase the proportion of young people with tertiary education.

- Improve primary health care including reproductive health care where institutions, procedures and outcomes are below the Region's average.

- Improve data systems for monitoring and evaluation of primary health care delivery where data system quality is below the Region's average.

- Prioritize and facilitate individualized home care for the elderly over institutional care, including support for informal caregivers.

- Improve gender equity in health care delivery, based on findings from the data monitoring system.

- Resist pressures for hasty privatization of health care.

- Increase the retirement age, limit early retirement options, and introduce tax credits for people who continue working after standard retirement age.

- Provide (tax) incentives for employers to retain older workers.

\section{Hot Issue 2: How can the Region's countries manage migration flows in the best interest of both countries and individual migrants?}

The analyses in Parts 1 and 2 indicate strong increasing incentives for persons to migrate across borders and probable resulting increases in actual migration. These analyses also point to broad-based consequences in both sending and receiving countries, consequences that transcend the traditional organizational units and geographic levels of governments.

Policy actions can be of two sorts: to control the migration flows or to adapt to them. Best practices identified in Part 2 tend to combine both approaches, although the mix for a particular jurisdiction can be an elusive juncture of domestic culture, economics and politics, along with international diplomacy.

- Institute language and culture classes to facilitate labor market success.

- Reduce residency and citizenship hurdles for desired immigrants.

- Improve employment and living conditions at home to reduce out-migration of schooled, ambitious and risk-taking young adults. 
- Involve local and province authorities in migration policies and decisions in both sending and receiving countries.

- Establish international community-to-community communication and coordination at either end of prominent migration corridors.

- Insure by law and regulation that remittances arrive at their intended destinations.

Hot Issue 3: How can the Region's countries facilitate the introduction of policies that reflect multiple family forms and that support women and men to have as many children as they want?

Household and family forms continue to evolve in the ECE region, where the future in the more traditional countries and cultures can almost undoubtedly be glimpsed in today's least traditional ones. In the wake of these changes come a multitude of other challenges and opportunities. How policies can adjust, much less get ahead of the curve, is yet being tried out and evaluated. Some matters, though are clear.

- Do not set a concrete numerical fertility goal and institute policies to attain it that do not reflect individuals' fertility desires.

- Seek family policies that aim to achieve the combined and mutually reinforcing objectives of child education, adult autonomy, and gender equity, rather than approaching these goals from different government ministries and policy directions.

- In particular, coordinate child care support and facilitation of parents' labour market re-entry in countries where these are disconnected.

- Support fathers' participation in child care.

- Avoid very long-term parental leaves or income-tested allowances for such leave, policies that can keep women out of the labour market too long for normal career progression.

- Institute childcare support for the period after parental return to work

- Invest in formal early childcare.

\section{Hot Issue 4: How can the Region's countries increase the well-being of the least well-off while supporting the growth of a vibrant middle class?}

The analyses in Parts 1 and 2 strongly suggest that equality of economic and social opportunity and reward is not the natural state to which societies tend. Evidence suggests, moreover, that tendencies toward inequality do emerge in vulnerable sub-populations, even in the most equalitarian countries. Meanwhile, although the evidence is only suggestive, the middle part of the income distribution, the middle class, may be shrinking through movement both up and down.

Again, the Region contains effective models for meeting some parts of this challenge, while policies to meet other parts, particularly for vulnerable sub-populations, remain elusive. While macro-economic, tax, and transfer policies lie outside the domain of this report, policies that invest directly in human capital are directly relevant. 
- Increase the proportion of young people with tertiary education.

- Increase the amount of public expenditure on children and young people relative to the amount spent for elderly people.

- Of all alternative investments in children and youth, emphasize early childhood education and care programs as producing the most effective benefits to society, both for the children and later when they are adults.

- Resist the apparent tendency of education expenditures on children to fall as a society's children become more ethnically different from the older population that is paying much of the supporting taxes.

- Reduce the public debt burden per child.

- Broaden health insurance coverage in countries where such coverage is below the ECE Region average.

- Place remedial programmatic and fiscal emphasis on aspects of life that affect principally women, namely legal, geographical and financial access to sexual, reproductive and maternal health care, in countries where such access is below the ECE Region average.

- Improve access to family planning in countries and regions of countries where such access is below the ECE Region average.

- Bring equal protection and anti-discrimination clauses, equal retirement ages, sexual harassment laws, minimum legal ages of marriage, and stand-alone gender inequality laws into compliance with the standards of industrialized countries.

- Implement laws and regulations already on the books regarding gender equity.

- Supply general information and education about women's existing rights to services and against domestic abuse, where knowledge in the population about such matters is below the ECE Region average.

- Involve young men, partners, and husbands, along with the police and military and community influentials in education about gender violence, in countries where the incidence is relatively high.

- Bring income tax compliance into line with tax laws, so that people pay their fair share and government revenue is increased.

- In the face of macroeconomic turbulence, retain the most effective programs to underserved populations, including formal education, in order to stabilize the household income distribution.

The policy areas considered here, varied as they are, form only part of the broader policy contexts that all governments must deal in. In no government is family policy, retirement policy, immigration policy or any other made in a vacuum. Hence, as foreshadowed at the beginning, we close this report by bringing the analysis of demographically related policies into realistic context through presentation of three very different policy scenarios at the global level. The population projections implied by these scenarios chart three different paths for demographic and education outcomes in the countries of the ECE Region. Though the choices are constrained severely in places, choices they still are. 


\section{Stark policy choices}

Slicing and dicing policy into discrete research areas, constituencies, ministry jurisdictions or parliamentary committees, even into country units, can run afoul of how policy is actually formulated and conducted. This is particularly true in the long view, over the decades in which governments must reconcile each policy with the others, and all with what other governments are doing.

Accordingly, we now embed the best-practice policies to handle each of the four Hot Issues into one overarching scenario. Called the "Sustainability scenario," this is a medley of progressive policies that can move the ECE countries successfully through the Hot Issues into a sustainable future. For emphasis, we compare the projections implied by this optimistic scenario with the projections from the competing "Continuation scenario" described in Part 1, assuming that relevant policies proceed on their current paths. Even more telling is the comparison with a pessimistic "Fragmentation scenario" in which countries' policies turn back from their current paths. ${ }^{23}$ Because the scenarios specify the directions of policy change (or lack of change) instead of describing the current status of policies, they are relevant for all countries in the ECE Region, regardless of where their histories and policies have placed them now. ${ }^{24}$ Following the scenario descriptions are population pyramids that starkly illustrate the differences.

In the Sustainability scenario, the world and the ECE Region within it are making relatively good progress with sustained efforts to achieve development goals. Elements that contribute to this are a reduction of inequality both globally and within economies, rapid technology development, and a high level of awareness regarding environmental degradation. Rapid economic growth with high employment levels reduces the number of people below the poverty line.

The policy emphasis shifts to strengthening education and health investments that raise schooling levels, increase labour market productivity, lower mortality, and extend healthy years of life. In the countries of the ECE Region, this emphasis on quality of life leads to policies that make it easier for women to combine work and family; hence, further fertility declines are unlikely. Migration is at intermediate levels. Although increasing integration of labour markets allows people to move around more freely, rapidly converging income levels reduce migration incentives.

In the Continuation scenario, trends of recent decades persist, with some continuing progress towards achieving development goals, reducing resource and energy intensity, and slowly decreasing fossil fuel dependency. Technology development proceeds in industrialized countries, but is not shared with lowincome countries. Population growth is slow or negative in countries where these trends have already emerged. Per-capita income levels grow at a medium pace. Intra-regional income distributions improve slightly with increasing national income. Achievement of the ICPD goals is delayed by several decades. There is evidence of degradation of the environment.

This middle-of-the-road scenario combines assumptions of medium fertility with medium mortality and medium migration for all countries. It corresponds to the medium variant of the new WIC population

\footnotetext{
${ }^{23}$ The Intergovernmental Panel on Climate Change (IPCC) is currently finalizing its Fifth Assessment Report. In this context the global modeling community on Integrated Assessment and Vulnerability, Risk and Adaptation has agreed to refer to a common set of Shared Socioeconomic Pathways (SSPs) that describe alternative future worlds with respect to social and economic mitigation and adaptation challenges. WIC/IIASA staff have contributed substantially to this formulation. The three scenarios described in this Report are selected from those developed for the IPCC.

${ }^{24}$ Fuller descriptions of the three scenarios can be found in Appendix 1
} 
projections displayed in Part 1. To the extent that the future follows trends of the recent past, this picture of policy and the outcomes that accompany it can be considered the most likely forecast. However, the future can be different, for better (the Sustainability scenario) or worse (the Fragmentation scenario).

In the Fragmentation scenario, the emphasis on security at the expense of international development is separating the world into regional blocks of countries with little coordination between them. Population growth is low in industrialized countries and high in developing countries. Investments in research and development and in human capital are low. Accordingly, there is little if any progress in reducing mortality or increasing education levels. Fertility remains very low in the ECE countries and high in less developed countries. Due to the emphasis on security and barriers to international exchange, international migration is low for all countries. Disadvantaged populations continue to move to unplanned settlements around large urban areas, often in places that are particularly vulnerable to weather and climate events.

Overall, these fragmented regions are characterized by extreme poverty, pockets of wealth particularly in the ECE region, and a bulk of countries that struggle to maintain living standards for a strongly growing population. This is a world failing to achieve global development goals, and with little progress in reducing resource intensity and fossil fuel dependency.

Figures 3.1 and Appendix 4 show by means of population pyramids the projected implications of these three scenarios on the age structure for the year $2050 .^{25}$ The ECE region as a whole is in Figure 3.1, showing 2010 and the three alternative 2050 pyramids for comparison. In addition to age and sex by fiveyear age groups, the pyramids also display the numbers of persons with no education and primary, secondary and tertiary education, actual for 2010 and projected for 2050. (Education for children younger than 15 is not shown because their education may not yet be completed.)

The pyramids in Figure 3.1 demonstrate the enormous differences in population numbers and population quality that alternative policy regimes can make over the next three decades. Population growth between 2010 and 2050 is identical at about 14 per cent under Continuation and Sustainability, but falls to only 3 per cent in the Fragmentation scenario, due largely to the failure of life expectancy to continue its rapid expansion and a decrease in migration intensity. Alongside, the standard old-age dependency ratio rises in all three scenarios, but by considerably more under Sustainability and considerably less under Fragmentation (for the exact figures see Appendix 4). To counterbalance this, the Sustainability world invests more in education and health, showing a 1.5 year gain in mean years of schooling of persons $25+$, compared to only 0.8 years under Fragmentation, so a health-adjusted measure might well come out ahead. For women 20-39 years old, the difference is even more extreme: years of schooling gains of 1.5 years, 1.0 years, and a projected decline of 0.3 years under Sustainability, Continuation and Fragmentation, respectively. For the wellbeing of the next generation, this may be the most important difference of all because higher education is related to better health outcomes, better reproductive health, and higher and longer employment, to mention just a few of the effects relevant to this report.

\footnotetext{
${ }^{25}$ More detailed pyramids for each sub-region and the ECE region as a whole for 2010, 2030 and 2050, along with the accompanying data discussed in this section, are displayed in Appendix 4.
} 
Figure 3.1 Population Pyramids for the ECE Region for Three Policy Scenarios. 2010, 2050
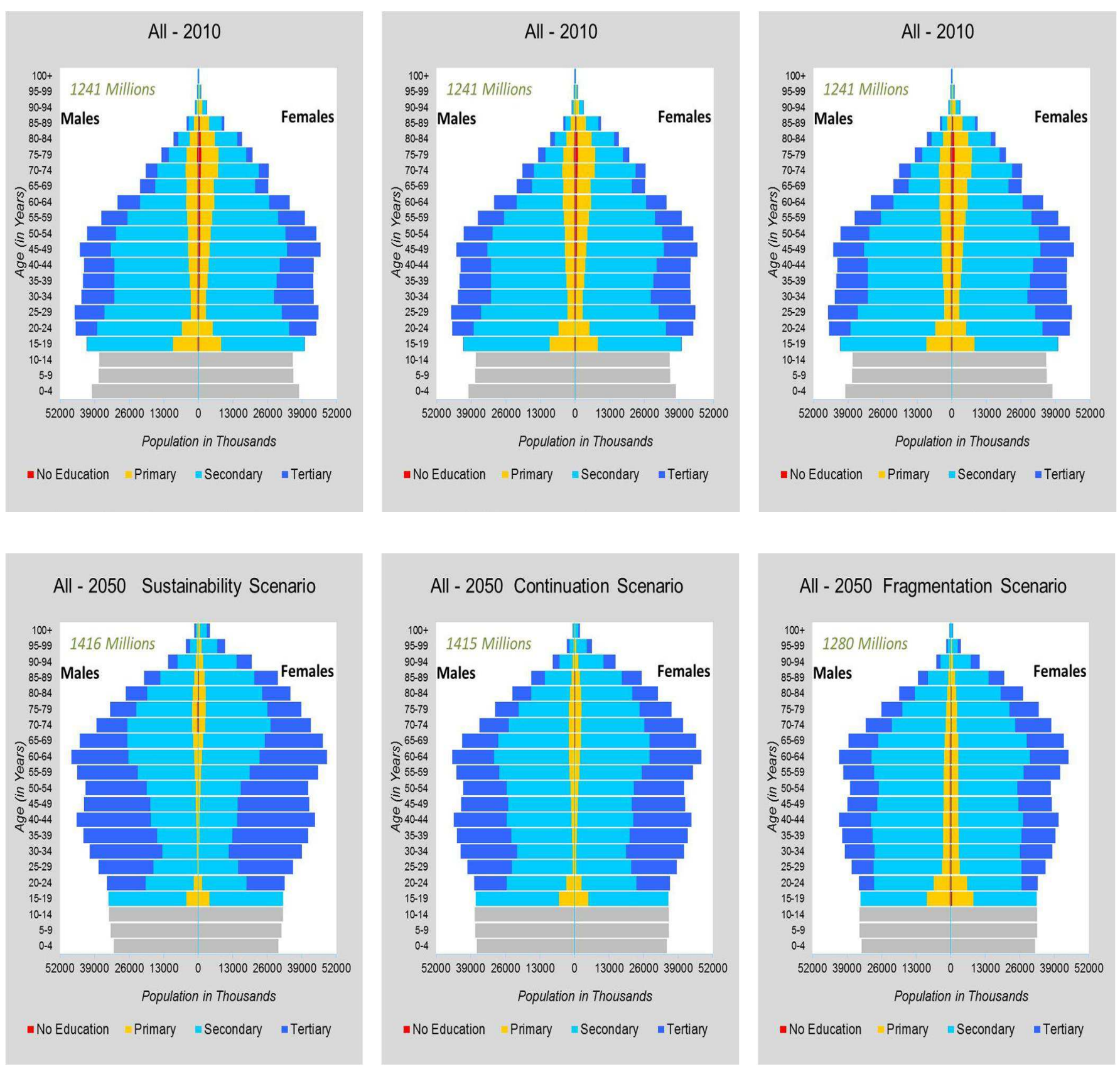

Note: Population pyramids for the ECE sub-regions are available in appendix 4.

Source: Lutz et al (2013). 
The sets of pyramids for each sub-region, as displayed in Appendix 4, show even more dramatic differences across the scenarios. Looking at South Eastern Europe, for example, note the large differences in population size and school attainment between business as usual in the Continuation scenario and best practice adoption in the Sustainability scenario. The differences are even more striking when compared to the Fragmentation scenario. This sub-region can, according to these projections, dramatically increase its schooling levels to compensate for a higher dependency ratio under the Sustainability scenario.

In general the future demographic prospects under different scenarios differ markedly across the ECE sub-regions. In South-Eastern Europe, Eastern Europe and Caucasus, and Central Asia, population growth and structure by education show the most extreme differences. There the Sustainability scenario produces slower population growth or even population decrease and faster population ageing than the Fragmentation scenario. At the same time, human capital improvement is close to zero under the Fragmentation scenario and expanding under Sustainability.

These two effects are interconnected and act together in molding the future demographic structure. If the population attains higher education, we may expect a convergence of fertility levels towards levels close to replacement and increased life expectancy, the two factors that underpin population ageing. At the same time, we can expect that such a population will be more healthy and productive, able to secure itself economically for a longer time, and less of a burden for society. Numerical population growth under the Fragmentation scenario results from the diverging fertility differential between higher and lower educated sub-populations. Population growth in this scenario is accompanied by stagnation of human capital, and consequently by growing social cleavages. Therefore the numerical advantage of higher population growth is not turned into a human capital and economic advantage. This development may mean the same or most likely even a larger burden to social systems and social cohesion.

These scenario projection comparisons demonstrate that countries' future population development goals should not include numerical population growth but instead emphasize growth of human capital.: Through focusing on quality education, health care, and increased economic activity of the population, including female and older populations, policymakers should be making better use of the human potential that already exists in their countries. Population ageing is a demographic issue, but it does not call for narrow demographic solutions.

In the New EU States and West ECE countries the differences in population growth are smaller across the scenarios. In the case of Western Europe and North America, the scenario pattern even reverses, with lower population growth under the Fragmentation scenario. This is because of diminished migration due to policy restrictions on migration, as well as the worsening mortality conditions of some population segments. ${ }^{26}$

\footnotetext{
${ }^{26}$ For detailed analyses of these and other projection differences across the scenarios, see Lutz, Butz and KC, forthcoming 2013.
} 


\section{The best policy}

Embedded in this Sustainability scenario are most of the best practices identified in this Report. Could governments pick and choose among them, attaining very particular targets while continuing or even weakening other parts of their social support and human capital investment portfolio? From history, the answer is yes ... for a while. But the social fabric is strong in all the ECE countries, woven as it is out of history and culture. Policy research is replete with examples of narrow policy interventions that after awhile ran up against these constraints and ceased to function effectively.

Within these constraints of history and culture and the more immediate challenge of recession-generated limitations, a better choice than investment in the quality of people--their schooling and health-will be hard to find. The economic returns are substantial, extending into the retirement years and forward into the next generation. The returns beyond economics are also substantial. Fortunately, there is no mystery how to make these investments and no starting point in 2013 too modest or two advanced that measurable progress cannot be made. 


\section{References}

Abadan-Unat, N., 1995. Turkish Migration to Europe, in: Cohen, R. (Ed.), The Cambridge Survey of World Migration. Cambridge University Press, Cambridge, pp. 279-284.

Abel, G.J., Riosmena, F., Sander, N., 2013. The Future of International Migration, in: Lutz, W., Butz, W.P., K.C., S. (Eds.), World Population and Human Capital in the 21st Century. Oxford University Press.

Acemoglu, D., Pischke, J.-S., 1999. The Structure of Wages and Investment in General Training. J. Polit. Econ. 107, 539-572.

Åkerman Börje, E., 2013. Unlocking the potential of migration for inclusive development (3:1), Migration Policy Practice. International Organization for Migration, Geneva.

Alesina, A., Baqir, R., Easterly, W., 1999. Public Goods and Ethnic Divisions. Q. J. Econ. 114, 12431284.

Alesina, A., Glaeser, E., 2004. Fighting Poverty in the US and Europe: A World of Difference. Oxford University Press, USA, New York.

Anxo, D., 2012. EEO Review: Employment policies to promote active ageing, 2012. European Commission, Stockholm.

Aubert, P., Crépon, B., 2006. Age, Wage and Productivity: Firm-Level Evidence. Mimeo, INSEE, Paris.

Ball, K., Berch, D.B., Helmers, K.F., Jobe, J.B., Leveck, M.D., Marsiske, M., Morris, J.N., Rebok, G.W., Smith, D.M., Tennstedt, S.L., Unverzagt, F.W., Willis, S.L., Advanced Cognitive Training for Independent and Vital Elderly Study Group, 2002. Effects of cognitive training interventions with older adults: a randomized controlled trial. Jama J. Am. Med. Assoc. 288, 2271-2281.

Bardsley, D.K., Hugo, G.J., 2013. Migration and climate change: examining thresholds of change to guide effective adaptation decision-making, in: Hugo, G.J. (Ed.), Climate Change and Migration. Edward Elgar, Cheltenham, UK, pp. 418-442.

Basten, S., Sobotka, T., Zeman, K., 2013. Future Fertility in Low Fertility Countries (VID Working Paper). Vienna Institute of Demography, Vienna.

Bhattacharya, J., Cutler, D.M., Goldman, D.P., Hurd, M.D., Joyce, G.F., Lakdawalla, D.N., Panis, C.W.A., Shang, B., 2004. Disability Forecasts and Future Medicare Costs, in: Cutler, D.M., Garber, A.M. (Eds.), Frontiers in Health Policy Research. MIT Press, Cambridge, MA, pp. 7594.

Bigot, R., Croutte, P., Muller, J., Osier, G., 2012. The middle classes in Europe : evidence from the LIS data (Luxembourg Income Study No. 580), Working Paper Series. LIS, Luxembourg.

Börsch-Supan, A., Chłoń-Domińczak, A., Skirbekk, V., 2012. Riding the Population Wave: Policy Options for the Ageing Baby-Boomer Generation in Europe. Popul. Policy Compact 4.

Börsch-Supan, A., Düzgün, I., Weiss, M., 2008. Labor productivity in an ageing society, in: Broeders, D., Eijffinger, S.C.W., Houben, A.C.F.J. (Eds.), Frontiers in Pension Finance. Edward Elgar Publishing, Cheltenham, pp. 83-98.

Börsch-Supan, A., Jürges, H., 2006. Early Retirement, Social Security and Well-Being in Germany (Working Paper No. 12303). University of Chicago Press, Chicago and London.

Bongaarts, J., Feeney, G., 1998. On the Quantum and Tempo of Fertility. Popul. Dev. Rev. 24, 271-291.

Bongaarts, J., Sobotka, T., 2012. A Demographic Explanation for the Recent Rise in European Fertility. Popul. Dev. Rev. 38, 83-120.

Brynjolfsson, E., McAfee, A., 2011. Race Against the Machine: How the Digital Revolution is Accelerating Innovation, Driving Productivity, and Irreversibly Transforming Employment and the Economy. Digital Frontier Press.

Butz, W.P., Sendzimir, J. (Eds.), 2013. Education and Differential Vulnerability to Natural Disasters. Special Issue of Ecology and Society. International Institute for Applied Systems Analysis, Laxenburg. 
Cerami, A., Vanhuysse, P., 2009. Post-Communist Welfare Pathways: Theorizing Social Policy Transformations in Central and Eastern Europe. Palgrave Macmillan, Basingstoke.

Chaloupková, J., 2005. Faktory ovlivňující dělbu domácí práce v českých domácnostech a hodnocení její spravedlnosti.' (Factors Influencing and the Division of Labour in Czech Households and an Assessment of Its Fairness). Sociol. Časopisczech Sociol. Rev. 41, 57-77.

Colombini, M., Mayhew, S.H., Rechel, B., 2011. Sexual and reproductive health in eastern Europe and central Asia: exploring vulnerable groups' needs and access to services. EntreNous 73, 16-17.

Colombo, F., Llena-Nozal, A., Mercier, J., Tjadens, F., 2011. Help Wanted? Providing and Paying for Long-Term Care. OECD Publishing.

Crompton ed, R., 1999. Restructuring gender relations and employment : the decline of the male breadwinner. Oxford University Press, Oxford.

Dallinger, U., 2013. The endangered middle class? A comparative analysis of the role played by income redistribution. J. Eur. Soc. Policy 23, 83-101.

De Haas, H., Vezzoli, S., 2011. Leaving matters: The nature, evolution and effects of emigration policies (DEMIG Project Pape No. 4), IMI Working Papers Series. University of Oxford: International Migration Institute.

Demeny, P., 1986. Population and the invisible hand. Demography 23, 473-487.

Duvander, A.-Z., Lappegård, T., Andersson, G., 2010. Family policy and fertility: fathers' and mothers' use of parental leave and continued childbearing in Norway and Sweden. J. Eur. Soc. Policy 20, 45-57.

Ediev, D., Mamolo, M., Potančoková, M., Scherbov, S., Sobotka, T., Zeman, K., 2012. European Demographic Data Sheet 2012.

Esping-Andersen, G., 2008. Childhood investments and skill formation. Int. Tax Public Finance 15, 1944.

European Commission, 2012a. Eurostat. European Commission, Luxembourg.

European Commission, 2013. Long-term Care. European Commission, Brussels.

European Commission, 2012b. White Paper on Pensions. European Commission, Brussels.

Flynn, J.R., 1987. Massive IQ gains in 14 nations: What IQ tests really measure. Psychol. Bull. 101, 171191.

Forslund, A., Johansson, P., Lindqvist, L., 2004. Employment subsidies - A fast lane from unemployment to work? (Working Paper Series No. 2004:18). IFAU - Institute for Evaluation of Labour Market and Education Policy.

Gauthier, A.H., 2007. The impact of family policies on fertility in industrialized countries: a review of the literature. Popul. Res. Policy Rev. 26, 323-346.

Goldin, C., Katz, L.F., 2008. The Race between Education and Technology. Harvard University Press, USA.

Golikova, T.A., 2010. Report of the Minister of Health and Social Development TA Golikova on the progress and perspectives of the national priority project "Health 2011-2013". Ministry of Health and Social Development (Presented at a meeting of the Federation Council), Moscow.

Heckman, J.J., 2006. Skill Formation and the Economics of Investing in Disadvantaged Children. Science 312, 1900-1902.

Ilmakunnas, P., Maliranta, M., 2007. Aging, Labor Turnover and Firm Performance (Discussion Paper No. 1092). The Research Institute of the Finnish Economy.

ILO, 2011. Key Indicators of the Labour Market (KILM), A multi-functional research tool of the ILO consisting of country-level data on 18 key indicators of the labour market from 1980 to the latest available year. Economic and Labour Market Analysis Department, Geneva.

Jenkins, S.P., Brandolini, A., Micklewright, J., Nolan, B., 2013. The Great Recession and the Distribution of Household Income. Oxford University Press, Oxford. 
Katsaga, A., Kulzhanov, M., Karanikolos, M., Rechel, B., 2012. Kazakhstan: Health system review ( No. 14/4), Health Systems in Transition. World Health Organization, Copenhagen.

Knoll, A., Keijzer, N., 2013. Will a post-2015 development framework acknowledge migration? (3:1), Migration Policy Practice. International Organization for Migration, Geneva.

Kollmeyer, C., 2012. Family Structure, Female Employment, and National Income Inequality: A CrossNational Study of 16 Western Countries. Eur. Sociol. Rev.

Kravdal, Ø. ystein, Rindfuss, R.R., 2008. Changing Relationships between Education and Fertility: A Study of Women and Men Born 1940 to 1964. Am. Sociol. Rev. 73, 854-873.

Kulhavý, V., Bartáková, H., 2007. Rodina a zaměstnání II. Mladé rodiny (Research Report). The Research Institute of Labour and Social Affairs, Prague.

Kureková, L., 2011. From job search to skill search: political economy of labour migration in Central and Eastern Europe (PhD thesis). Department of International Relations and European Studies, Central European University, Budapest.

Lappegård, T., 2009. Family Policies and Fertility in Norway. Presented at the Paper prepared for the XXVI IUSSP International Population Conference, Marrakech, Marroco.

Le Carret, N., Lafont, S., Mayo, W., Fabrigoule, C., 2003. The effect of education on cognitive performances and its implication for the constitution of the cognitive reserve. Dev. Neuropsychol. $23,317-337$.

Leridon, H., 2008. A New Estimate of Permanent Sterility by Age: Sterility Defined as the Inability to Conceive. Popul. Stud. 62, 15-24.

Lindqvist, L., 2007. Uppföljning av plusjobb (Evaluation of Job Plus) (IFAU Report No. 2007:14). IFAU - Institute for Labour Market Policy Evaluation, Stockholm.

Lutz, W., KC, S., 2011. Global human capital: Integrating education and population. Science 333, 587592.

Lutz, W., Butz, W.P., K.C., S. (Eds.), 2013. World Population and Human Capital in the 21st Century. Oxford University Press.

Luy, M., Wegner, C., Lutz, W., 2011. Adult Mortality in Europe, in: Rogers, R.G., Crimmins, E.M. (Eds.), International Handbook of Adult Mortality, International Handbooks of Population. Springer, New York, pp. 49-82.

Manyika, J., Chui, M., Bughin, J., Dobbs, R., Bisson, P., Marrs, A., 2013. Disruptive technologies: Advances that will transform life, business, and the global economy. McKinsey Global Institute, New York.

Mahlberg, B., Freund, I., Crespo Cuaresma, J., Prskawetz, A., 2013. Ageing, productivity and wages in Austria. Labour Econ. 22, 5-15.

Massey, D.S., Arango, J., Hugo, G., Kouaouci, A., Pellegrino, A., Taylor, J.E., 1993. Theories of International Migration: A Review and Appraisal. Popul. Dev. Rev. 19, 431-466.

Mather, M., 2007. The new generation gap. Population Reference Bureau, Washington, D.C.

McKee, M., Healy, J., Falkingham, J., 2002. Health care in central Asia (Policy Brief). World Health Organization.

Mossialos, E., Dixon, A., Figueras, J., Kutzin, J., 2002. Funding health care: options for Europe (Policy Brief No. 4). World Health Organization, Copenhagen.

Newport, S., 2009. A Review of Progress in Maternal Health in Eastern Europe and Central Asia. UNFPA, New York.

Neyer, G., 2005. Family policies in Western Europe: Fertility policies at the intersection of gender, employment and care policies. Österreichische Z. Für Polit. 34, 91-102.

Ní Bhrolcháin, M., Beaujouan, É., 2012. Fertility postponement is largely due to rising educational enrolment. Popul. Stud. 66, 311-327.

OECD, 2008. Growing Unequal? Income Distribution and Poverty in OECD Countries. OECD Publishing, Paris.

OECD, 2012. OECD Pensions Outlook 2012.

OECD, 2012. StatExtracts Database. Organisation for Economic Co-operation and Development, Paris. 
Oláh, L.S., Bernhardt, E., 2008. Sweden: Combining childbearing and gender equality. Demogr. Res. 19, $1105-1144$.

Olejaz, M., Juul Nielsen, A., Rudkjøbing, A., Okkels Birk, H., Krasnik, A., Hernández-Quevedo, C., 2012. Denmark health system review. Health Syst. Transit. 14, 1-192.

Philipov, D., Berghammer, C., 2007. Religion and fertility ideals, intentions and behaviour: a comparative study of European countries. Vienna Yearb. Popul. Res. 5, 271-305.

Popovich, L., Potapchik, E., Shishkin, S., Richardson, E., Vacroux, A., Mathivet, B., 2011. Russian Federation: Health system review ( No. 13/7), Health Systems in Transition. World Health Organization, Copenhagen.

Population Europe, 2013. Recession and Social Vulnerability in Europe: Insights from Demography. Population Europe, Brussels.

Rees, P., Zuo, C., Wohland, P., Jagger, C., Norman, P., Boden, P., \& Jasinska, M. (2013). The Implications of Ageing and Migration for the Future Population, Health, Labour Force and Households of Northern England. Appl. Spatial Analysis 6, 93-122.

Rocca, C.H., Doherty, I., Padian, N.S., Hubbard, A.E., Minnis, A.M., 2010. Pregnancy Intentions and Teenage Pregnancy Among Latinas: A Mediation Analysis. Perspect. Sex. Reprod. Health 42, $186-196$.

Rüütel, K., Trummal, A., Salekešin, M., Pervilhac, C., 2011. HIV epidemic in Estonia: analysis of strategic information. Case study. WHO Regional Office for Europe, Copenhagen.

Sacuiu, S., Gustafson, D., Sjögren, M., Guo, X., Östling, S., Johansson, B., Skoog, I., 2010. Secular changes in cognitive predictors of dementia and mortality in 70-year-olds. Neurology 75, 779785.

Sanderson, W.C., Scherbov, S., 2008. Conventional and Prospective measures of population aging, 1995, 2005, 2025, and 2045. Population Reference Bureau.

Sanderson, W.C., Scherbov, S., 2007. A Near Electoral Majority of Pensioners: Prospects and Policies. Popul. Dev. Rev. 33, 543-554.

Sanderson, W.C., Scherbov, S., 2010. Remeasuring Aging. Science 329, 1287-1288.

Schmidt, L., Sobotka, T., Bentzen, J.G., Nyboe Andersen, A., 2012. Demographic and medical consequences of the postponement of parenthood. Hum. Reprod. Update 18, $29-43$.

Serdar, S., Karahan, \& Saka, R. (2002). Health care systems in transition: Turkey (No. 4). Copenhagen: European Observatory on Health Care Systems. Retrieved from http://www.euro.who.int/_data/assets/pdf_file/0007/96415/e79838.pdf

Singh, S., Sedgh, G., Hussain, R., 2010. Unintended pregnancy: worldwide levels, trends, and outcomes. Stud. Fam. Plann. 41, 241-250.

Skirbekk, V., Loichinger, E., Weber, D., 2012. Variation in cognitive functioning as a refined approach to comparing aging across countries. Proc. Natl. Acad. Sci. 109, 770-774.

Sobotka, T., Lutz, W., 2011. Misleading policy messages from the period TFR: Should we stop using it? Comp. Popul. Stud. - Z. Für Bevölkerungswissenschaft 35, 637-664.

Sobotka, T., Skirbekk, V., Philipov, D., 2011. Economic Recession and Fertility in the Developed World. Popul. Dev. Rev. 37, 267-306.

Sobotka, T., Št' astná, A., Zeman, K., Hamplová, D., Kantorová, V., 2008. Czech Republic: A rapid transformation of fertility and family behaviour after the collapse of state socialism. Demogr. Res. S7, 403-454.

Striessnig, E., Lutz, W., 2013. Can below-replacement fertility be desirable? Empirica 1-17.

Tjadens, F., \& Colombo, F. (2011). Long term care: valuing care providers. Eurohealth, 17(2-3), 13-17.

Tepe, M., Vanhuysse, P., 2009. Are Aging OECD Welfare States on the Path to Gerontocracy? J. Public Policy 29, 1-28.

Tepe, M., Vanhuysse, P., 2010. Elderly Bias, New Social Risks, and Social Spending: Investigating Change and Timing in Eight Programs Across Four Worlds of Welfare, 1980-2003. Journal of European Social Policy 20, 218-234. 
Testa, M.R., 2006. Childbearing preferences and family issues in Europe (Special Eurobarometer No. 253/Wave 65.1 - TNS Opinion \& Social). European Commission.

Testa, M.R., 2012. Family Sizes in Europe: Evidence from the 2011 Eurobarometer Survey (European Demographic Research Papers 2012 No. 2). Vienna Institute of Demography, Vienna.

Testa, M.R., Sobotka, T., Morgan, S.P., 2011. Reproductive decision-making: towards improved theoretical, methodological and empirical approaches. Vienna Yearb. Popul. Res. 2011, 1-9.

Thévenon, O., 2011. Family Policies in OECD Countries: A Comparative Analysis. Popul. Dev. Rev. 37, 57-87.

Thielemann, E.R., 2005. Does Policy Matter?: On Governments' Attempts to Control Unwanted Migration (SSRN Scholarly Paper No. 495631). Social Science Research Network, Rochester, NY.

Tichenor, D.J., 2002. Dividing Lines: The Politics of Immigration Control in America. Princeton University Press, Princeton.

Tuddenham, R.D., 1948. Soldier intelligence in World Wars I and II. Am. Psychol. 3, 54-56.

UNAIDS, 2012. Global report: UNAIDS report on the global AIDS epidemic 2012. United Nations, Geneva.

UNDP, 2011. Human Development Report 2011: Sustainability and Equity: A Better Future for All. United Nations Development Program, New York.

UNDP, IOM, ILO, UNFPA, UNHCR, 2013. Joint Migration and Development Initiative (JMDI) [WWW Document]. URL http://www.migration4development.org/content/about-jmdi

UNECE, 2012. Ensuring a society for all ages: promoting quality of life and active ageing (Declaration). UNECE, Vienna.

UNFPA, 2009. Partnering with men to end gender-based violence: Practices that work from Eastern Europe and Central Asia. UNFPA, New York.

UNFPA, UNICEF, WHO, World Bank, 2012. Trends in Maternal Mortality:1990-2010. World Health Organization, Geneva.

UNICEF, 2012. The Transformative Monitoring for Enhanced Equity (TransMonEE) Database. Innocenti Research Centre, Florence.

United Nations, 2012. World Urbanization Prospects: The 2012 Revision. Department of Economic and Social Affairs, Population Division, United Nations, New York, NY.

Van Bavel, J., Różańska-Putek, J., 2010. Second birth rates across europe: interactions between women's level of education and child care enrolment. Vienna Yearb. Popul. Res. 8, 107-138.

Van Dalen, H.P., Henkens, K., Henderikse, W., Schippers, J., 2010. Do European employers support later retirement? Int. J. Manpow. 31, 360-373.

Vanhuysse, P., 2004. The pensioner booms in post-communist Hungary and Poland: political sociology perspectives. Int. J. Sociol. Soc. Policy 24, 86-102.

Vanhuysse, P., 2008. The New Political Economy of Skill Formation. Public Adm. Rev. 68, 955-959.

Vanhuysse, P., 2013. Intergenerational Justice in Aging Societies: A Cross-national Comparison of 29 OECD Countries. Bertelsmann Stiftung, Gütersloh.

Vanhuysse, P., Goerres, A., 2012. Ageing Populations in Post-Industrial Democracies: Comparative Studies of Policies and Politics. Routledge/ECPR Studies in European Political Science, Abingdon.

Vobecká, J., Piguet, V. 2012. "Fertility, natural growth and migration in the Czech Republic: an urbansuburban-rural gradient analysis of long-term trends and recent reversals". Population, Space and Place 18 (3): 225-240.

Wiesbrock, A., 2011. The Integration of Immigrants in Sweden: a Model for the European Union? Int. Migr. 49, 48-66.

WHO, 2013. European Health for all Database (HFA-DB). World Health Organization Regional Office for Europe, Copenhagen. 
World Bank, 2006. 2006 World Development Report: Equity and Development. World Bank, Washington, D.C.

World Bank, 2012. World Development Report 2012: Gender Equality and Development. World Bank, Washington, D.C.

World Bank, 2012. World Development Indicators (WDI). 


\section{List of Appendices}

Appendix 1: Policy Scenario Descriptions

Appendix 2: Indicators of Population and Socio-Economic Development in the ECE Region, its SubRegions and Individual Countries

Appendix 3: UNECE Region Countries and Grouping into Sub-regions

Appendix 4: Population size, age, sex structure by level of education 2010-2050

\section{Please see the other Appendices in the document available at http://eeca.unfpa.org/public/pid/14622}

